San Jose State University

SJSU ScholarWorks

Master's Theses

Master's Theses and Graduate Research

Summer 2011

\title{
Diet of the Gopher Rockfish (Sebastes carnatus) Inside and Outside of Marine Protected Areas in Central California
}

Erin Kimberly Loury

San Jose State University

Follow this and additional works at: https://scholarworks.sjsu.edu/etd_theses

\section{Recommended Citation}

Loury, Erin Kimberly, "Diet of the Gopher Rockfish (Sebastes carnatus) Inside and Outside of Marine Protected Areas in Central California" (2011). Master's Theses. 4060.

DOI: https://doi.org/10.31979/etd.ds8c-qwga

https://scholarworks.sjsu.edu/etd_theses/4060

This Thesis is brought to you for free and open access by the Master's Theses and Graduate Research at SJSU ScholarWorks. It has been accepted for inclusion in Master's Theses by an authorized administrator of SJSU ScholarWorks. For more information, please contact scholarworks@sjsu.edu. 
DIET OF THE GOPHER ROCKFISH (SEBASTES CARNATUS) INSIDE AND OUTSIDE OF MARINE PROTECTED AREAS IN CENTRAL CALIFORNIA

A Thesis

Presented to The Faculty of the Department of Marine Science

San José State University

In Partial Fulfillment

of the Requirements for the Degree

Master of Science

by

Erin K. Loury

August 2011 
(C) 2011

Erin K. Loury

ALL RIGHTS RESERVED 
The Designated Thesis Committee Approves the Thesis Titled

DIET OF THE GOPHER ROCKFISH (SEBASTES CARNATUS) INSIDE AND OUTSIDE OF MARINE PROTECTED AREAS IN CENTRAL CALIFORNIA

by

Erin K. Loury

APPROVED FOR THE DEPARTMENT OF MARINE SCIENCE

SAN JOSÉ STATE UNIVERSITY

August 2011

Dr. Gregor M. Cailliet

Department of Marine Science, Moss

Landing Marine Laboratories

Dr. David A. Ebert

Department of Marine Science, Moss

Landing Marine Laboratories

Dr. Shannon M. Bros-Seemann

Department of Biological Sciences, San José State University 


\begin{abstract}
DIET OF THE GOPHER ROCKFISH (SEBASTES CARNATUS) INSIDE AND OUTSIDE OF MARINE PROTECTED AREAS IN CENTRAL CALIFORNIA
\end{abstract}

\author{
by Erin K. Loury
}

Marine protected areas (MPAs) can potentially impact food web dynamics by increasing the density of predatory fishes within their borders. Such increases in density can cause shifts in the prey use of generalist predators. This study investigated the effects of increased conspecific density on the diet of Gopher Rockfish (Sebastes carnatus) at a 35-year-old MPA at Point Lobos and four newly established central California MPAs at Año Nuevo, Point Lobos, Piedras Blancas, and Point Buchon. Analysis of 710 stomachs collected in 2007-2009 indicated the most important overall prey were crabs, especially of the family Pisidae and the genus Cancer, as well as brittle stars and mysids. Diets did not differ inside versus outside the old Point Lobos MPA in terms of prey richness, evenness, and composition. Trophic level and individual specialization also did not differ. No consistent differences in these metrics were observed inside versus outside the four new MPAs, although prey evenness and composition did differ significantly among geographic locations. Diets at Año Nuevo, the most northern and shallow collection location, were dominated by Cancer crabs and porcelain crabs, while diets from southern, deeper locations were dominated by brittle stars. The case study of the old Point Lobos MPA indicates that changes in fish feeding ecology in MPAs may take decades to occur, if at all. Differences in prey observed among geographic locations suggest variation in the community composition among central California's new MPAs, which may influence the effect of each MPA on food web dynamics over time. 


\section{ACKNOWLEDGEMENTS}

This project was funded in part by the California Sea Grant College Program through project R/ENV-213EPD. Other funding sources included the Myers Oceanographic and Marine Biology Trust, the Packard Foundation, the John Martin Scholarship, the San José State University Alumni Association Dean's Scholarship, the Harvey Fellowship, the Bertha Kalm Scholarship, the Stockton Sportsmen's Club, the California Collaborative Fisheries Research Program (CCFRP), and the Pacific Shark Research Center.

Many thanks to my committee members Dr. David Ebert, Dr. Gregor Cailliet, and Dr. Shannon Bros-Seamann for their guidance and support of my thesis research. Your passion and enthusiasm for your work and that of your students is truly inspiring. Thank you for challenging me to think independently and do my best work. I am a better scientist for all I have learned from you. Thank you also to Dr. Richard Starr for connecting me with this project, and for providing me the support and resources of his lab and the CCFRP.

The 1,018 Gopher Rockfish sacrificed for this project have my extreme gratitude. I hope that this research contributes to a greater understanding of the species, and will ultimately aid its conservation. I am also deeply indebted to all of the CCFRP staff, boat captains, and volunteer anglers from 2007 to 2009 for collecting the fish and other data that made this project possible. Thank you for many memorable days on the water and great fish stories to tell. In particular, I would like to thank Noëlle Yochum, Cassandra 
Brooks, Katie Schmidt, Jahnava Duryea, Selena McMillan, and Leslie Longabach for all of their hours at sea and at the computer.

Many people assisted with sample organization and data recording during my fish dissections. I would like to thank Kara Ritchie for being such a hardworking and cheerful volunteer. Thank you also to Eden Gonzalez, Kelsey James, Jennifer Bigman, Katie Schmidt, and Sarah Jefferies.

I would like to thank the Moss Landing Marine Laboratories (MLML) Ichthyology Lab for all of their assistance and support. Thank you to Kristin HunterThomson for being so forthcoming with her invaluable help, especially for the countless hours spent teaching me programming in $\mathrm{R}$ and making maps. Thank you to Dr. Scott Hamilton for offering enthusiastic support and fresh ideas, even while in the field. Thanks also to Joe Bizzarro, Simon Brown, Mariah Boyle, and Jenny Kemper for sharing their firsthand knowledge of dietary analysis.

I would like to thank Cristie Boone from UC Santa Cruz for her extensive time and help in identifying fish specimens. Thank you to Dr. Jim Watanabe from Hopkins Marine Station for knowledgeable and enjoyable conversations about the ecology of marine invertebrates. Thank you also to the MLML Invertebrate Lab for their assistance with prey identification.

I would like to thank Larry Young for his IACUC assistance. This research was conducted under IACUC Protocol \#824. Data used in this study were acquired, processed, archived, and distributed by the Seafloor Mapping Lab of California State University Monterey Bay. Thank you to Pat Iampietro, Ashley Knight, and Carrie Bretz 
for their help in obtaining and analyzing these data. This study also utilized data collected by the Partnership for Interdisciplinary Studies of Coastal Oceans, a long-term ecological consortium funded primarily by the Gordon and Betty Moore Foundation and David and Lucile Packard Foundation. Thank you to Scott Gabara for helping to obtain and analyze these data, and for his great emotional support.

I would like to thank all MLML students, faculty, and staff for creating a wonderful culture of learning and friendship that has made my graduate experience so enjoyable. I would especially like to thank Elsie Tanadjaja and Cassandra Brooks for editing my graphics and manuscript, and for their incredible friendship and support. Thank you to other friends near and far for their love and support as we each venture on our journeys, living the lives we have imagined.

Finally, I dedicate this thesis to my family, who has my deepest gratitude for their constant love and encouragement, and their unwavering faith in my abilities. Thank you for believing in me, for supporting my dreams, and for making all that I do possible. 


\section{TABLE OF CONTENTS}

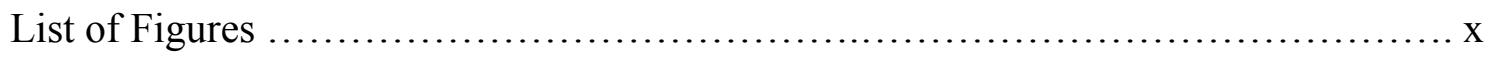

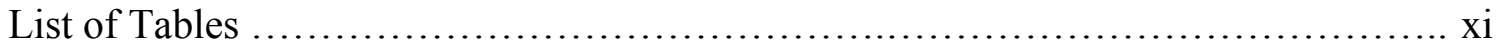

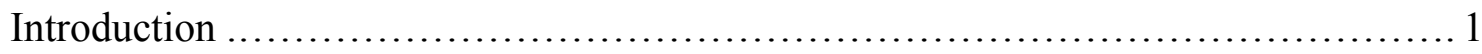

Materials and Methods .................................................... 5

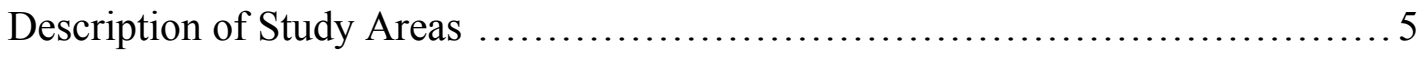

Año Nuevo ........................................................... 7

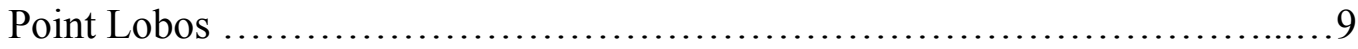

Piedras Blancas ..................................................... 11

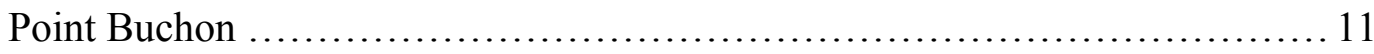

Sample Collection .................................................. 14

Overall Diet Description and Trophic Level .................................16

Determining Long-Term Effects of Fishing Exclusion at Point Lobos ............. 18

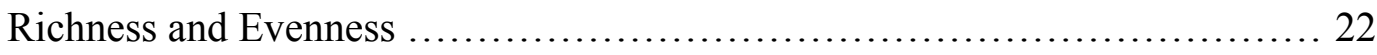

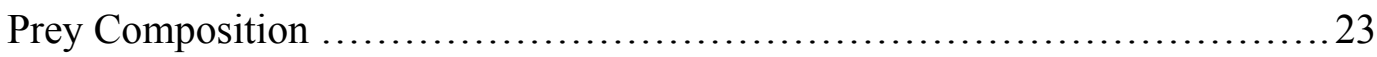

Trophic Level ...................................................... 24

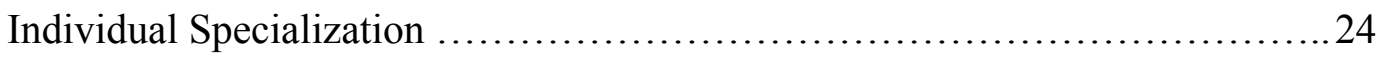

Determining Short-Term Effects of Fishing Exclusion at Four Newly Established

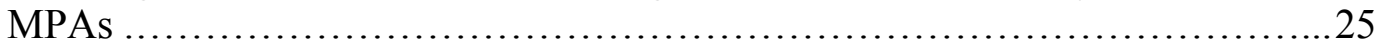

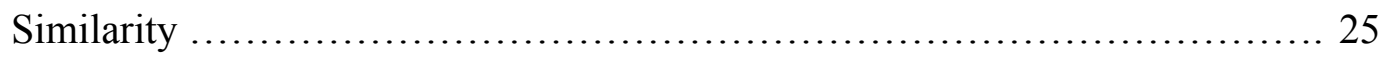

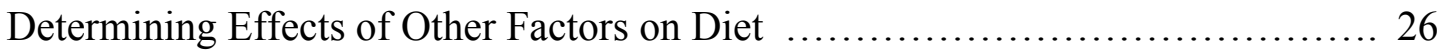

Relationship Between Diet and Fish Density ............................26

Relationship Between Diet and Environmental Variables ................... 27 


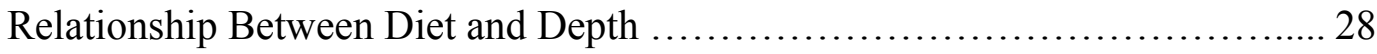

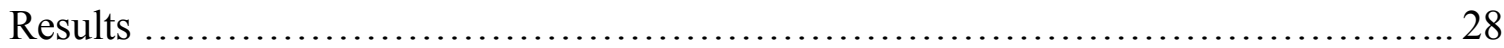

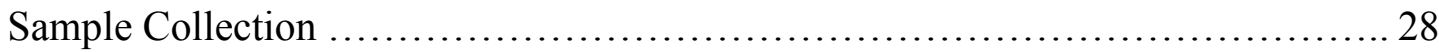

Overall Diet Description and Trophic Level ...............................30

Determining Long-Term Effects of Fishing Exclusion at Point Lobos ............. 37

Richness and Evenness .......................................... 37

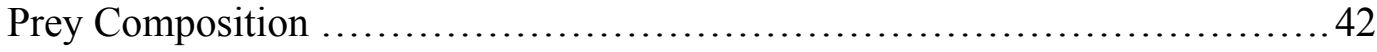

Trophic Level ................................................... 43

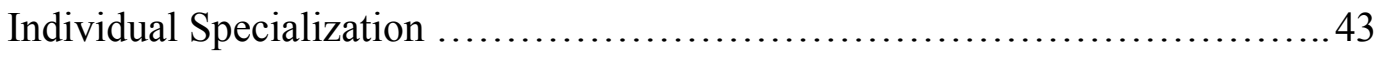

Determining Short-Term Effects of Fishing Exclusion at Four Newly Established

MPAs .............................................................43

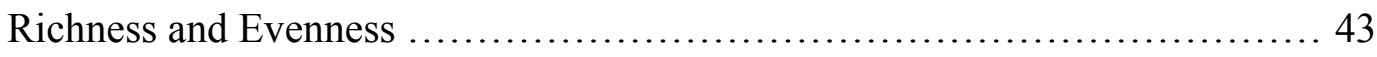

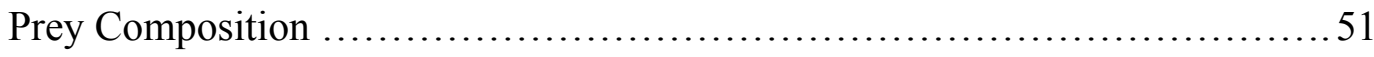

Trophic Level ....................................................... 59

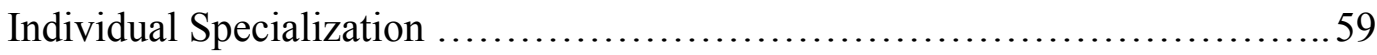

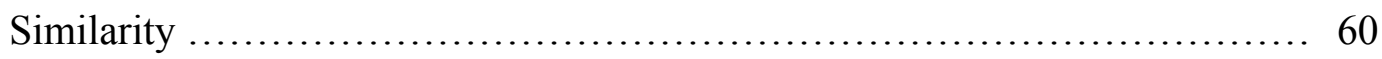

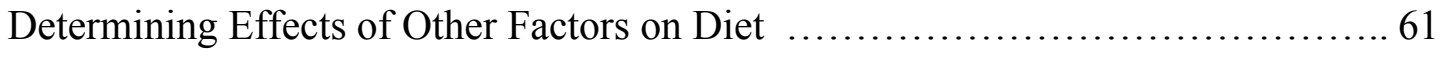

Relationship Between Diet and Fish Density .............................61

Relationship Between Diet and Environmental Variables .................. 62

Relationship Between Diet and Depth ................................ 67

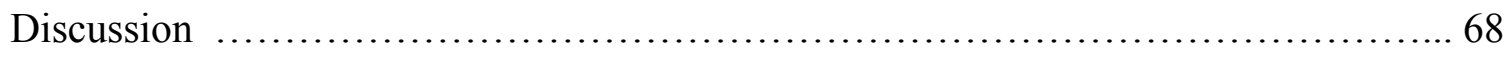

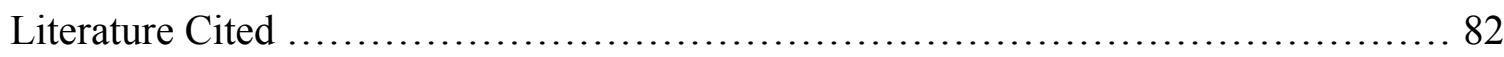




\section{LIST OF FIGURES}

Page

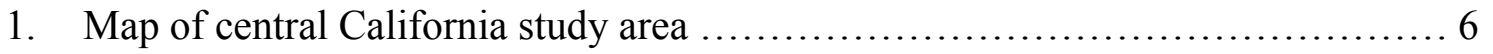

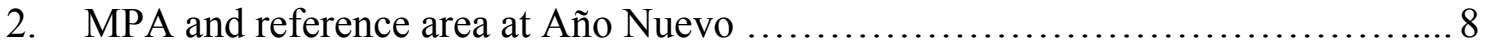

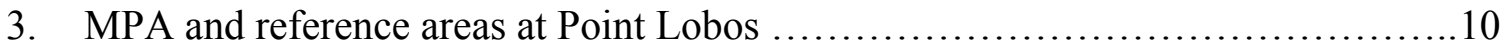

4. MPA and reference area at Piedras Blancas ................................. 12

5. MPA and reference area at Point Buchon ................................... 13

6. Methods flow chart for determining the effects of fishing exclusion in MPAs ......19

7. Total length frequency distribution of Gopher Rockfish by location and area ......30

8. Percent importance of major Gopher Rockfish prey groups ..................... 35

9. Percent prey-specific number and weight values of major prey groups............ 36

10. Cumulative prey curves at the prey taxon level for the old MPA and reference

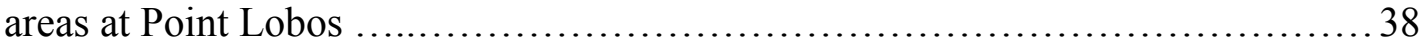

11. Cumulative prey curves at the prey guild level for the old MPA and reference areas at Point Lobos ...................................................... 39

12. Cumulative prey curves at the prey taxon level for all new MPAs and reference

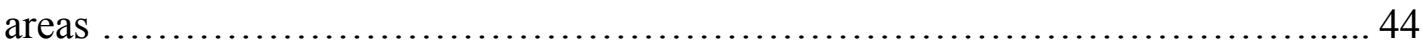

13. Cumulative prey curves at the prey guild level for all new MPAs and reference

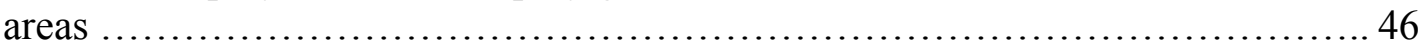

14. Plot of Principal Components Analysis with prey taxa ........................52

15. Prey composition by location and area at the prey taxon level ....................53

16. Plot of Principal Components Analysis with prey guilds ......................56

17. Prey composition by location and area at the prey guild level $\ldots \ldots \ldots \ldots \ldots \ldots \ldots . \ldots 57$

18. Mean individual specialization at new MPAs and reference areas .................59

19. Relationship between prey taxon evenness and Gopher Rockfish density ..........6 62

20. Plot of Canonical Correlation Analysis with prey taxa $\ldots \ldots \ldots \ldots \ldots \ldots \ldots \ldots \ldots \ldots . \ldots 64$

21. Plot of Canonical Correlation Analysis with prey guilds ...................... 66

22. Relationship between diet and depth .....................................67 


\section{LIST OF TABLES}

Page

1. List of prey taxonomic groups used in dietary analysis $\ldots \ldots \ldots \ldots \ldots \ldots \ldots \ldots \ldots \ldots \ldots \ldots \ldots \ldots$

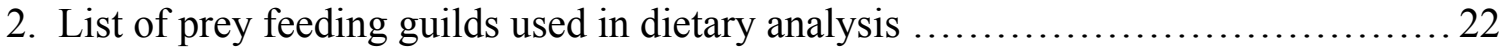

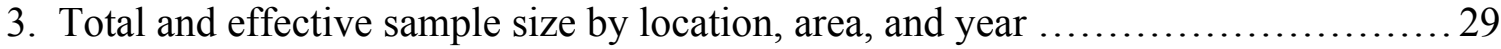

4. Diet composition of the Gopher Rockfish ................................... 32

5. Means of dietary metrics for the old MPA and reference areas at Point Lobos .......41

6. Slopes of cumulative prey curves for new MPAs and reference areas .............. 48

7. Means of dietary metrics for new MPAs and reference areas ....................50

8. Diet similarity between all MPAs and reference areas ......................... 60

9. Relationship between diet metrics and Gopher Rockfish density .................61

10. Summary of Canonical Correlation Analysis performed on prey taxa $\ldots \ldots \ldots \ldots \ldots 63$

11. Summary of Canonical Correlation Analysis performed on prey feeding guilds .....65 


\section{INTRODUCTION}

The decline of many fisheries and coastal marine ecosystems has prompted the increasing adoption of marine protected areas (MPAs) as ecosystem-based management practices that can protect both marine species and ecosystem services (Allison et al. 1998, Crowder et al. 2008). Fishing alters marine ecosystems directly through the removal of targeted and untargeted stocks, and indirectly through subsequent changes to marine food webs that result from the loss of predators (Botsford et al. 1997, Pinnegar et al. 2000). In turn, MPAs that exclude fishing pressure within their borders can produce direct effects on marine communities by increasing the density and size of fishes (McClanahan \& Arthur 2001, Halpern \& Warner 2002, Micheli et al. 2004, Guidetti \& Sala 2007, Tetreault \& Ambrose 2007, Lester et al. 2009). Increases in the densities of predators inside MPAs can subsequently cause indirect effects that cascade across multiple trophic levels via predator-prey interactions, sometimes altering community structure by affecting the abundance and distribution of prey species and primary producers (Babcock et al. 1999, Guidetti 2006, Mumby et al. 2007). These direct and indirect effects are encapsulated in two common objectives of MPAs, which are to protect 1) the abundance and diversity of marine species, and 2) the structure, function and integrity of marine ecosystems.

Recognizing the need to protect California's marine species and habitats from human impacts, the California Department of Fish and Game passed the Marine Life 
Protection Act (MLPA) in 1999, which called for a network of MPAs to span the California coast. The first section of this statewide network was established in central California in April 2007, when the California Fish and Game Commission adopted 29 MPAs between Pigeon Point and Point Conception. These MPAs, effective as of September 2007, include 13 no-take State Marine Reserves (SMRs) that prohibit all commercial and recreational fishing within their borders, and 15 State Marine Conservation Areas (SMCAs), which permit limited fishing. In addition to creating new MPAs, the MLPA process expanded pre-existing ones such as the Point Lobos State Marine Reserve, which has been closed to fishing since 1973. As one of the oldest notake marine reserves in the United States, Point Lobos offers a unique opportunity to examine the long-term effects of fishing exclusion inside an MPA, including potential effects on marine food webs.

Studying fish feeding habits inside and outside of MPAs provides a means to investigate potential indirect effects of increased fish density on marine food webs. Predators play a fundamental role in structuring food webs, which connect all the species in an ecosystem (Fanshawe et al. 2003, Gascuel 2005). While previous studies have looked for the effects of MPAs across trophic levels, such as the effects of specialist predators on the distribution of their prey (Babcock et al. 1999, McClanahan 2000, Fanshawe et al. 2003, Guidetti 2006, Clemente et al. 2009), few studies have focused on a single trophic level to investigate the indirect effects of fishing exclusion on a predator's feeding habits (Badalamenti et al. 2008, Fanelli et al. 2009, Fanelli et al. 2010). One potential mechanism of within-trophic level diet changes in MPAs is the 
increased density of competitors. Manipulative experiments have demonstrated that increased densities of conspecifics can lead to increased diet specialization in sticklebacks (Svanbäck \& Bolnick 2007), supporting the theory that competing populations will diverge from each other in resource use (Brown \& Wilson 1956). Changes in diets can therefore be used to infer changes in ecological relationships between predators and prey, as well as the indirect effects of increased competitor densities in MPAs.

The Gopher Rockfish (Sebastes carnatus) was chosen to investigate potential changes in feeding ecology in four MPAs located at Año Nuevo, Point Lobos, Piedras Blancas, and Point Buchon. The Gopher Rockfish is one of the most commonly occurring nearshore fishes in central California (Starr et al. 2010), and is frequently caught in recreational and commercial live-fish fisheries (Key et al. 2005). Its abundance, territorial behavior, restricted movements, and generalist feeding habits (Larson 1980) also make it a good candidate to investigate localized changes in food web structure that may occur in protected areas. While previous studies have investigated the diet of Gopher Rockfish, the taxonomic resolution of prey identification was relatively low in most cases (Larson 1972, Hallacher \& Roberts 1985, Lea et al. 1999, Bonacci 2003). Detailed prey identification is necessary to clarify the predatory role of this fish as well as its ecological relationships, which may be site-specific.

Differences in Gopher Rockfish density enable an investigation of potential MPA effects. Baseline monitoring surveys from 2007 to 2009 in the MPAs chosen for this study documented significantly greater Gopher Rockfish densities inside three of the four 
MPAs compared to nearby fished areas (Starr et al. 2010). These pre-existing differences, though likely not caused solely by the MPAs themselves, provide an opportunity to examine the effects of changes in population density on fish feeding ecology. Such changes may be amplified if fish densities increase in the MPAs over time.

The goal of this study was to characterize the diet of the Gopher Rockfish in central California and investigate the effects of increased conspecific densities on diet in MPAs. Specific objectives were to: (1) describe the diet of the Gopher Rockfish in taxonomic detail to better characterize the role of this fish as a predator; (2) assess the long-term effects of fishing exclusion and increased conspecific density on feeding ecology by comparing Gopher Rockfish diets inside and outside of an MPA that has been established for more than 30 years; (3) assess the short-term effects of fishing exclusion and increased conspecific density on feeding ecology across the central California region by comparing Gopher Rockfish diets inside and outside of four newly established MPAs; and (4) investigate environmental factors that could potentially contribute to variation in Gopher Rockfish diet. 


\section{MATERIALS AND METHODS}

\section{Description of Study Areas}

This study included four MPAs and four corresponding reference areas surveyed by the California Collaborative Fisheries Research Program (CCFRP). Each MPA and reference area pair was located in a different geographic location (Fig. 1): Año Nuevo (AN), Point Lobos (PL), Piedras Blancas (BL), and Point Buchon (PB). These locations contain extensive nearshore rocky habitats that are representative of the central California coastal region. To assess the impacts of excluding fishing pressure inside the MPAs, a reference area that had no restrictions on fishing was sampled near each MPA for comparison. Each reference area shared similar size, depth, habitat, and oceanographic conditions with the nearby MPA (Starr et al. 2008). 


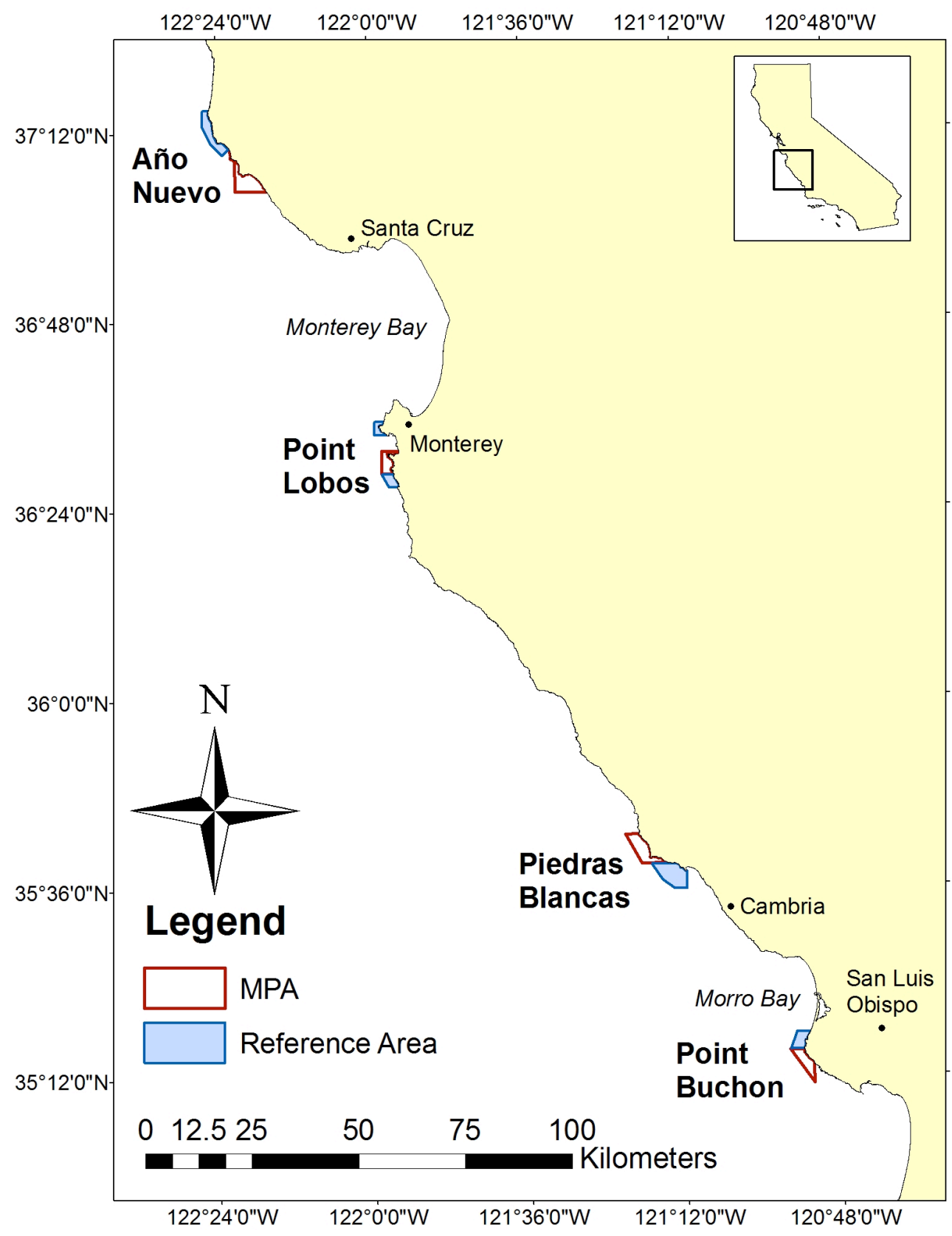

Fig. 1. Map of central California study area. Red lines denote marine protected areas (MPAs) and blue shaded areas denote unprotected reference areas where Gopher Rockfish were collected. 
Año Nuevo. The Año Nuevo MPA encompasses Point Año Nuevo and Año Nuevo Island, and is referred to as the Año Nuevo State Marine Conservation Area. The MPA encompasses an area of $\sim 28.7 \mathrm{~km}^{2}$ and permits the commercial take of giant kelp (Macrocystis pyrifera) by hand harvest, but prohibits all fishing. The southern boundary of the MPA adjoins Greyhound Rock SMCA, which only permits commercial and recreational hand harvest of giant kelp, commercial and recreational take of market squid (Doryteuthis opalescens) and salmon (Oncorhynchus spp.), and the recreational harvest of finfish by hook and line from shore (California Department of Fish and Game 2008). The MPA and corresponding reference area cover a depth range of 0-53 m (Fig. 2). These areas both include primary habitat types such as the rocky intertidal, sandy beach, estuary, offshore rocks, shale reef, and kelp forests (California Department of Fish and Game 2008). In a monitoring survey conducted during the timeframe of this study, Gopher Rockfish constituted $23.9 \%$ of the catch and occurred at a density of 1.5 fish caught per angler hour in the MPA, compared to a composition of $13.2 \%$ and a density of 0.9 fish caught per angler hour in the reference area (Starr et al. 2010). 


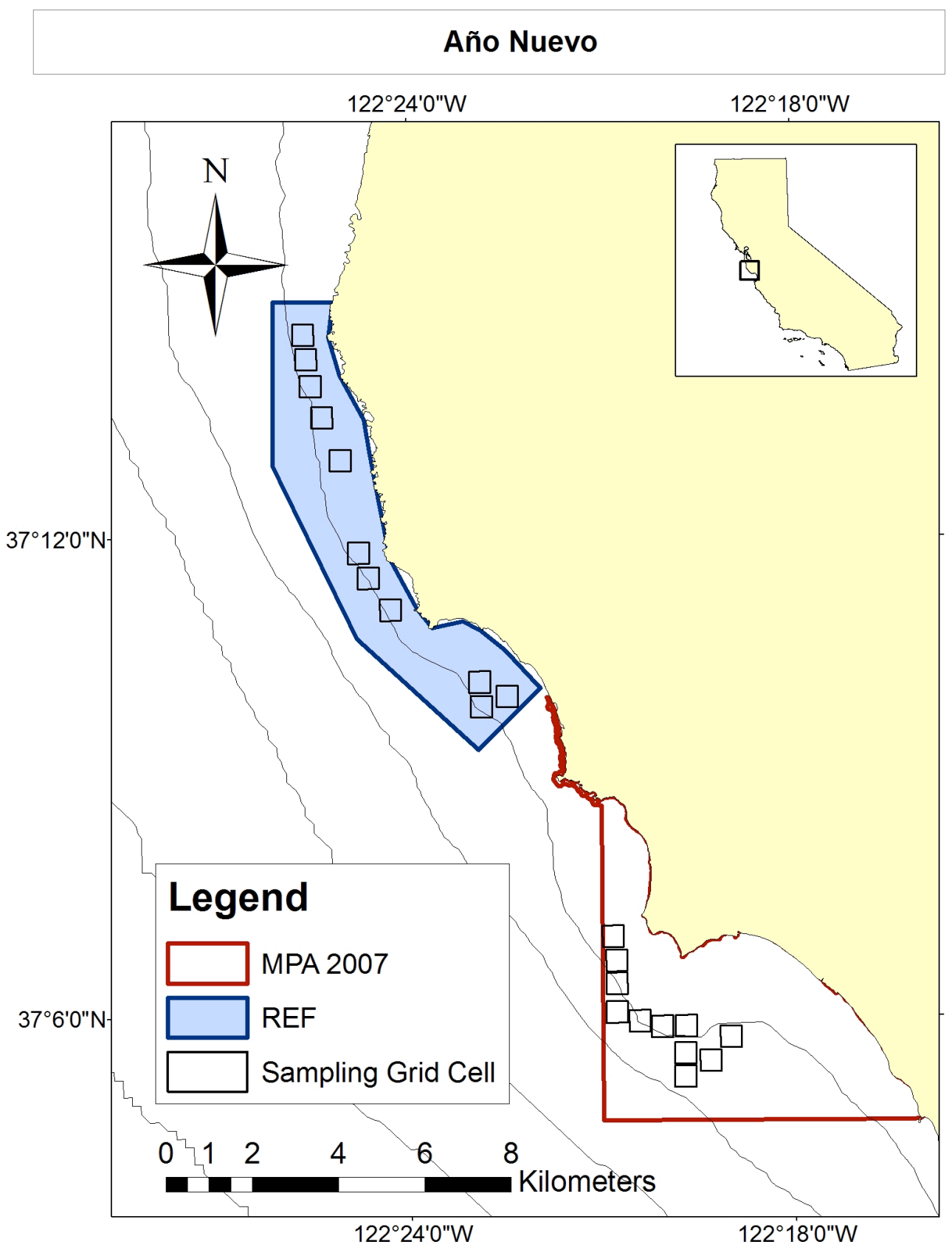

Fig. 2. MPA and reference area at Año Nuevo. The unshaded red area denotes the Año Nuevo MPA, and the shaded blue area represents the unprotected reference area (REF). Black squares represent the $500 \times 500 \mathrm{~m}$ sampling grid cells where fishing with hook and line occurred. Contour lines deonate $20 \mathrm{~m}$ isobaths. 
Point Lobos. The Point Lobos MPA is located offshore of the Point Lobos State Natural Reserve and is referred to as the Point Lobos State Marine Reserve. The MPA includes Pinnacle Point and Yankee Point, encompasses an area of $\sim 13.8 \mathrm{~km}^{2}$, and prohibits the take of all living resources. The western reserve boundary adjoins the Point Lobos State Marine Conservation Area, which encompasses part of Carmel Submarine Canyon and permits only the commercial and recreational take of salmon, Albacore (Thunnus alalunga), and spot prawn (Pandalus platyceros). Part of the northern reserve boundary adjoins the Carmel Bay SMCA, which permits only the recreational take of finfish and the commercial take of giant kelp by hand.

The Point Lobos MPA established in 2007 encompasses the pre-existing Point Lobos Ecological Reserve. The 750 submerged acres $\left(\sim 3 \mathrm{~km}^{2}\right)$ of the Ecological Reserve were added to the terrestrial Point Lobos State Reserve in 1960, and this submerged area was closed to fishing in 1973. As one of the oldest no-take MPAs in the United States, Point Lobos provides a unique opportunity to examine the effects of fishing exclusion after several decades. The area encompassed by the 1973 boundary will hereafter be referred to as the old Point Lobos MPA, and the area inside the extended 2007 boundary will hereafter be referred to as the new Point Lobos MPA.

The Point Lobos MPAs and reference areas cover a depth range of 0-125 m (Fig. 3). Primary habitat types include sandy beach, rocky intertidal, surfgrass, shallow hard and soft bottom, pinnacles, and kelp forests (California Department of Fish and Game 2008). In a monitoring survey performed during the timeframe of this study, Gopher Rockfish constituted $20.7 \%$ of the total catch and occurred at a density of 2.9 fish caught 
per angler hour in the MPA (old and new MPAs combined), compared to a composition of $31.1 \%$ and a density of 1.8 fish caught per angler hour in the reference area (Starr et al. 2010).

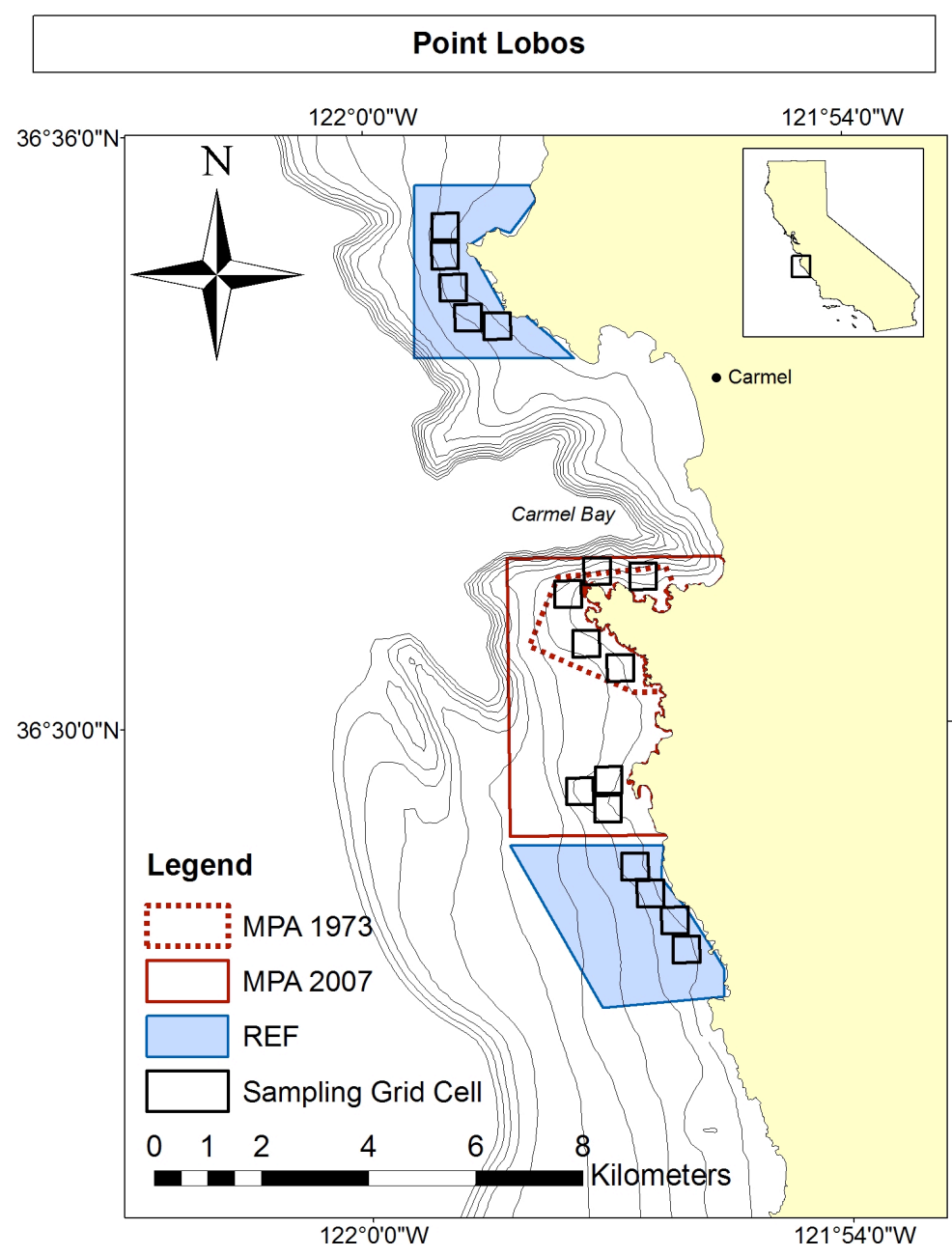

Fig. 3. MPA and reference areas at Point Lobos. The dotted, unshaded red area denotes the boundary of the old Point Lobos MPA that was closed to fishing in 1973. The solid unshaded red area denotes the expanded boundary of the new Point Lobos MPA that was established in 2007. The shaded blue areas represent the unprotected reference areas. Black squares represent the $500 \times 500 \mathrm{~m}$ sampling grid cells where fishing with hook and line occurred. Contour lines deonate $20 \mathrm{~m}$ isobaths to $200 \mathrm{~m}$. 
Piedras Blancas. The Piedras Blancas MPA includes Point Sierra Nevada and Point Piedras Blancas, and is referred to as the Piedras Blancas State Marine Reserve. The MPA encompasses an area of $\sim 26.9 \mathrm{~km}^{2}$ and prohibits the take of all living resources. The western boundary of the reserve adjoins the Piedras Blancas SMCA, which only permits the commercial and recreational take of salmon and Albacore.

The MPA and corresponding reference area cover a depth range of 0-48 m (Fig. 4). Primary habitat types include sandy beach, rocky intertidal, surfgrass, shallow hard and soft bottom, and kelp forests (California Department of Fish and Game 2008). In a monitoring survey performed during the timeframe of this study, Gopher Rockfish constituted $29.9 \%$ of the total catch and occurred at a density of 2.3 fish caught per angler hour in the MPA, compared to a composition of $43.0 \%$ and a density of 2.4 fish caught per angler hour in the reference area (Starr et al. 2010).

Point Buchon. The Point Buchon MPA is located just south of Morro Bay and Point Buchon, and is referred to as the Point Buchon State Marine Reserve. The MPA encompasses an area of $\sim 17.2 \mathrm{~km}^{2}$ and prohibits the take of all living resources. The western reserve boundary adjoins the Point Buchon SMCA, which permits only the commercial and recreational take of salmon and Albacore.

The MPA and corresponding reference area cover a depth range of 0-63m (Fig. 5). Primary habitat types include sandy beach, rocky intertidal, shallow hard and soft bottom, pinnacles, and kelp forests (California Department of Fish and Game 2008). In a monitoring survey performed during the timeframe of this study, Gopher Rockfish constituted $48.0 \%$ of the total catch and occurred at a density of 3.6 fish caught per angler 
hour in the MPA, compared to a composition of $51.8 \%$ and a density of 2.6 fish caught per angler hour in the reference area (Starr et al. 2010).

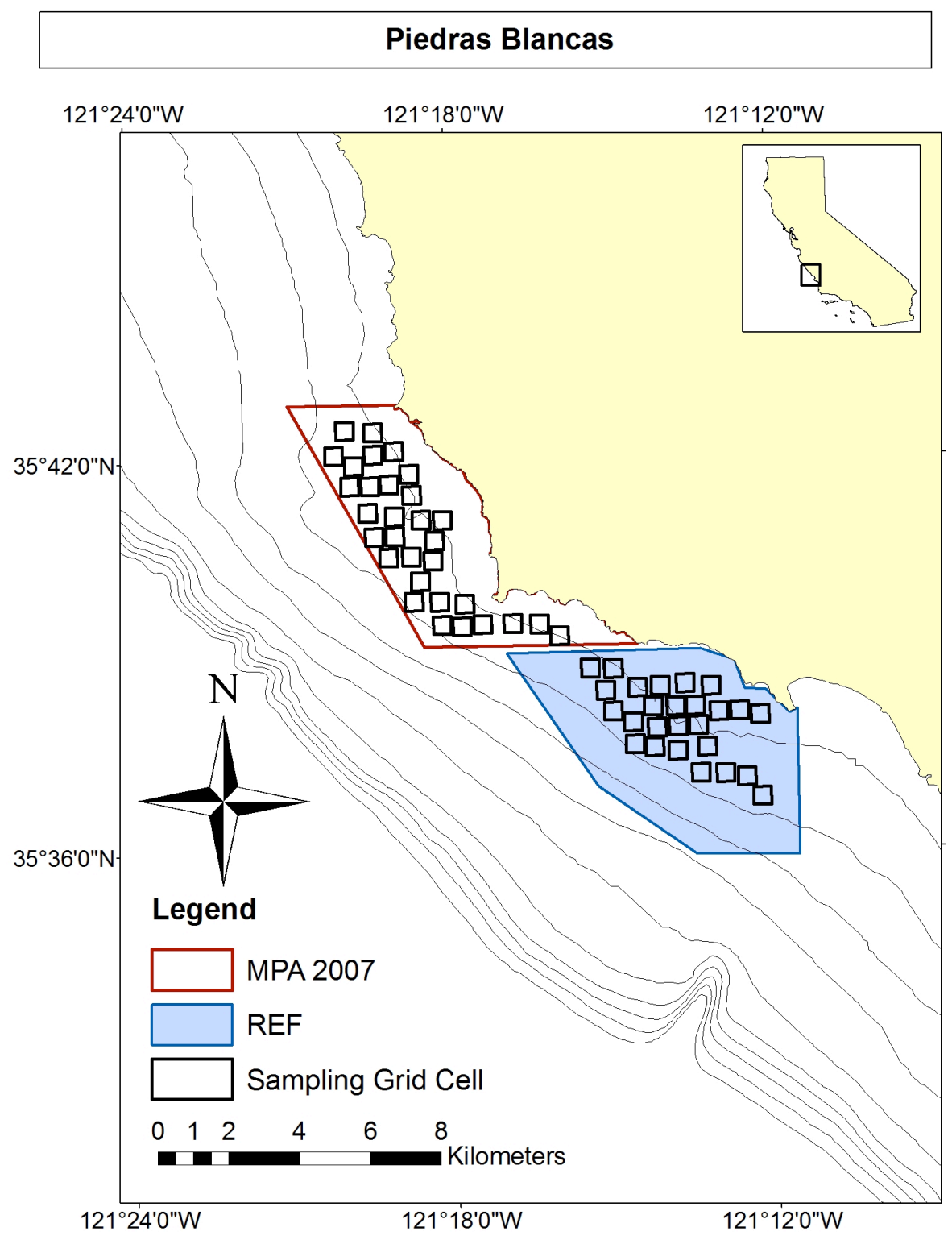

Fig. 4. MPA and reference area at Piedras Blancas. The unshaded red area denotes the MPA, and the shaded blue area denotes the unprotected reference area. Black squares represent the $500 \times 500 \mathrm{~m}$ sampling grid cells where fishing with hook and line occurred. Contour lines deonate $20 \mathrm{~m}$ isobaths to $200 \mathrm{~m}$. 


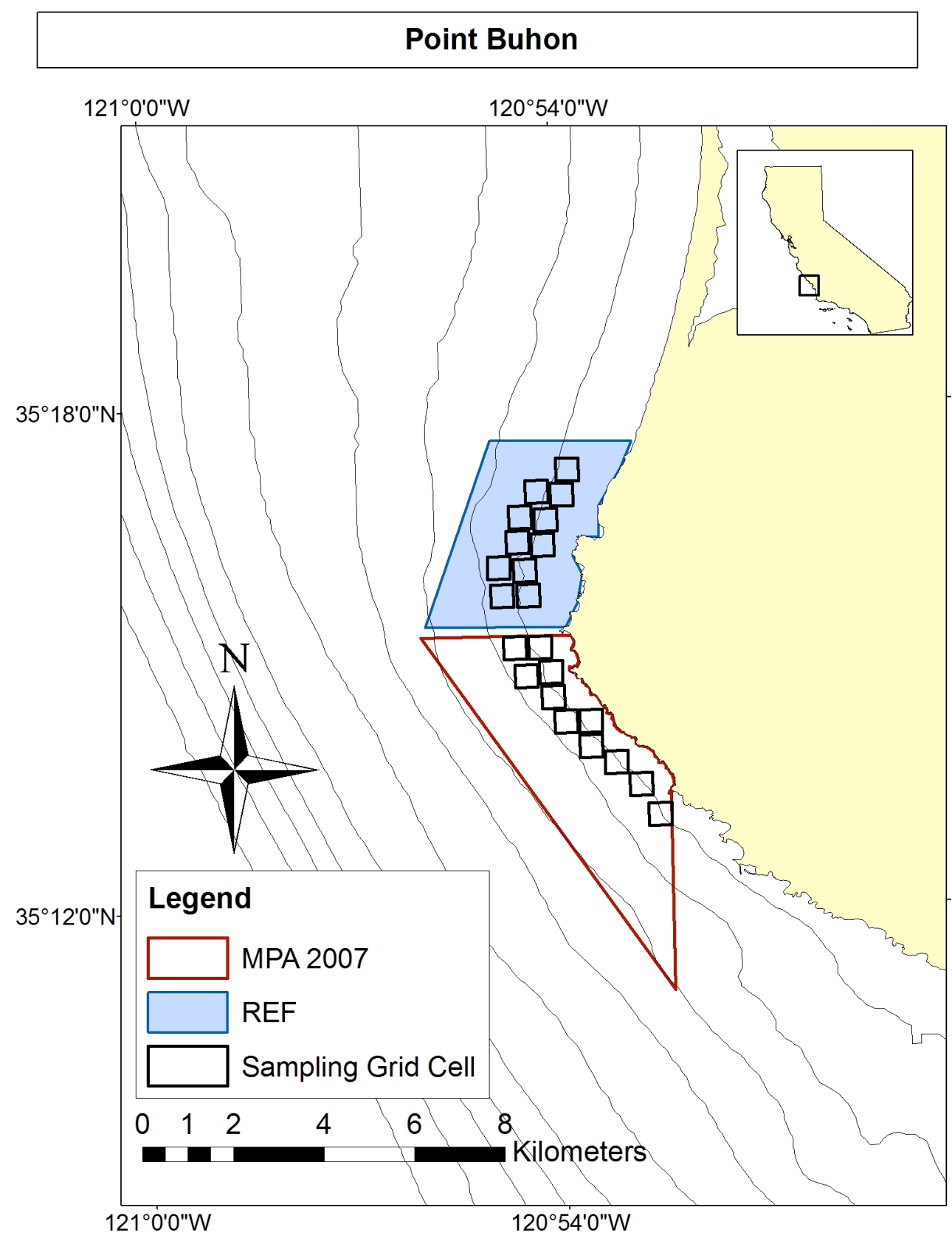

Fig. 5. MPA and reference area at Point Buchon. The unshaded red area denotes the Point Buchon MPA, and the shaded blue area denotes the unprotected reference area. Black squares represent the $500 \times 500 \mathrm{~m}$ sampling grid cells where fishing with hook and line occurred. Contour lines deonate $20 \mathrm{~m}$ isobaths to $200 \mathrm{~m}$. 


\section{Sample Collection}

Within each MPA and reference area, 500 x $500 \mathrm{~m}$ grid cells were established as part of the CCFRP sampling protocol with approximately equal numbers of grid cells located in the MPA and reference areas at each geographic location (Starr et al. 2008). These grid cells were established in locations of nearshore rocky habitat that did not exceed $40 \mathrm{~m}$ in depth and that local fishermen had previously identified as productive. At Point Lobos, grid cells were established in both the old and new sections of the MPA.

Gopher Rockfish were collected with hook and line and trapping gear in the summer and fall of 2007-2009 as part of monitoring surveys conducted by the CCFRP (Starr et al. 2008, 2010). The great majority of samples were collected during hook-andline surveys. Each location was sampled for four days each month from August to October of 2007, from July to September in 2008, and in July and August of 2009. The Piedras Blancas MPA and corresponding reference area were added to the survey in 2008. Thus, no fish were collected at Piedras Blancas in 2007. Sampling was alternated daily between MPAs and reference areas. Four of the grid cells in a given MPA or reference area were randomly chosen and sampled during each day, and a total sampling time of 45 min was divided among three discrete, productive fishing locations within each grid cell. A portion of the Gopher Rockfish catch was retained opportunistically for the present study.

To supplement the total number of samples at Año Nuevo and Point Lobos, fish were obtained opportunistically during CCFRP trapping surveys in 2008 and 2009 within 
the MPAs and corresponding reference areas. Trapping surveys used 500 x $500 \mathrm{~m}$ grid cells in each MPA and reference area that differed from the hook-and-line survey, and were located in 3-20 $\mathrm{m}$ of water (Starr et al. 2010). These surveys used customized traps similar to those used in the live fin-fish fishery (Starr et al. 2010). Traps were baited with cut squid and left to soak for $45 \mathrm{~min}$ to $1.5 \mathrm{~h}$.

Fish with empty stomachs were not included in the data analysis. Care was taken to retain fish that did not show extruded stomachs or regurgitated stomach contents whenever possible. Any prey items found in the mouth or gill rakers were saved with the fish to be included in the later dietary analysis. The retained fish were euthanized and stored frozen. In the laboratory all fish were partially thawed, and the stomach and esophagus of each fish was removed and refrozen for stomach content analysis.

Fish lengths and weights were measured to account for potential biases in feeding related to fish size. The total and standard lengths of each fish were measured to the nearest $1.0 \mathrm{~cm}$, and total fish weight was measured to the nearest $1.0 \mathrm{~g}$. Total lengths were compared inside and outside of MPAs using an equal number of fish randomly selected from each area in a Randomized Complete Block Analysis of Variance (RCB ANOVA). Sex was determined by a visual inspection of gonads.

Stomachs were later thawed and dissected at room temperature and the contents were examined with a dissecting microscope. The prey items of each stomach were identified to the lowest possible taxonomic level, enumerated, and weighed wet to the nearest $0.001 \mathrm{~g}$ after blotting away excess moisture. Bait used to catch fish was easily indentified as cut squid still in the mouth and was excluded from dietary analysis. 
Although care was taken to avoid retaining Gopher Rockfish with everted stomachs whenever possible, a high proportion of the fish displayed signs of barotrauma. To minimize the effect of potential partial regurgitation, stomachs that contained less than $0.100 \mathrm{~g}$ of prey were considered empty and excluded from further dietary analysis.

\section{Overall Diet Description and Trophic Level}

Invertebrate prey items were each identified to the lowest possible taxon using a variety of taxonomic keys (Schmitt 1921, Morris et al. 1980, Jensen 1995, Carlton 2007). Fishes, which were usually highly digested, were identified from bones with the help of an archeological expert from the University of California, Santa Cruz (C. Boone, personal communication, August 2010). Invertebrate taxonomic nomenclature follows Carlton (2007), and fish taxonomic nomenclature follows Eschmeyer and Herald (1983). Prey were counted using the minimum number of individual prey items represented by the body parts present (Lance et al. 2001).

The contribution of each prey type to the diet was determined using three indices: prey-specific abundance (Amundsen et al. 1996, Brown 2010), average abundance (Hyslop 1980), and percent occurrence (Cortés 1997). Prey-specific abundances by number and weight $\left(\% \mathrm{PN}_{\mathrm{i}}, \% \mathrm{PW}_{\mathrm{i}}\right)$ were calculated as:

$$
\% P A_{i}=\frac{\sum_{j=1}^{n} \% A_{i j}}{n_{i}}
$$

where $A_{i j}$ is the abundance by number or weight for prey $i$ in an individual stomach 
sample $j$, and $n_{i}$ is the number of stomachs containing prey $i$, with $n$ being the total number of stomachs. These same variables were used to calculate the average percent abundance $\left(\% \mathrm{~N}_{\mathrm{i}}, \% \mathrm{~W}_{\mathrm{i}}\right)$ as:

$$
\% A_{i}=\frac{\sum_{j=1}^{n} \% A_{i j}}{n}
$$

Percent occurrence $\left(\% \mathrm{O}_{\mathrm{i}}\right)$ was calculated as:

$$
\% O=\frac{n_{i}}{n} * 100
$$

The Index of Relative Importance (IRI) is a compound index used to determine the importance of each prey type to the diet (Pinkas et al. 1971, Cortés 1997). It is traditionally calculated as:

$$
I R I=(\% N+\% W) * \% O
$$

However, the average percent abundance values $\% \mathrm{~N}$ and $\% \mathrm{~W}$ are already compound indices that result from multiplying prey-specific abundance values by $\% \mathrm{O}$. Therefore, again combining average percent abundance values with $\% \mathrm{O}$ in the IRI grossly overemphasizes $\% \mathrm{O}$ (Brown 2010). Thus, a modified prey-specific version of the IRI (PSIRI) was calculated following Brown (2010):

$$
\text { PSIRI }_{\mathrm{i}}=\left(\% \mathrm{PN}_{\mathrm{i}}+\% \mathrm{PW}_{\mathrm{i}}\right) * \% \mathrm{O}
$$

These PSIRI values were standardized as a percentage following Cortés (1997). Another benefit of the PSIRI is that, unlike the IRI, it is additive with respect to taxonomic levels. The sum of \%PSIRI for a group of species will equal the \%PSIRI of the family containing those species, and so forth. This characteristic makes \%PSIRI 
more comparable within and among species and across studies than the \%IRI (Brown 2010).

Trophic level of each fish was calculated from stomach contents following Cortés (1999) and Ebert and Bizzarro (2007):

$$
T L_{k}=1+\left(\sum_{j=1}^{n} P_{j} * T L_{j}\right)
$$

where $T L_{k}$ is the trophic level of species $k, P_{j}$ is the proportion of prey category $j$ in the diet of species $k, n$ is total number of prey categories, and $T L_{j}$ is the trophic level of prey category $j$. Percent weight values were used for $P_{j}$, and prey groups were assigned trophic levels following the characterization of Ebert and Bizzarro (2007). A linear regression was used to test for a relationship between trophic level and fish total length.

\section{Determining Long-Term Effects of Fishing Exclusion at Point Lobos}

Diets were compared between fish collected at the old Point Lobos MPA and corresponding reference areas to assess the effects of increased conspecific densities after more than 30 years of fishing closure. Diets were compared using the following metrics: 1) richness; 2) evenness; 3 ) composition; 4) trophic level and 5) individual specialization (Fig. 6). The Point Lobos reference area consists of two locations situated north and south of the MPA (Fig. 3). The results of a preliminary study, using the analyses described in the subsequent paragraphs, indicated that diets in the north and south reference areas did not differ significantly from each other in terms of the five metrics 
listed above $(\mathrm{p}>0.05)$ except for prey composition $(\mathrm{p}<0.05)$. Therefore, these reference areas were pooled for subsequent comparison to the old MPA in all analyses except for prey composition.

Determining the Effects of Fishing Exclusion

Marine Protected Areas Studied
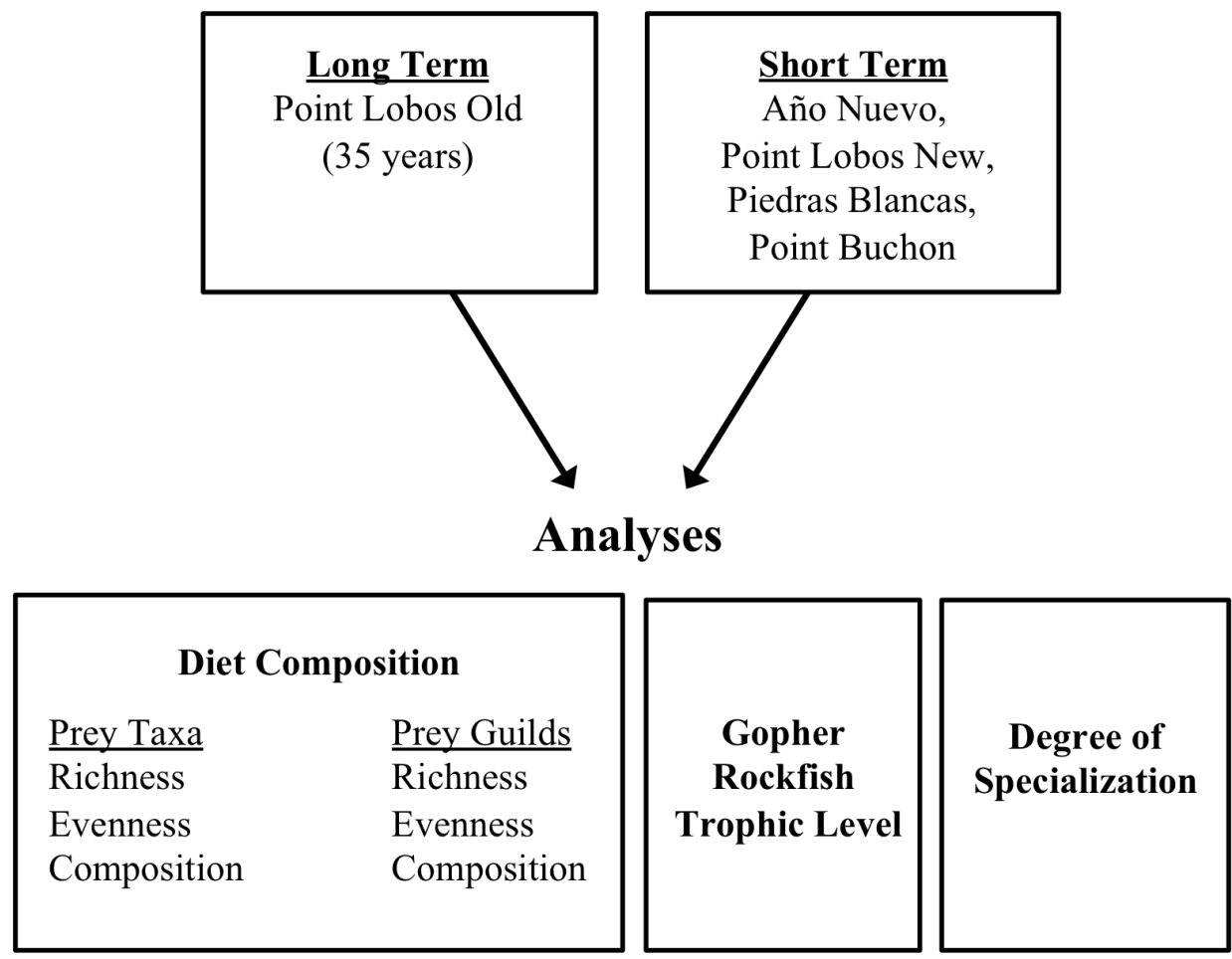

Fig. 6. Methods flow chart for determining the effects of fishing exclusion in MPAs. A similar suite of analyses was performed to compare the diets inside and outside of the old Point Lobos MPA (long-term effects), and inside and outside of four newly established MPAs (short-term effects). 
Diet richness, evenness, and composition were characterized at two levels by organizing prey into 1) taxonomic groups and 2) feeding guilds. Prey were classified into 18 taxonomic groups (Table 1). This classification strikes a balance between richness and ecological similarity by seeking to incorporate the lowest taxonomic groups to which prey were consistently identified, and grouping taxa with highly similar morphologies and ecologies. These taxa exclude crabs and shrimp that could not be identified to the family level, and also exclude sipunculans, urchins, and anemones, which were only encountered in one or two fish stomachs. To assess the functional role of the Gopher Rockfish as a predator and investigate differences in food web structure inside and outside of MPAs, prey were also classified into seven ecological feeding guilds based on a literature review (Simenstad et al. 1979, Morris et al. 1980, Carroll \& Winn 1989, Jensen 1995, Love 1996, Carlton 2007). A local expert in invertebrate natural history from Hopkins Marine Station was also consulted (J. Watanabe, personal communication, March 11, 2011). These classifications were made recognizing that feeding occurs across a continuous spectrum, and many organisms may show plasticity in their feeding habits (Table 2). 
Table 1. List of prey taxonomic groups used in dietary analysis.

\begin{tabular}{|l|l|}
\hline Prey Taxon & Groups Included \\
\hline amphipod & Amphipoda \\
brittle star & Ophiuroidea \\
Cancer crab & Cancer spp. \\
cephalopod & Cephalopoda \\
crangon shrimp & Crangonidae \\
fish & Actinopterygii \\
hermit crab & Paguridae \\
hippolytid shrimp & Hippolytidae \\
isopod & Isopoda \\
kelp crab & Epialtidae \\
mollusc & Mollusca, excluding Cephalopoda \\
mysids & Mysidacea \\
other crab & Grapsidae, Lithodidae, Panopeidae, \\
& Parthenopidae, Xanthidae, \\
pandalid shrimp & Pandalidae \\
pistol shrimp & Alpheidae \\
polychaete & Polychaeta \\
porcelain crab & Porcellanidae \\
spider crab & Pisidae \\
\hline
\end{tabular}


Table 2. List of prey feeding guilds used in dietary analysis.

\begin{tabular}{|c|c|}
\hline Prey Feeding Guild & Description \\
\hline Herbivore & Grazes on macro or microalgae \\
\hline Suspension Feeder & Filters particles out of the water \\
\hline Detritivore & Eats detritus \\
\hline Detriti-Carnivore & Eats detritus and invertebrates \\
\hline Multivore & $\begin{array}{l}\text { Eats algae and mostly sessile } \\
\text { invertebrates, may eat detritus }\end{array}$ \\
\hline Carnivore (Invertebrates) & Eats mobile invertebrates \\
\hline $\begin{array}{l}\text { Carnivore (Invertebrates } \\
\text { and Fishes) }\end{array}$ & Eats mobile invertebrates and fishes \\
\hline
\end{tabular}

Richness and Evenness. Prey accumulation as a function of number of samples was plotted to determine if sufficient samples were collected to characterize the diets of the MPA and reference areas at the level of both taxonomic groups and feeding guilds (Ferry \& Cailliet 1996). The relationships were plotted using the "specaccum" function in the Vegan Community Ecology package of the software program R 2.10.1 (Oksanen et al. 2010). The inflection points of curves were compared by visual inspection to determine if adequate samples had been collected to make comparisons between areas. An additional criterion was also applied to determine if the curves reached an asymptote by performing a linear regression using the last four points of each curve (Bizzarro et al. 2007). If the slope of the regression line $(b)$ was $\leq 0.05$, curves were considered to have reached an asymptote.

Diet evenness was calculated using Pielou's evenness measure $\left(\mathrm{J}^{\prime}\right)$ :

$$
J^{\prime}=\frac{-\sum p_{j} \log p_{j}}{\log n}
$$


Where $p_{j}$ is the proportion of individuals that ate prey type $j$, and $n$ is the total number of prey types, or richness (Krebs 1999).

Prey Composition. To reduce the effects of variation in diet biomass among fish of different sizes, differences in prey composition were investigated at the prey taxon and guild levels using standardized prey weights. These standardized weights were calculated for each stomach by dividing the raw weight of the prey taxon or guild of interest by the weight of the fish to reduce the potential influence of fish size on prey quantity. Prey weight was used because it is an approximation of the energetic contribution of a prey type in an animal's diet, and it does not overemphasize the contribution of highly numerous prey items (Hyslop 1980). Population prey composition was then determined by summing the standardized prey weights for an equal number of fish randomly drawn from the areas being compared.

To reduce the bias from unequal numbers of fish collected at each area, population totals for the old Point Lobos MPA and reference area were calculated by randomly drawing four fish from each of six sampling grid cells in each area, and summing the standardized prey weights of the four fish in each grid cell. These sample sizes included grid cells from both hook-and-line and trapping surveys, and maximized the number of grid cells and number of fish per grid cell in each area.

A Randomized Complete Block Multivariate Analysis of Variance (RCB MANOVA, Quinn \& Keough 2002) was used to determine if prey composition differed between the MPA and reference areas. Because the number of diet categories was very large relative to the number of samples and could introduce type I error, a Principal 
Components Analysis (PCA, Quinn \& Keough 2002) was performed prior to analysis on total prey weights to reduce prey composition into two factors. RCB MANOVAs were performed on ten random draws of equal numbers of fish from each area, and the percentage of significant results was calculated. PCAs and MANOVAs were performed using the software package PASW Statistics 18.0.

Trophic Level. The trophic level of each fish was calculated from stomach contents as described above. An independent two-sample t-test was used to detect differences in mean trophic level between the MPA and pooled areas.

Individual Specialization. Individual specialization (IS) was calculated following Bolnick et al. (2002). This index incorporates Czekanowski's proportional similarity index (PS) calculated as the overlap between an individual and the population:

$$
P S_{i}=\sum_{j} \min \left(p_{i j}, q_{j}\right)
$$

where $P S_{i}$ is the proportional overlap between individual $i$ and its population, $p_{i j}$ is the proportion of prey group $j$ in the individual $i$ 's diet, and $q_{j}$ is the proportion of prey group $j$ in the population as a whole. Percent number data were used to calculate $p_{i j}$ and $q_{j}$.

The index of individual specialization (IS) is then calculated as:

$$
I S=\frac{1}{N} \sum_{i} P S_{i}
$$

where $N$ is the total number of individuals in the population. An independent two-sample t-test was used to detect differences in IS values between the MPA and reference area. 


\section{Determining Short-Term Effects of Fishing Exclusion at Four Newly Established MPAs}

To examine the effects of conspecific density on Gopher Rockfish feeding habits across the central California region, diets were compared inside and outside of four MPAs established in 2007 at Año Nuevo, Point Lobos, Piedras Blancas, and Point Buchon. Only data from 2008 and 2009 were included in comparisons of all locations because the Piedras Blancas location was not sampled in 2007. Analyses were essentially the same as for the comparison between the old MPA and reference areas at Point Lobos (Fig. 6). However, there were a few differences, such as the scale of the measurements. In this set of analyses, a population value derived from combining fish from multiple grid cells was used as a sample rather than an individual grid cell.

To detect differences at the population level that could be obscured by averaging individual variation, population total values were calculated for each measure (i.e., richness, evenness, composition). These population totals were calculated after summing prey contents for 31 fish randomly drawn from each MPA and reference area. This number represents the smallest number of fish collected at a given area in 2008 and 2009 (Point Buchon reference area). Geographic location was treated as a block effect in all analyses.

Similarity. In addition to the diet metrics listed above, similarity was compared among 31 stomachs randomly drawn from each MPA and reference area using the HornMorisita Index (Krebs 1999): 


$$
C_{H}=\frac{2 \sum_{i=1}^{n} p_{i j} p_{i k}}{\sum_{i=1}^{n} p_{i j}^{2}+\sum_{i=1}^{n} p_{i k}^{2}}
$$

This measure calculates the similarity between group $j$ and group $k$ where $p_{i j}$ is the proportion that prey type $i$ constitutes in the total resources used by group $j, p_{i k}$ is the proportion that prey type $i$ constitutes in the total resources used by group $k$, and $n$ is the total number of prey types. This measure is appropriate when resources are expressed as proportions. The old Point Lobos MPA was included in this analysis for comparison to the other MPAs. All pair-wise comparisons of MPAs and reference areas were qualitatively evaluated with an index value $>0.70$ considered similar and an index value $<0.40$ considered dissimilar.

\section{Determining Effects of Other Factors on Diet}

The remainder of the study investigated factors other than fishing exclusion that could affect Gopher Rockfish diet. Therefore, the following analyses were conducted without taking the effects of MPAs and reference areas into account. The factors examined included overall fish density at an area regardless of its protected status, as well as environmental variables.

Relationship Between Diet and Fish Density. Individual linear regressions were used to investigate the relationship between Gopher Rockfish density and dietary variables. Mean prey taxon and guild richness and evenness, trophic level, and individual 
specialization were calculated for each area as described above. Linear regressions were then used to test for relationships between these variables and the average Gopher Rockfish density at each area expressed as catch per unit effort (CPUE), which is calculated as the number of fish caught per hour spent fishing with hook and line (Starr et al. 2010).

Relationship Between Diet and Environmental Variables. To investigate the potential influence of environmental variables on diet that could contribute to differences among geographic locations, a Canonical Correlation Analysis (Quinn \& Keough 2002) was conducted using environmental and dietary variables calculated for each sampling grid cell. Environmental variables included depth, temperature at depth, area of hard substrate, and latitude. Depth of collection for each fish was measured using the boat's depth finder, and was averaged for all fish collected within a grid cell. Temperature at depth in each grid cell was collected throughout the study in each grid cell using a continuously recording sensor lowered to ten feet above the seafloor. All temperature at depth measurements were averaged for a grid cell. The proportion of hard substrate within each grid cell was calculated in the software program ArcGIS 9.2 using habitat layers from the Seafloor Mapping Lab of California State University Monterey Bay. The habitat layers classify substrate as rock or sediment based on rugosity. The area of rock was calculated for each grid cell and expressed as a proportion of grid cell area because mapable habitat area differed among grid cells. Latitude data were taken from the coordinates of the center point of each sampling grid cell. Diet variables were calculated as standardized prey weights averaged for all fish caught in a given grid cell. Analyses 
were run at both the prey taxon and prey guild levels. Canonical correlation analysis was performed using the software package PASW Statistics 18.0.

Relationship Between Diet and Depth. A linear regression was used to further examine the relationship between diet and depth. PCA Factor 1 from the PCA analysis described above was used to summarize dietary variation. A linear regression was used to test for a relationship between the mean PCA Factor 1 score and the mean depth of fish collection at each sampling area.

\section{RESULTS}

\section{Sample Collection}

A total of 1,018 Gopher Rockfish was collected across four locations and three years. (Table 3). These fish consisted of 491 females (48\%), 515 males (51\%) and 12 fish that were too immature to confidently determine sex (1\%). An equal sex ratio was found at the Point Lobos and Point Buchon areas, while Año Nuevo had more females (56\% females, 44\% males) and Piedras Blancas had more males (34\% females, $65 \%$ males, $1 \%$ unidentified). The ratio of females to males was comparable inside and outside of the MPA at all locations. Total lengths of all fish collected ranged from $16.7 \mathrm{~cm}$ to $32.9 \mathrm{~cm}$, with a mean of $26.4 \mathrm{~cm}$ (Fig. 7); and an RCB ANOVA showed that length did not significantly differ inside and outside of MPAs $\left(\mathrm{F}_{1,243}=1.944, \mathrm{p}=0.164\right)$; however, the block factor of geographic location was significant $\left(\mathrm{F}_{3,243}=21.045, \mathrm{p}<0.001\right)$. Of the 
1,018 fish collected, 308 had empty stomachs (30.3\%), and diet composition was analyzed for the remaining 710 fish.

Table 3. Total and effective sample size by location, area, and year. Unbolded numbers represent the total number of Gopher Rockfish collected and numbers in bold represent Gopher Rockfish with stomach contents used for dietary analyses. "Point Lobos MPA" refers to fish collected without a record of whether they were from the old or new MPA, and these fish were not included in dietary analyses.

\begin{tabular}{|l|cc|cc|cc|cc|}
\hline Location and Area & \multicolumn{2}{|c|}{2007} & \multicolumn{2}{|c|}{2008} & \multicolumn{2}{c|}{2009} & \multicolumn{2}{c|}{ Totals } \\
\hline Año Nuevo MPA & 28 & $\mathbf{1 9}$ & 53 & $\mathbf{4 6}$ & 60 & $\mathbf{5 6}$ & 141 & $\mathbf{1 2 1}$ \\
Año Nuevo REF & 31 & $\mathbf{2 3}$ & 41 & $\mathbf{3 9}$ & 53 & $\mathbf{4 9}$ & 125 & $\mathbf{1 1 1}$ \\
Point Lobos Old MPA & 49 & $\mathbf{2 3}$ & 56 & $\mathbf{3 8}$ & 60 & $\mathbf{4 5}$ & 165 & $\mathbf{1 0 6}$ \\
Point Lobos New MPA & 45 & $\mathbf{2 0}$ & 22 & $\mathbf{1 5}$ & 55 & $\mathbf{4 1}$ & 122 & $\mathbf{7 6}$ \\
Point Lobos MPA & 5 & $\mathbf{3}$ & 0 & $\mathbf{0}$ & 0 & $\mathbf{0}$ & 5 & $\mathbf{3}$ \\
Point Lobos REF & 58 & $\mathbf{3 0}$ & 53 & $\mathbf{3 6}$ & 66 & $\mathbf{5 6}$ & 177 & $\mathbf{1 2 2}$ \\
Piedras Blancas MPA & 0 & $\mathbf{0}$ & 31 & $\mathbf{2 3}$ & 31 & $\mathbf{1 6}$ & 62 & $\mathbf{3 9}$ \\
Piedras Blancas REF & 0 & $\mathbf{0}$ & 25 & $\mathbf{1 4}$ & 36 & $\mathbf{3 0}$ & 61 & $\mathbf{4 4}$ \\
Point Buchon MPA & 37 & $\mathbf{1 1}$ & 28 & $\mathbf{1 8}$ & 29 & $\mathbf{2 2}$ & 94 & $\mathbf{5 1}$ \\
Point Buchon REF & 11 & $\mathbf{6}$ & 27 & $\mathbf{1 4}$ & 28 & $\mathbf{1 7}$ & 66 & $\mathbf{3 7}$ \\
\hline Totals & 264 & $\mathbf{1 3 5}$ & 336 & $\mathbf{2 4 3}$ & 418 & $\mathbf{3 3 2}$ & 1018 & $\mathbf{7 1 0}$ \\
\hline
\end{tabular}



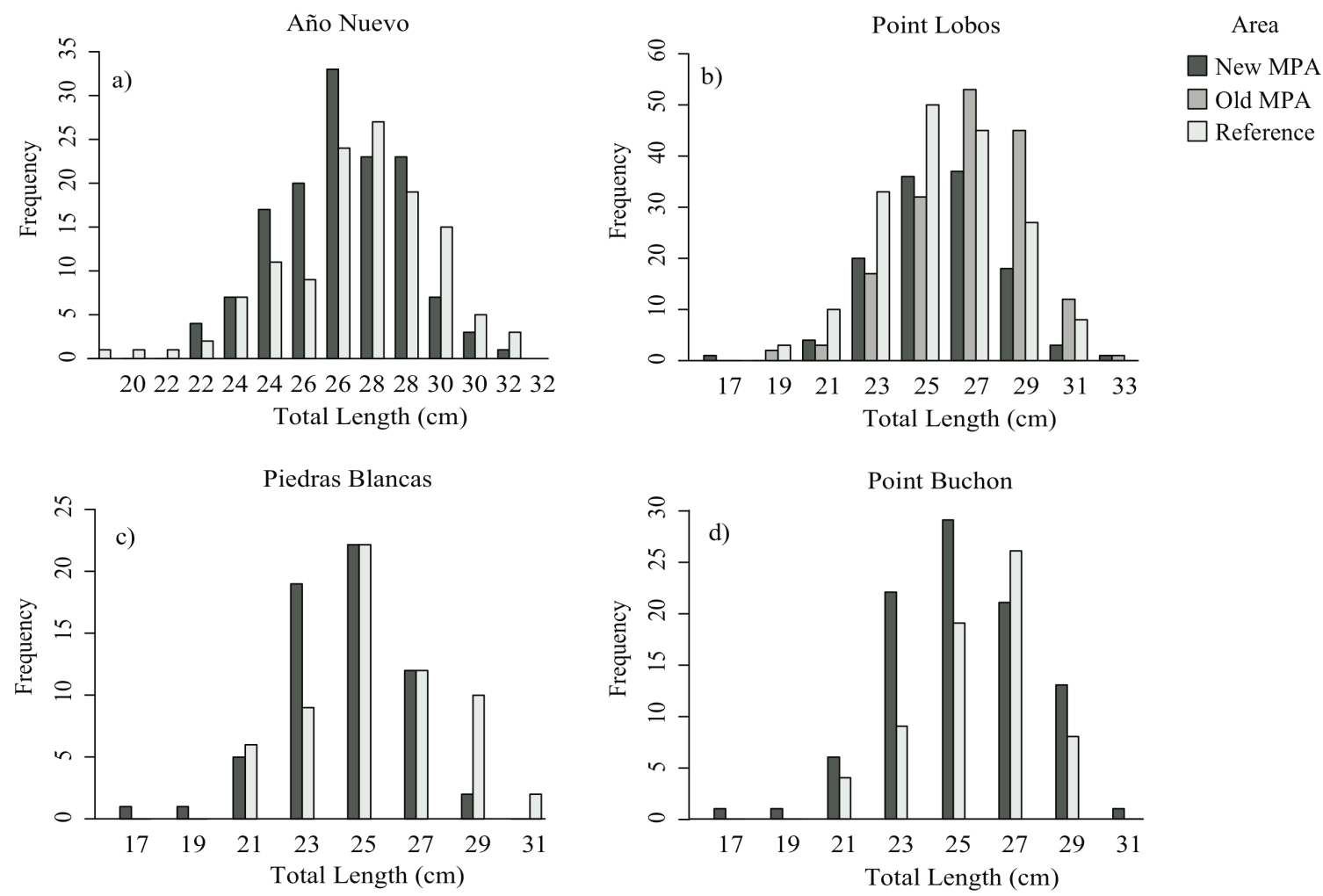

Fig. 7. Total length frequency distribution of Gopher Rockfish by location and area. a) Año Nuevo. Mean length in the MPA $=27.9 \mathrm{~cm}$, and mean length in the reference area $=$ $28.1 \mathrm{~cm}$. b) Point Lobos. Mean length in the old MPA $=27.0 \mathrm{~cm}$, mean length in the new MPA $=26.0 \mathrm{~cm}$, and mean length in the reference area $=25.81 \mathrm{~cm}$. c) Piedras Blancas. Mean length in the MPA $=24.5 \mathrm{~cm}$, and mean length in the reference area $=$ $25.6 \mathrm{~cm}$. d) Point Buchon. Mean length in the MPA $=25.2 \mathrm{~cm}$, and mean length in the reference area $=25.9 \mathrm{~cm}$.

\section{Overall Diet Description and Trophic Level}

More than 10,500 prey items were identified and categorized into 83 taxonomic groups representing 7 phyla and at least 60 distinct species (Table 4). Overall, decapod crustaceans dominated the diet by far (70.04\% PSIRI), and consisted primarily of 20 different crab species (45.9\% PSIRI), shrimps (14.5\% PSIRI), and mysids (7.2\% PSIRI, 
Fig. 8). Echinoderms consisting predominantly of brittle stars were also important to the $\operatorname{diet}(18.26 \%$ PSIRI). At the highest level of taxonomic resolution, the most important individual taxa in the overall diet were Ophiothrix spiculata (15.5\% PSIRI), crabs of the family Pisidae that consisted of Scyra acutifrons and Loxorhynchus crispatus $(14.0 \%$ PSIRI), Cancer antennarius (8.3\% PSIRI), and mysids (7.2\% PSIRI). Due to the difficulty in distinguishing Scyra acutifrons from juvenile Loxorhynchus crispatus, these crabs were identified only to family. Some mature females with eggs were positively identified as Scyra acutifrons, since mature Loxorhynchus crispatus are too large to be consumed whole by Gopher Rockfish. Mysids constituted about 70\% of the total number of prey items identified, and had the highest percent prey-specific number values of any prey group (Fig. 9). Gopher Rockfish also consumed a few organisms generally considered unpalatable, including nudibranchs and anemones. 
Table 4. Diet composition of the Gopher Rockfish. Diet indices include average percent number $(\% \mathrm{~N})$, average percent weight $(\% \mathrm{~W})$, percent occurrence $(\% \mathrm{O}$, percent prey-specific number ( $\% \mathrm{PSN})$, percent prey-specific weight $(\% \mathrm{PSW})$, and percent prey-specific index of relative importance (\%PSIRI). Guild codes: $\mathrm{CI}=$ Carnivore (Invertebrates), $\mathrm{CIF}=$ Carnivore (Invertebrates and Fishes), $\mathrm{D}=$ Detritivore, $\mathrm{DC}=$ Detriti-Carnivore, $\mathrm{H}=$ Herbivore, $\mathrm{M}=$ Multivore, $\mathrm{S}=$ Suspension Feeder. ${ }^{\dagger}$ Indicates only mature females.

\begin{tabular}{|c|c|c|c|c|c|c|c|}
\hline $\begin{array}{l}\text { Lowest } \\
\text { Identification }\end{array}$ & $\% \mathbf{N}$ & $\% W$ & $\% \mathrm{O}$ & $\%$ PSN & \%PSW & $\%$ PSIRI & Guild \\
\hline Arthropoda & 73.19 & 66.89 & & & & 70.04 & \\
\hline Pisidae & 10.27 & 11.44 & 30.99 & 33.15 & 36.91 & 10.85 & M \\
\hline$\overline{\text { Scyra acutifrons }}{ }^{\dagger}$ & 2.59 & 3.76 & 6.90 & 37.58 & 54.55 & 3.18 & M \\
\hline \multicolumn{8}{|l|}{ Cancridae } \\
\hline Cancer antennarius & 6.11 & 10.45 & 18.31 & 33.35 & 57.06 & 8.28 & $\mathrm{CI}$ \\
\hline Cancer sp. & 4.51 & 3.85 & 16.62 & 27.14 & 23.18 & 4.18 & $\mathrm{CI}$ \\
\hline Cancer jordani & 1.55 & 2.56 & 5.92 & 26.25 & 43.19 & 2.05 & CI \\
\hline Cancer productus & 0.46 & 0.22 & 1.83 & 25.36 & 12.24 & 0.34 & $\mathrm{CI}$ \\
\hline Cancer branneri & 0.01 & 0.05 & 0.14 & 8.33 & 34.46 & 0.03 & CI \\
\hline Mysidacea & 10.11 & 4.35 & 13.94 & 72.51 & 31.19 & 7.23 & $\mathrm{~S}$ \\
\hline Porcellanidae & 0.18 & 0.14 & 0.70 & 25.56 & 20.09 & 0.16 & $\mathrm{~S}$ \\
\hline $\begin{array}{l}\text { Pachycheles sp. } \\
\text { Pachycheles }\end{array}$ & 4.00 & 3.70 & 13.52 & 29.56 & 27.35 & 3.85 & $\mathrm{~S}$ \\
\hline pubescens & 1.27 & 1.53 & 3.52 & 36.01 & 43.33 & 1.40 & $\mathrm{~S}$ \\
\hline Pachycheles rudis & 0.07 & 0.14 & 0.56 & 12.64 & 25.66 & 0.11 & $\mathrm{~S}$ \\
\hline Petrolisthes eriomerus & 0.81 & 0.69 & 2.54 & 32.11 & 27.30 & 0.75 & S \\
\hline Petrolisthes sp. & 0.52 & 0.28 & 2.96 & 17.57 & 9.46 & 0.40 & $\mathrm{~S}$ \\
\hline Hippolytidae & 4.37 & 2.27 & 18.45 & 23.68 & 12.30 & 3.32 & $\mathrm{DC}$ \\
\hline Spirontocaris prionota & 1.78 & 0.99 & 8.73 & 20.38 & 11.28 & 1.38 & DC \\
\hline Heptacarpus sp. & 0.45 & 0.61 & 1.27 & 35.37 & 48.08 & 0.53 & $\mathrm{DC}$ \\
\hline$\underline{\text { Alpheidae }}$ & 0.28 & 0.32 & 1.69 & 16.65 & 18.74 & 0.30 & $\mathrm{DC}$ \\
\hline Alpheus bellimanus & 1.73 & 2.38 & 5.49 & 31.56 & 43.36 & 2.06 & DC \\
\hline Alpheus clamator & 0.38 & 0.45 & 1.55 & 24.74 & 29.36 & 0.42 & DC \\
\hline Betaeus setosus & 0.10 & 0.05 & 0.99 & 10.15 & 5.37 & 0.08 & $\mathrm{DC}$ \\
\hline $\begin{array}{l}\text { Synalpheus lockingtoni } \\
\text { Pandalidae }\end{array}$ & 0.02 & 0.01 & 0.14 & 14.29 & 5.35 & 0.01 & $\mathrm{DC}$ \\
\hline $\begin{array}{l}\text { Pandalus sp. } \\
\text { Epialtidae }\end{array}$ & 1.93 & 2.91 & 7.89 & 24.46 & 36.90 & 2.42 & $\mathrm{DC}$ \\
\hline Pugettia richii & 1.70 & 2.29 & 4.37 & 38.84 & 52.41 & 1.99 & M \\
\hline Pugettia sp. & 1.08 & 0.99 & 4.08 & 26.34 & 24.16 & 1.03 & M \\
\hline Pugettia gracillis & 0.65 & 0.70 & 2.54 & 25.62 & 27.56 & 0.67 & M \\
\hline Pugettia producta & 0.26 & 0.16 & 0.99 & 26.80 & 15.94 & 0.21 & M \\
\hline Mimulus foliatus & 0.34 & 0.66 & 1.27 & 26.95 & 52.29 & 0.50 & M \\
\hline
\end{tabular}




\begin{tabular}{|c|c|c|c|c|c|c|c|}
\hline $\begin{array}{l}\text { Lowest } \\
\text { Identification }\end{array}$ & $\% \mathbf{N}$ & $\% W$ & $\% \mathrm{O}$ & $\%$ PSN & $\%$ PSW & \%PSIRI & Guild \\
\hline \multicolumn{8}{|l|}{ Panopeidae } \\
\hline $\begin{array}{l}\text { Lophopanopeus bellus } \\
\text { Crangonidae }\end{array}$ & 1.06 & 1.25 & 3.52 & 30.01 & 35.44 & 1.15 & M \\
\hline $\begin{array}{l}\text { Crangon sp. } \\
\text { Amphipoda }\end{array}$ & 1.13 & 0.64 & 4.93 & 22.86 & 13.03 & 0.88 & $\mathrm{DC}$ \\
\hline Gammaridea & 1.38 & 0.18 & 5.92 & 23.28 & 3.04 & 0.78 & $\mathrm{DC}$ \\
\hline Caprellidae & 0.45 & 0.02 & 2.39 & 18.73 & 0.78 & 0.23 & $\mathrm{M}$ \\
\hline Xanthidae & & & & & & & \\
\hline Paraxanthias taylori & 0.49 & 0.74 & 1.27 & 38.70 & 58.19 & 0.61 & $\mathrm{H}$ \\
\hline Isopoda & 0.80 & 0.36 & 4.08 & 19.60 & 8.76 & 0.58 & $\mathrm{D}$ \\
\hline Idotea resecata & 0.26 & 0.38 & 0.85 & 31.15 & 44.66 & 0.32 & $\mathrm{H}$ \\
\hline Idotea $\mathrm{sp}$. & 0.46 & 0.18 & 1.83 & 24.86 & 10.06 & 0.32 & $\mathrm{H}$ \\
\hline Idotea rufescens & 0.18 & 0.11 & 0.56 & 32.74 & 19.07 & 0.15 & $\mathrm{H}$ \\
\hline Lithodidae & & & & & & & \\
\hline Phyllolithodes & & & & & & & \\
\hline papillosus & 0.37 & 0.76 & 1.69 & 22.14 & 45.23 & 0.57 & M \\
\hline $\begin{array}{l}\text { Cryptolithodes typicus } \\
\text { Hapalogaster }\end{array}$ & 0.12 & 0.16 & 0.42 & 28.89 & 38.64 & 0.14 & M \\
\hline cavicauda & 0.05 & 0.14 & 0.14 & 33.33 & 99.03 & 0.09 & M \\
\hline Paguridae & 0.62 & 0.31 & 3.24 & 19.22 & 9.44 & 0.46 & M \\
\hline Pagurus granosimanus & 0.09 & 0.04 & 0.28 & 33.33 & 13.99 & 0.07 & M \\
\hline Grapsidae & & & & & & & \\
\hline Hemigrapsus nudus & 0.00 & 0.12 & 0.14 & 1.27 & 81.85 & 0.06 & M \\
\hline $\begin{array}{l}\text { Parthenopidae } \\
\text { Heterocrypta } \\
\text { occidentalis }\end{array}$ & 0.05 & 0.04 & 0.14 & 33.33 & 28.36 & 0.04 & CI \\
\hline Unidentified shrimp & 5.05 & 1.14 & 17.75 & 28.47 & 6.44 & 3.10 & DC \\
\hline Unidentified crab & 2.85 & 2.32 & 10.42 & 27.34 & 22.23 & 2.58 & $\mathrm{CI}$ \\
\hline Unidentified crustacean & 0.24 & 0.06 & 0.85 & 27.84 & 7.16 & 0.15 & \\
\hline Echinodermata & 16.27 & 20.24 & & & & 18.26 & \\
\hline Ophiothrix spiculata & 13.89 & 17.04 & 32.25 & 43.05 & 52.82 & 15.46 & $\mathrm{D}$ \\
\hline Ophiopholis kennerlyi & 1.62 & 2.22 & 7.46 & 21.71 & 29.69 & 1.92 & $\mathrm{D}$ \\
\hline $\begin{array}{l}\text { Ophiopteris papillosa } \\
\text { Strongylocentrotrus }\end{array}$ & 0.69 & 0.97 & 1.83 & 37.95 & 52.76 & 0.83 & $\mathrm{DC}$ \\
\hline purpuratus & 0.07 & 0.02 & 0.28 & 25.00 & 8.23 & 0.05 & $\mathrm{H}$ \\
\hline Chordata & & & & & & & \\
\hline Actinopterygii) & 3.33 & 5.18 & & & & 4.26 & \\
\hline Unidentified fish & 1.64 & 2.13 & 7.61 & 21.51 & 28.05 & 1.88 & CIF \\
\hline Cottidae & 0.76 & 1.75 & 4.08 & 18.69 & 42.87 & 1.26 & $\mathrm{CI}$ \\
\hline Sebastes sp. & 0.42 & 0.59 & 1.83 & 23.10 & 32.43 & 0.51 & CI \\
\hline Clupeidae & 0.18 & 0.17 & 0.85 & 21.77 & 20.51 & 0.18 & CIF \\
\hline Sardinops sagax & 0.05 & 0.14 & 0.42 & 12.56 & 34.24 & 0.10 & $\mathrm{CI}$ \\
\hline
\end{tabular}




\begin{tabular}{|c|c|c|c|c|c|c|c|}
\hline $\begin{array}{l}\text { Lowest } \\
\text { Identification }\end{array}$ & $\% \mathbf{N}$ & $\% W$ & $\% \mathrm{O}$ & $\%$ PSN & $\%$ PSW & \%PSIRI & Guild \\
\hline Gobiidae & 0.13 & 0.09 & 0.42 & 30.56 & 20.14 & 0.11 & CI \\
\hline Hexagrammidae & 0.05 & 0.15 & 0.28 & 18.33 & 51.72 & 0.10 & CIF \\
\hline Pleuronectiformes & 0.05 & 0.12 & 0.14 & 33.33 & 87.26 & 0.08 & CIF \\
\hline Atherinopsidae & 0.02 & 0.02 & 0.14 & 14.29 & 15.14 & 0.02 & CI \\
\hline Stichaeidae & 0.02 & 0.01 & 0.14 & 16.67 & 8.72 & 0.02 & M \\
\hline Mollusca & 3.24 & 4.79 & & & & 4.01 & \\
\hline Cephalopoda & 0.36 & 0.15 & 2.25 & 15.94 & 6.66 & 0.25 & CIF \\
\hline $\begin{array}{l}\text { Octopus sp. } \\
\text { Doryteuthis }\end{array}$ & 1.34 & 2.91 & 5.35 & 25.07 & 54.28 & 2.12 & $\mathrm{CIF}$ \\
\hline opalescens & 0.02 & 0.23 & 0.42 & 3.91 & 55.10 & 0.12 & CIF \\
\hline Gastropoda & 0.33 & 0.10 & 1.97 & 16.96 & 4.92 & 0.22 & $\mathrm{M}$ \\
\hline$\overline{\text { Haliotis sp. }}$ & 0.28 & 0.28 & 1.97 & 14.05 & 14.10 & 0.28 & $\mathrm{H}$ \\
\hline Opisthobranchia & 0.05 & 0.05 & 0.14 & 33.33 & 36.40 & 0.05 & M \\
\hline $\begin{array}{l}\text { Triopha catalinae } \\
\text { Fissurellidea }\end{array}$ & 0.13 & 0.15 & 0.56 & 22.22 & 26.48 & 0.14 & M \\
\hline bimaculata & 0.05 & 0.08 & 0.14 & 33.33 & 57.54 & 0.06 & $\mathrm{H}$ \\
\hline Polyplacophora & 0.19 & 0.34 & 0.99 & 19.69 & 34.20 & 0.27 & $\mathrm{H}$ \\
\hline Tonicella $\mathrm{sp}$. & 0.30 & 0.31 & 0.70 & 42.02 & 43.78 & 0.30 & $\mathrm{H}$ \\
\hline$\underline{\text { Bivalvia }}$ & 0.12 & 0.13 & 0.70 & 17.65 & 18.25 & 0.13 & $\mathrm{~S}$ \\
\hline Unidentified mollusc & 0.08 & 0.07 & 0.42 & 18.65 & 16.54 & 0.07 & M \\
\hline Annelida & 2.80 & 2.16 & & & & 2.48 & \\
\hline Polychaeta & 2.40 & 1.47 & 11.13 & 21.54 & 13.23 & 1.93 & $\mathrm{DC}$ \\
\hline Aphrodita sp. & 0.41 & 0.69 & 1.83 & 22.27 & 37.70 & 0.55 & $\mathrm{D}$ \\
\hline Cnidaria & 0.08 & 0.08 & & & & 0.08 & \\
\hline Corynactis californica & 0.08 & 0.08 & 0.14 & 55.56 & 60.26 & 0.08 & $\mathrm{~S}$ \\
\hline Sipuncula & 0.06 & 0.01 & & & & $\mathbf{0 . 0 3}$ & \\
\hline Phascolosoma agassizii & 0.06 & 0.01 & 0.28 & 20.00 & 2.96 & 0.03 & $\mathrm{D}$ \\
\hline Unidentified & 1.03 & 0.64 & 4.51 & 22.77 & 14.29 & 0.84 & \\
\hline
\end{tabular}




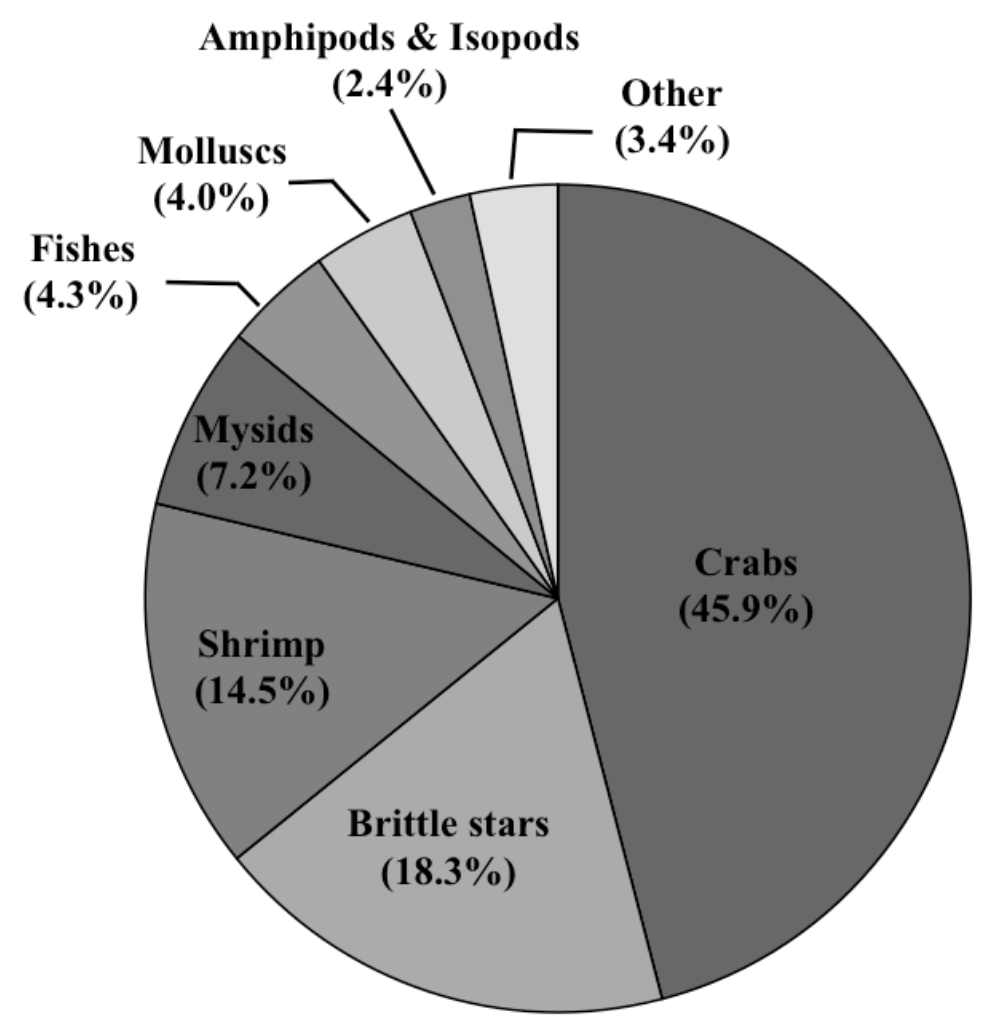

Fig. 8. Percent importance of major Gopher Rockfish prey groups. Percentages represent the Prey-Specific Index of Relative Importance (\%PSIRI) calculated for prey from all Gopher Rockfish collected. 


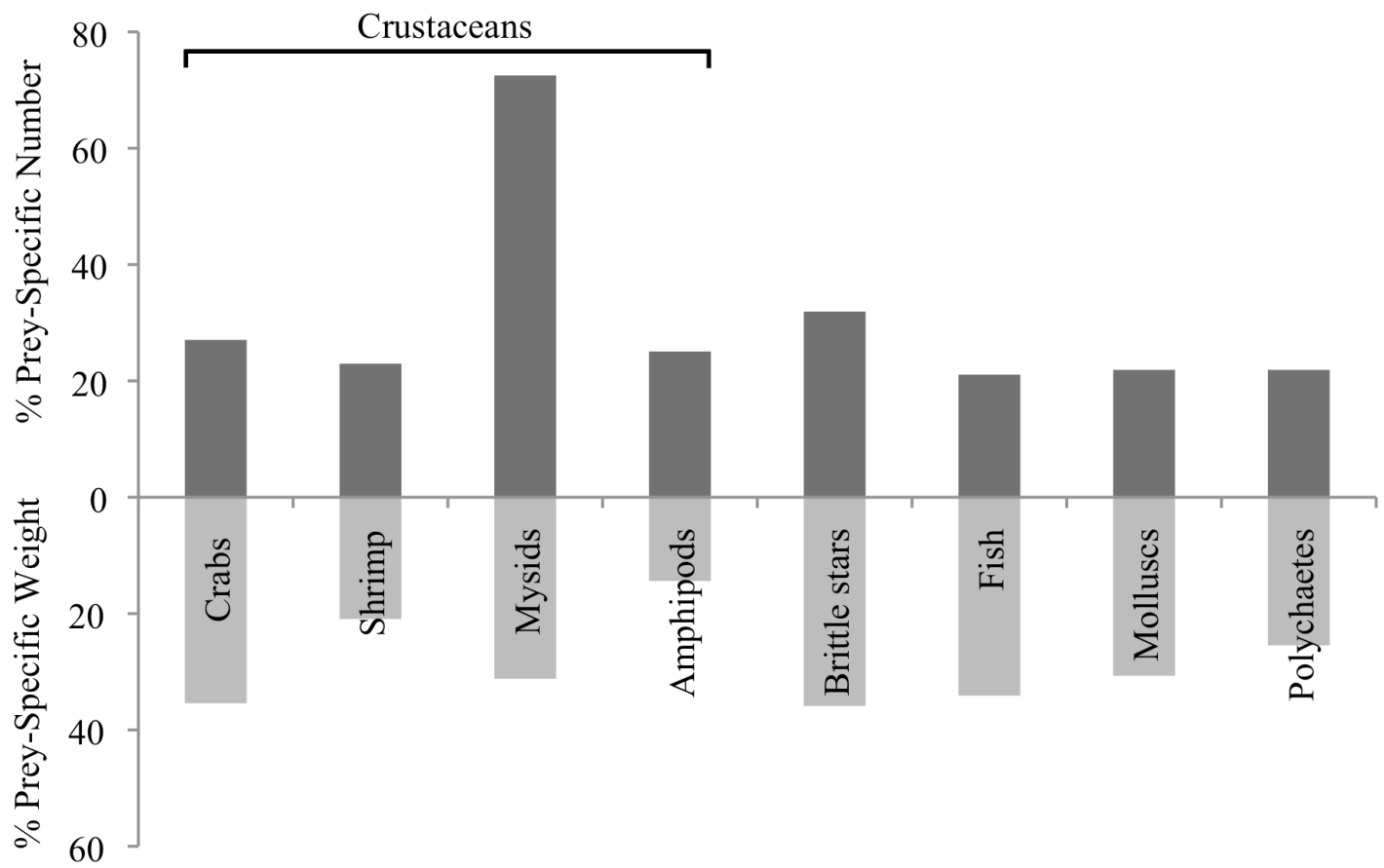

Fig. 9. Percent prey-specific number and weight values of major prey groups. Due to the high numeric abundance of mysids, dietary analyses were primarily performed using prey weights. 
Trophic level calculated from stomach contents ranged from 3.10 to 4.24 . The minimum and maximum trophic levels reflect diets composed solely of non-cephalopod molluscs and fishes, respectively. The mean trophic level calculated for all Gopher Rockfish was 3.57 , and the most frequently observed trophic level was 3.52 , which reflects a diet composed solely of decapod crustaceans (199 observations). No significant relationship $\left(p=0.23, R^{2}=0.003\right)$ was observed between trophic level and total fish length.

Determining Long-Term Effects of Fishing Exclusion at Point Lobos

Richness and Evenness. The number of stomachs used for dietary analyses was deemed sufficient. All cumulative prey curves reached an inflection point between 20 and 40 stomachs, and all curves reached an asymptote $(b<0.05)$, indicating sufficient sample size for prey taxon analysis (Fig. 10) and prey guild analysis (Fig. 11). The 122 fish with stomach contents collected at the Point Lobos reference areas included 61 fish from the north reference area, 58 from the south reference area, and 3 fish for which the location of the reference area was not recorded. 

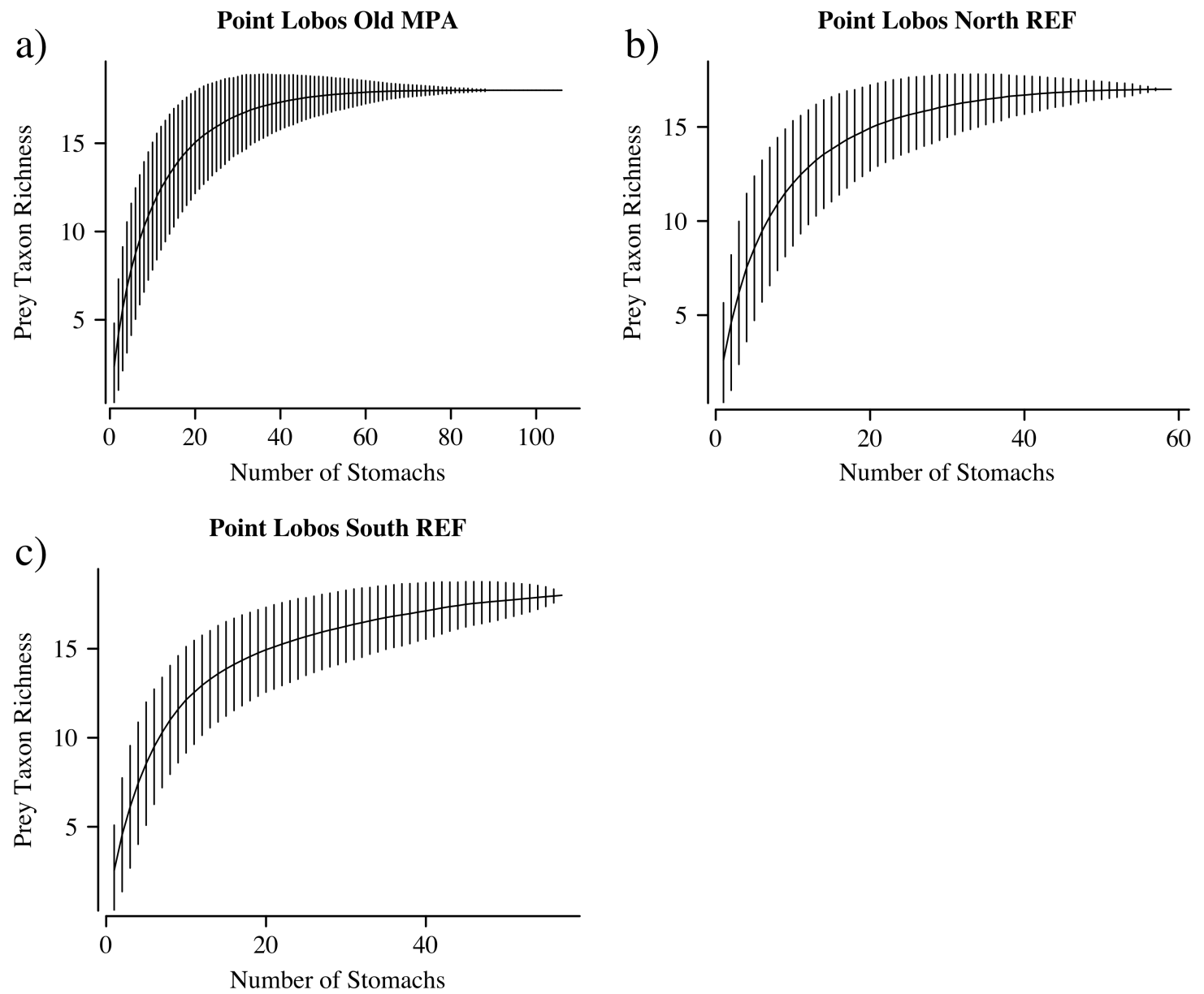

Fig. 10. Cumulative prey curves at the prey taxon level for the old MPA and reference areas at Point Lobos. a) Old Point Lobos MPA. Slope through last four points $=0$. b) Point Lobos north reference area. Slope through last four points $=0.002$. c) Point Lobos south reference area. Slope through last four points $=0.039$. 

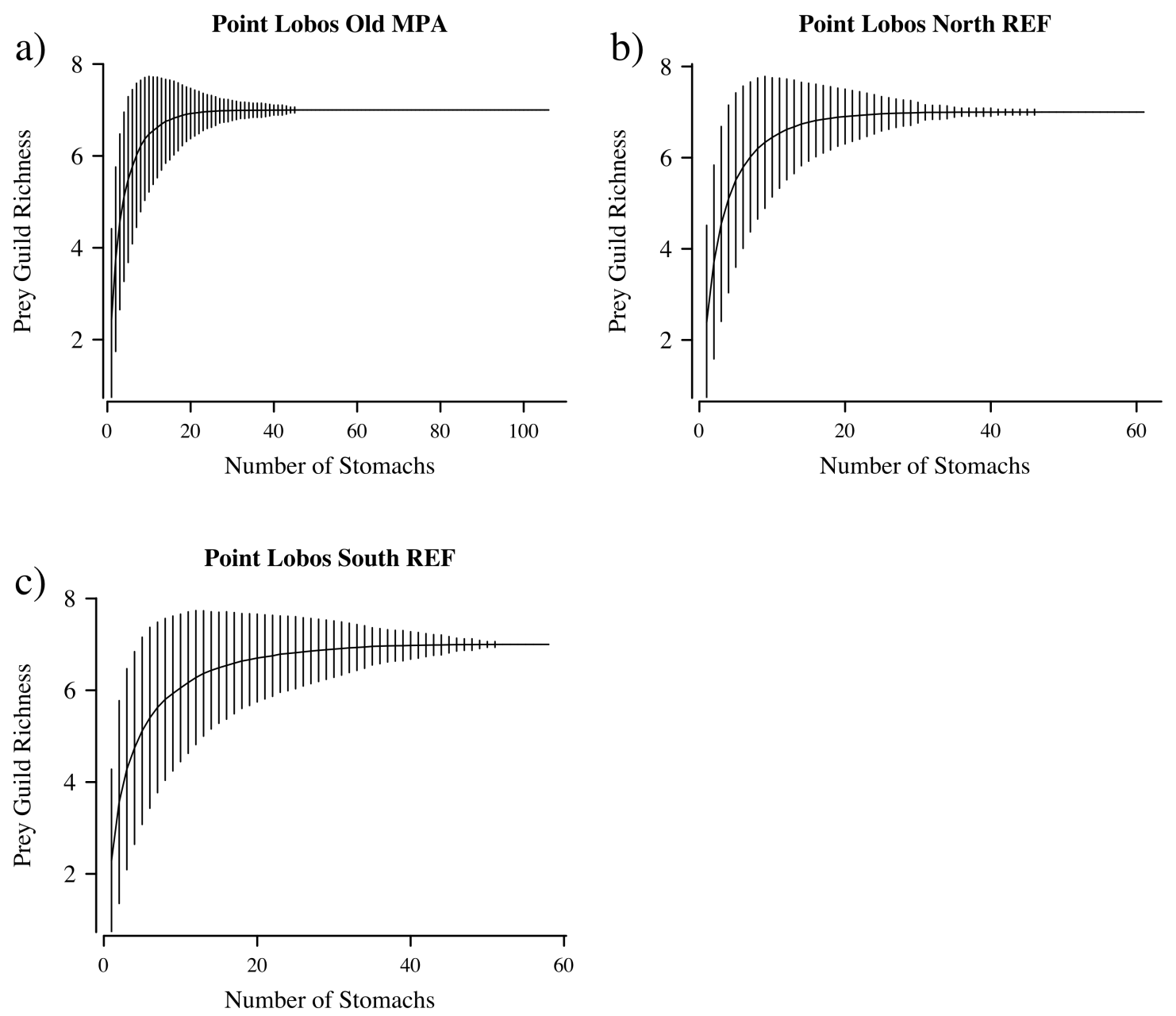

Fig. 11. Cumulative prey curves at the prey guild level for the old MPA and reference areas at Point Lobos. a) Old Point Lobos MPA. Slope through last four points $=0$. b) Point Lobos north reference area. Slope through last four points $=0$. c) Point Lobos north reference area. Slope through last four points $=0$. 
There was no detectable difference in prey richness or evenness of Gopher Rockfish diet items between the old MPA and the pooled reference areas. The MANOVA revealed that diets from the old Point Lobos MPA and pooled reference areas did not differ significantly in mean prey taxon richness (Table $5 ; \mathrm{F}_{210}=1.841, \mathrm{p}=0.176$ ) or evenness $\left(\mathrm{F}_{1,210}=1.043, \mathrm{p}=0.308\right)$. Overall diversity (the multivariate effect of richness and evenness) also did not differ between areas $\left(\mathrm{F}_{2,209}=1.024, \mathrm{p}=0.361\right)$. Likewise, a MANOVA showed that mean richness, evenness, and overall diversity of prey at the guild level did not differ significantly (respectively $F_{1,210}=0.004, p=0.948$; $\left.\mathrm{F}_{1,210}=0.012, \mathrm{p}=0.912 ; \mathrm{F}_{2,209}=0.006, \mathrm{p}=0.994\right)$ between the old MPA and the pooled reference areas. 


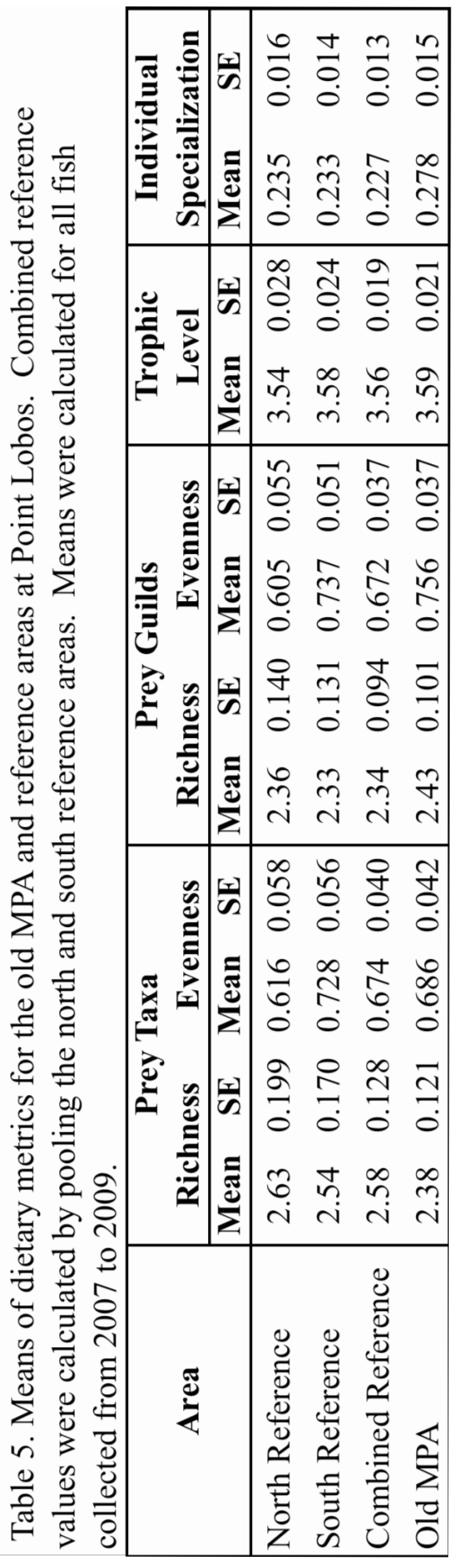


Prey Composition. Prey taxon composition, as measured by Principal Components 1 and 2, slightly differed between the north and south reference areas. Three of ten random draws of 56 fish from each area revealed significant differences $(\mathrm{p}$ $<0.05)$ between north and south reference areas, and nearly significant differences $(\mathrm{p}<$ 0.10 ) in an additional $30 \%$ of analyses. Therefore, the north and south reference areas were not pooled for comparisons in prey taxon composition among the old Point Lobos MPA and the reference areas. Prey guild composition, as measured by Principal Components 1 and 2, did not differ significantly $(p>0.05)$ between north and south reference areas. Therefore, these areas were pooled for comparison to the old MPA at the prey guild level.

There were no detectable differences in prey taxon composition (as measured by Principal Components 1 and 2) between the old MPA and the reference areas. For all ten random draws of 106 fish from each area, MANOVA showed that prey taxon composition did not differ significantly $(\mathrm{p}>0.05)$ among the old Point Lobos MPA and the north and south reference areas. Principal Components 1 and 2 respectively explained $17.5 \%$ and $14.9 \%$ of the dietary variation on average.

Prey guild composition, as measured by Principal Components 1 and 2, also did not significantly differ between the old MPA and pooled reference areas. For all ten random draws of 106 fish from each area, MANOVA showed that prey taxon composition did not differ significantly $(\mathrm{p}>0.05)$ among the old Point Lobos MPA and the pooled reference areas. Principal Components 1 and 2 respectively explained $30.4 \%$ and $25.0 \%$ of the dietary variation on average. 
Trophic Level. More than 30 years of fishing exclusion did not appear to alter the trophic level of the Gopher Rockfish calculated from stomach contents. Trophic level in the old Point Lobos MPA ranged from 3.16 to 4.24, with a mean of 3.59, as opposed to the pooled reference areas, which ranged from 3.10 to 4.24 with a mean of 3.56 (Table 5). The two-tailed $t$-test showed that these differences were not significant $(\mathrm{t}(210)=$ $0.775, \mathrm{p}=0.439)$

Individual Specialization. The extent of individual specialization differed significantly between the old MPA and pooled reference areas. Mean IS, the overlap between individuals and their population, was 0.227 for the combined north and south reference areas, as opposed to a mean of 0.278 for the old MPA. The two-tailed t-test showed that these differences were significant $(\mathrm{t}(201)=2.566, \mathrm{p}=0.011)$. Thus, in comparison to the old MPA, individuals in the reference area were on average 5\% more specialized in relation to their population as a whole.

\section{Determining Short-Term Effects of Fishing Exclusion at Four Newly Established} MPAS

Richness and Evenness. The number of stomachs used for dietary analyses was deemed sufficient. All cumulative prey curves reached an inflection point between 20 and 40 stomachs. Additionally, all curve slopes for prey guild analysis met the criterion $(b<0.05)$ of an asymptote (Table 6). While some of the curve slopes for prey taxon 
analysis deviated from an asymptote, these deviations were not considered severe, and were likely caused by rare prey items. Therefore, analyses were still performed using these prey taxonomic groups while recognizing the potential underestimate of richness at these areas.
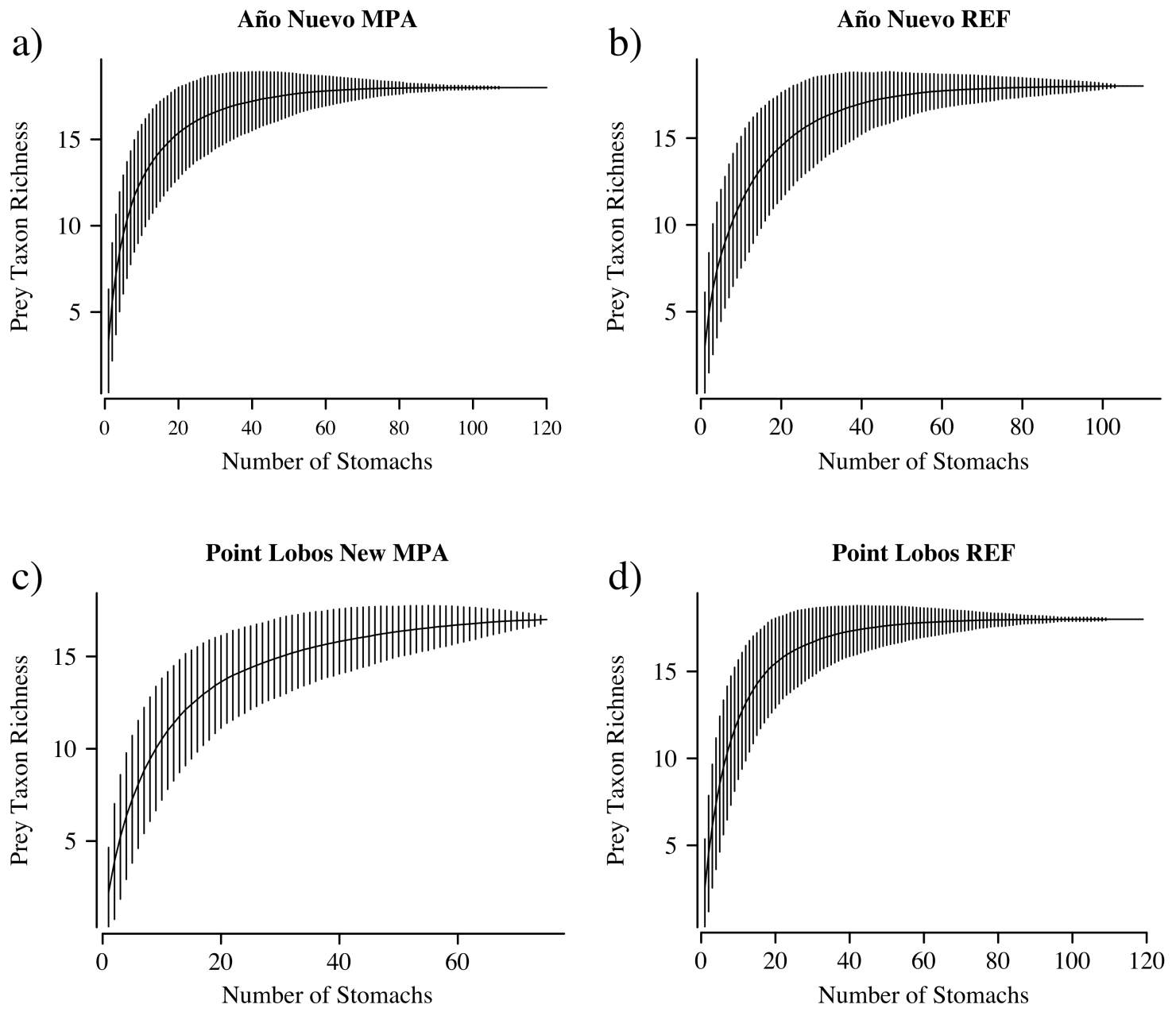

Fig. 12. Cumulative prey curves at the prey taxon level for all new MPAs and reference areas. a) Año Nuevo MPA. Slope through last four points $=0$. b) Año Nuevo reference area. Slope through last four points $=0$. c) New Pont Lobos MPA. Slope through last four points $=0.012$. d) Point Lobos reference area. Slope through last four points $=0$. 

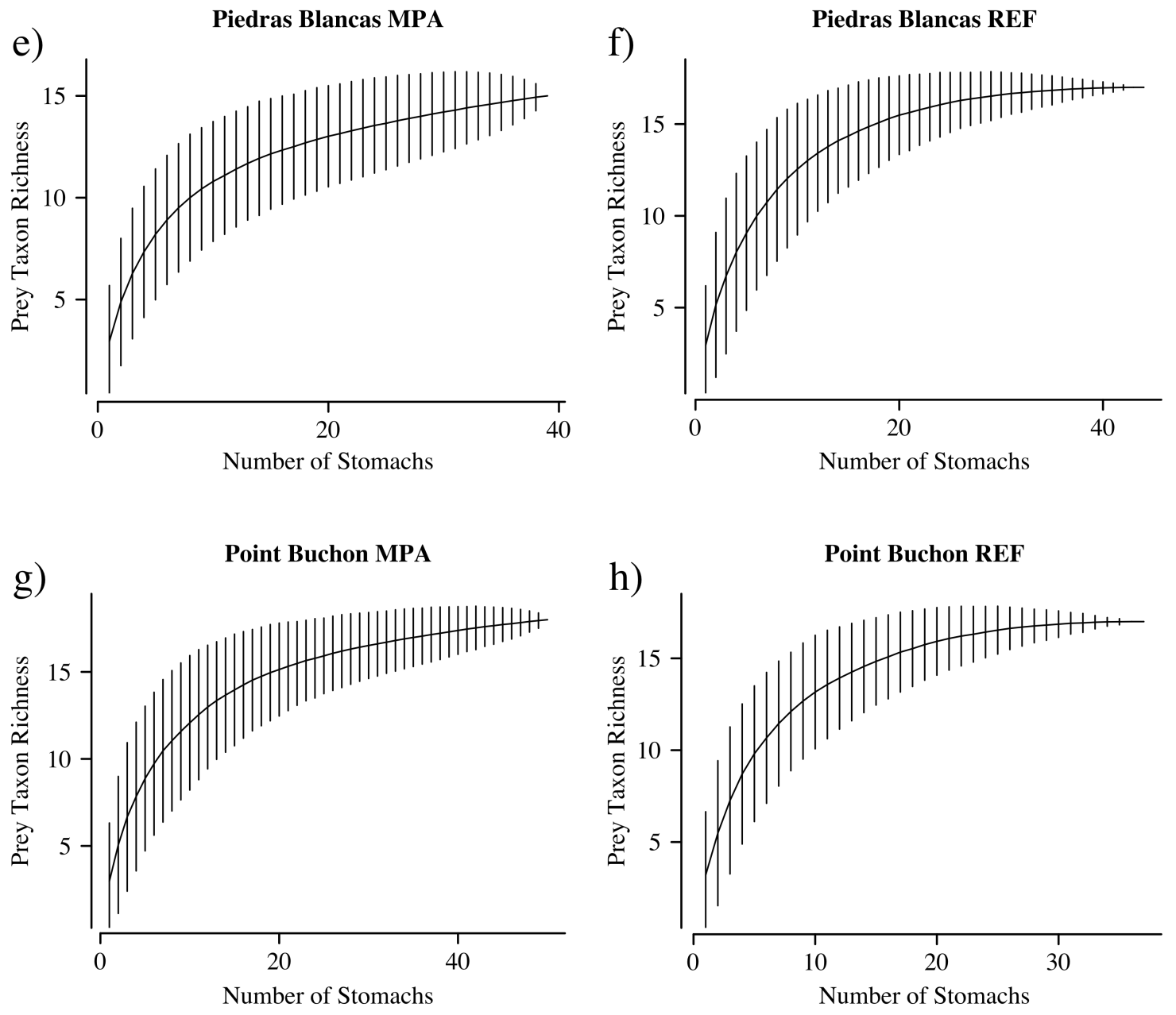

Fig. 12 continued. Cumulative prey curves at the prey taxon level for all new MPAs and reference areas. e) Piedras Blancas MPA. Slope through last four points $=0.079$. f) Piedras Blancas reference area. Slope through last four points $=0.002$. g) Point Buchon MPA. Slope through last four points $=0.063$. h) Point Buchon reference area. Slope through last four points $=0.005$. 

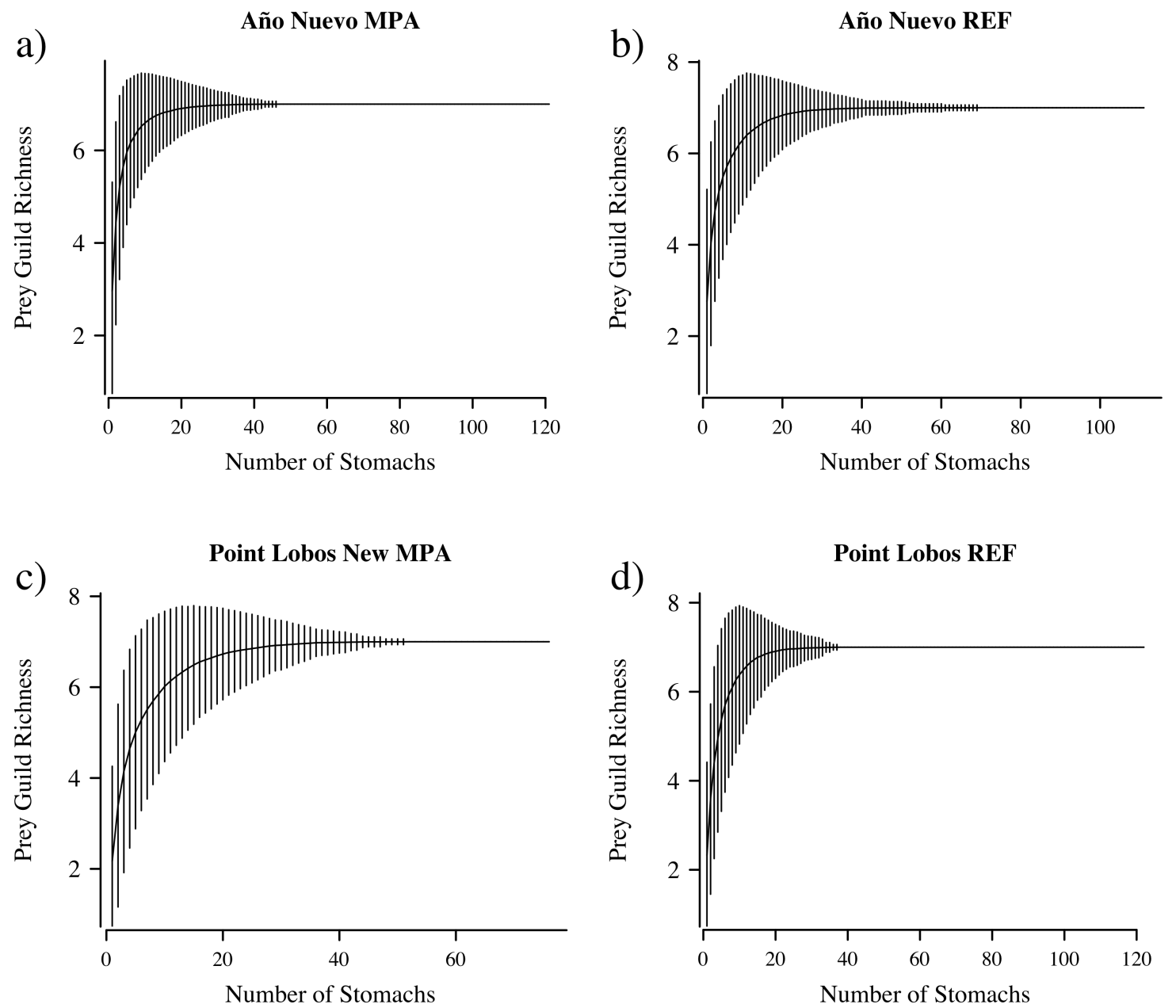

Fig. 13. Cumulative prey curves at the prey guild level for all new MPAs and reference areas. a) Año Nuevo MPA. Slope through last four points $=0$. b) Año Nuevo reference area. Slope through last four points $=0$. c) New Point Lobos MPA. Slope through last four points $=0$. d) Point Lobos reference area. Slope through last four points $=0$. 

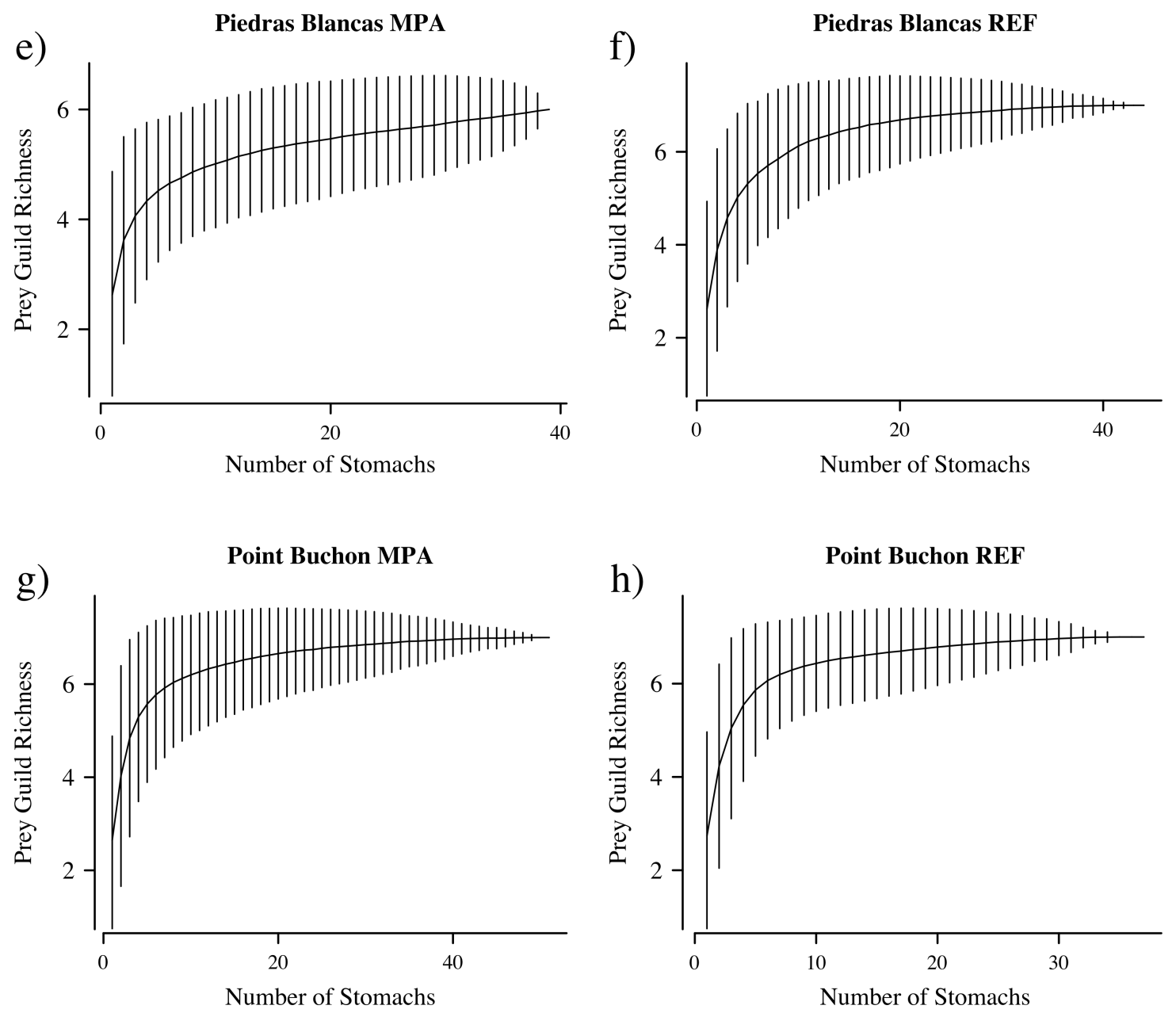

Fig. 13 continued. Cumulative prey curves at the prey guild level for all new MPAs and reference areas. f) Piedras Blancas MPA. Slope through last four points $=0.026$. g) Piedras Blancas reference area. Slope through last four points $=0.001$. h) Point Buchon MPA. Slope through last four points $=0.001$. i) Point Buchon reference area. Slope through last four points $=0.002$. 
Table 6. Slopes of cumulative prey curves for new MPAs and reference areas. Cumulative prey curves were run at both the prey taxon and prey guild levels. "Total" refers to the number of samples from each area used in analysis. Guild totals are larger than taxa totals due to samples containing prey that could be assigned to a guild but not to a taxon, such as unidentified shrimp. Slopes were calculated for the regression line through the last four points of each curve at the total number of samples and at 31 samples.

\begin{tabular}{|c|c|c|c|c|c|c|}
\hline \multirow{2}{*}{ Area } & \multicolumn{3}{|c|}{ Prey Taxa } & \multicolumn{3}{|c|}{ Prey Guilds } \\
\hline & Total & $\begin{array}{c}\text { Slope } \\
\text { (total) }\end{array}$ & $\begin{array}{c}\text { Slope } \\
(31)\end{array}$ & Total & $\begin{array}{c}\text { Slope } \\
\text { (total) }\end{array}$ & $\begin{array}{c}\text { Slope } \\
(31)\end{array}$ \\
\hline Año Nuevo MPA & 120 & 0 & 0.088 & 121 & 0 & 0.007 \\
\hline Año Nuevo REF & 110 & 0 & 0.113 & 111 & 0 & 0.007 \\
\hline Point Lobos New MPA & 75 & 0.012 & 0.103 & 76 & 0 & 0.012 \\
\hline Point Lobos REF & 119 & 0 & 0.092 & 122 & 0 & 0.002 \\
\hline Piedras Blancas MPA & 39 & 0.079 & 0.093 & 39 & 0.026 & 0.027 \\
\hline Piedras Blancas REF & 44 & 0.002 & 0.077 & 44 & 0.001 & 0.014 \\
\hline Point Buchon MPA & 50 & 0.063 & 0.099 & 51 & 0.001 & 0.013 \\
\hline Point Buchon REF & 37 & 0.005 & 0.039 & 37 & 0.002 & 0.011 \\
\hline
\end{tabular}


There were no detectable differences in prey taxon richness or evenness of Gopher Rockfish diet items between fish from new MPAs and reference areas. The RCB MANOVA performed on population totals indicated that diets inside and outside of the new MPAs did not differ significantly in terms of total taxon richness $\left(\mathrm{F}_{1,3}=0.600, \mathrm{p}=\right.$ $0.495)$ or evenness $\left(\mathrm{F}_{1,3}=4.163, \mathrm{p}=0.134\right)$. Overall diversity (multivariate effect of richness and evenness) also did not differ significantly inside and outside of MPAs ( $\mathrm{F}_{2,2}=$ 7.144, $\mathrm{p}=0.123)$. The block factor of geographic location was significant for total taxon evenness $\left(\mathrm{F}_{3,3}=47.487, \mathrm{p}=0.005\right)$, but not significant for total taxon richness $\left(\mathrm{F}_{3,3}=\right.$ $1.000, \mathrm{p}=0.500)$ or diversity $\left(\mathrm{F}_{6,6}=1.220, \mathrm{p}=0.408\right)$. A similar analysis of mean prey taxon richness, evenness, and diversity indicated similar results, except the block factor of geographic location was not significant for mean taxon evenness (Table $7, \mathrm{~F}_{3,3}=$ $1.275, \mathrm{p}=0.423)$.

There were also no detectable differences in prey guild richness or evenness of Gopher Rockfish diet items between fish from new MPAs and reference areas. The RCB MANOVA performed on population totals indicated that diets inside and outside of the new MPAs did not significantly differ in terms of total prey guild richness $\left(\mathrm{F}_{1,3}=1.000\right.$, $\mathrm{p}=0.391)$, evenness $\left(\mathrm{F}_{1,3}=2.005, \mathrm{p}=0.252\right)$, or diversity $\left(\mathrm{F}_{2,2}=1.421 \mathrm{p}=0.413\right)$. The block factor of geographic location was significant for total guild evenness $\left(\mathrm{F}_{3,3}=43.646\right.$, $\mathrm{p}=0.006)$, but not significant for total guild richness $\left(\mathrm{F}_{3,3}=1.000, \mathrm{p}=0.500\right)$ or diversity $\left(\mathrm{F}_{6,6}=2.644, \mathrm{p}=0.131\right)$. A similar analysis of mean prey guild richness, evenness, and diversity indicated similar results, except the block factor of geographic location was not significant for mean guild evenness (Table $7, \mathrm{~F}_{3,3}=1.561, \mathrm{p}=0.362$ ). 


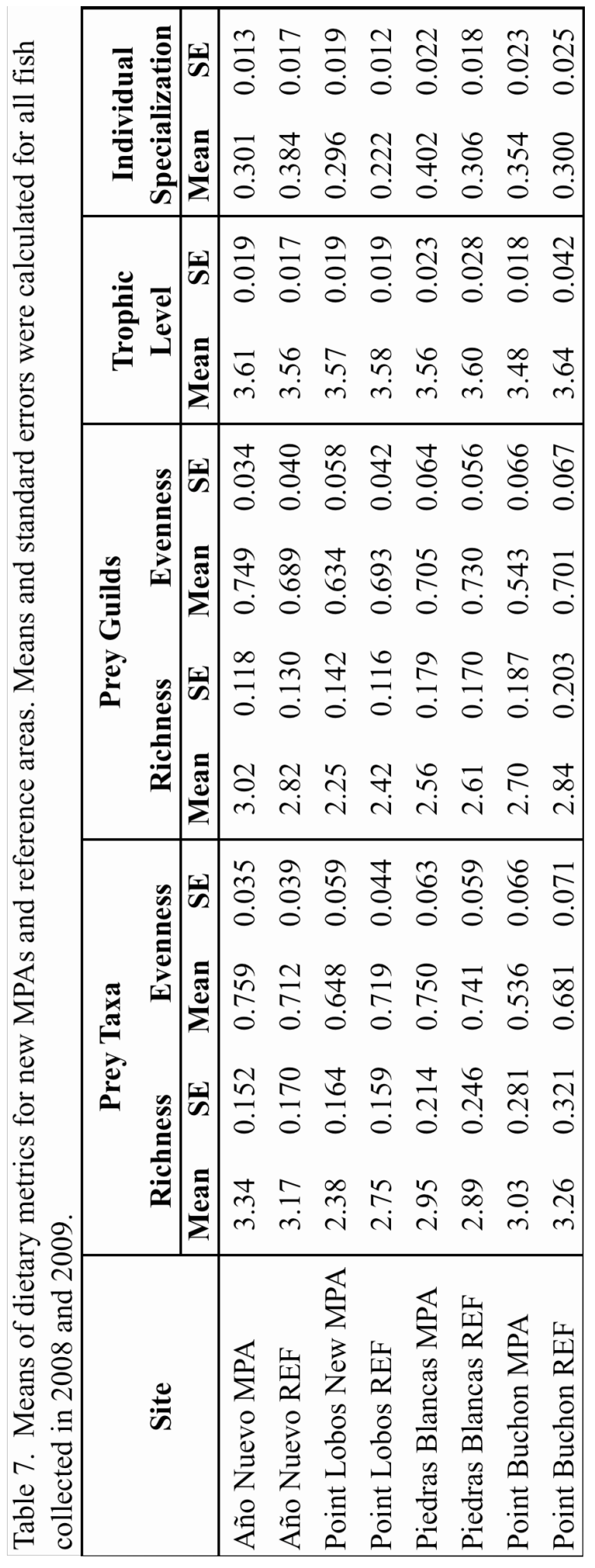


Prey Composition. Prey taxon composition did not differ significantly inside and outside of MPAs; however, significant differences were observed among geographic locations. One of ten random draws of 31 fish from each area showed a significant difference in taxon composition inside and outside of MPAs in terms of PCA Factor 2 $\left(F_{1,3}=12.266, p=0.039\right)$. The inconsistency of significant results suggests that the observed difference is an artifact of resampling. However, prey taxon composition significantly differed among geographic locations in seven of the ten random draws (Fig. 14; first significant trial: PCA Factor $1: \mathrm{F}_{3,3}=16.593, \mathrm{p}=0.023$; PCA Factor 2: $\mathrm{F}_{3,3}=$ $4.017, \mathrm{p}=0.142$ ). Principal Component 1 explained $30.8 \%$ of the variation on average, and Principal Component 2 explained $20.6 \%$ of the variation on average. The amonglocation differences in prey taxon composition were also reflected in the most important taxa at each location, as measured by the PSIRI, which included Cancer crabs at Año Nuevo, brittle stars at Point Lobos and Piedras Blancas, and mysids at Point Buchon (Fig. $15)$. 


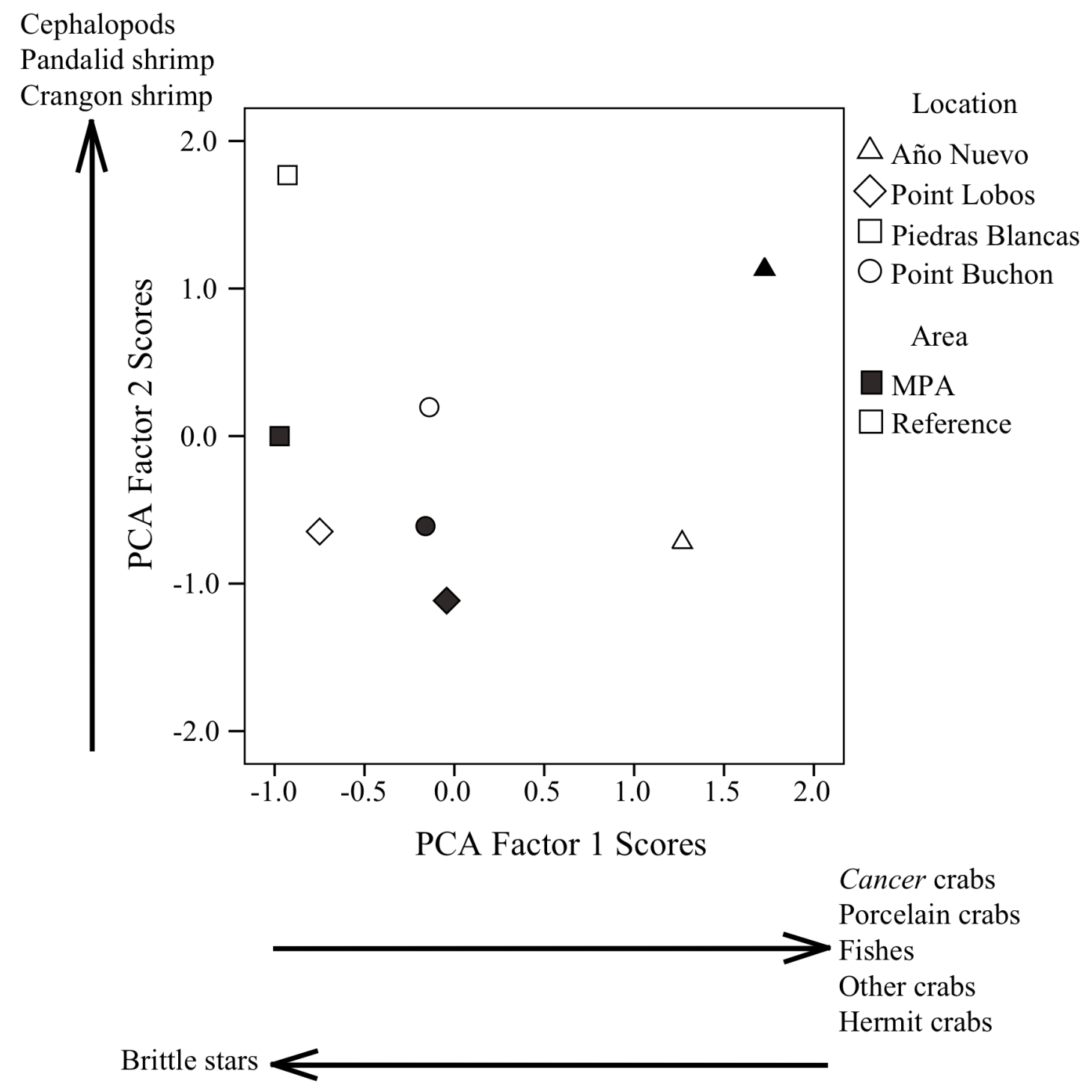

Fig. 14. Plot of Principal Components Analysis with prey taxa. While there was no consistent separation of MPAs and reference areas (shaded vs. unshaded symbols), the geographic locations (symbol shapes) significantly differed along factor 1. Arrows represent loadings greater than 0.70 . 

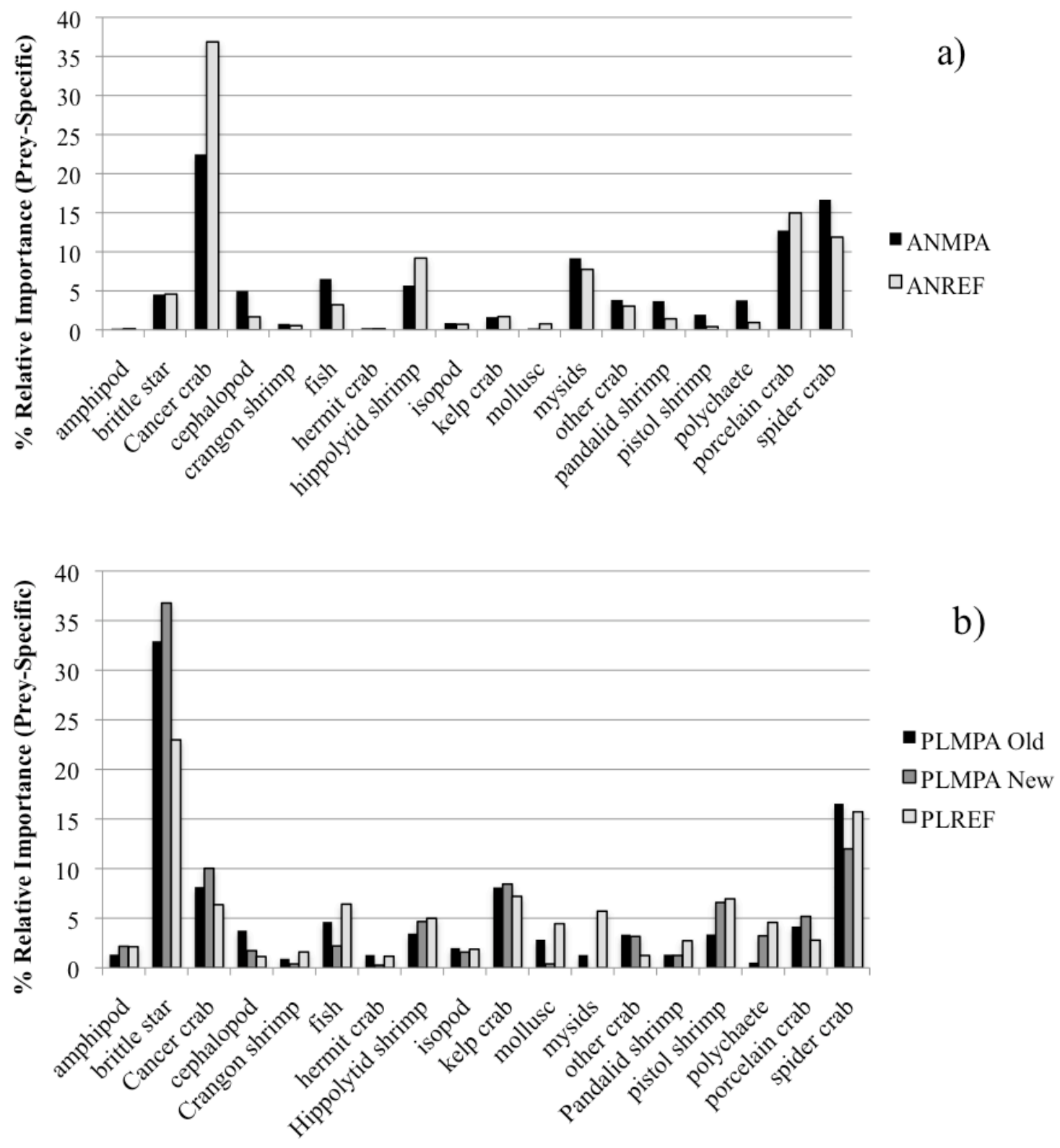

Fig. 15. Prey composition by location and area at the prey taxon level. a) Año Nuevo. Cancer crabs, porcelain crabs, and spider crabs were the most important taxa at both areas b) Point Lobos. Brittle stars and spider crabs were the most important prey taxa at all areas. 

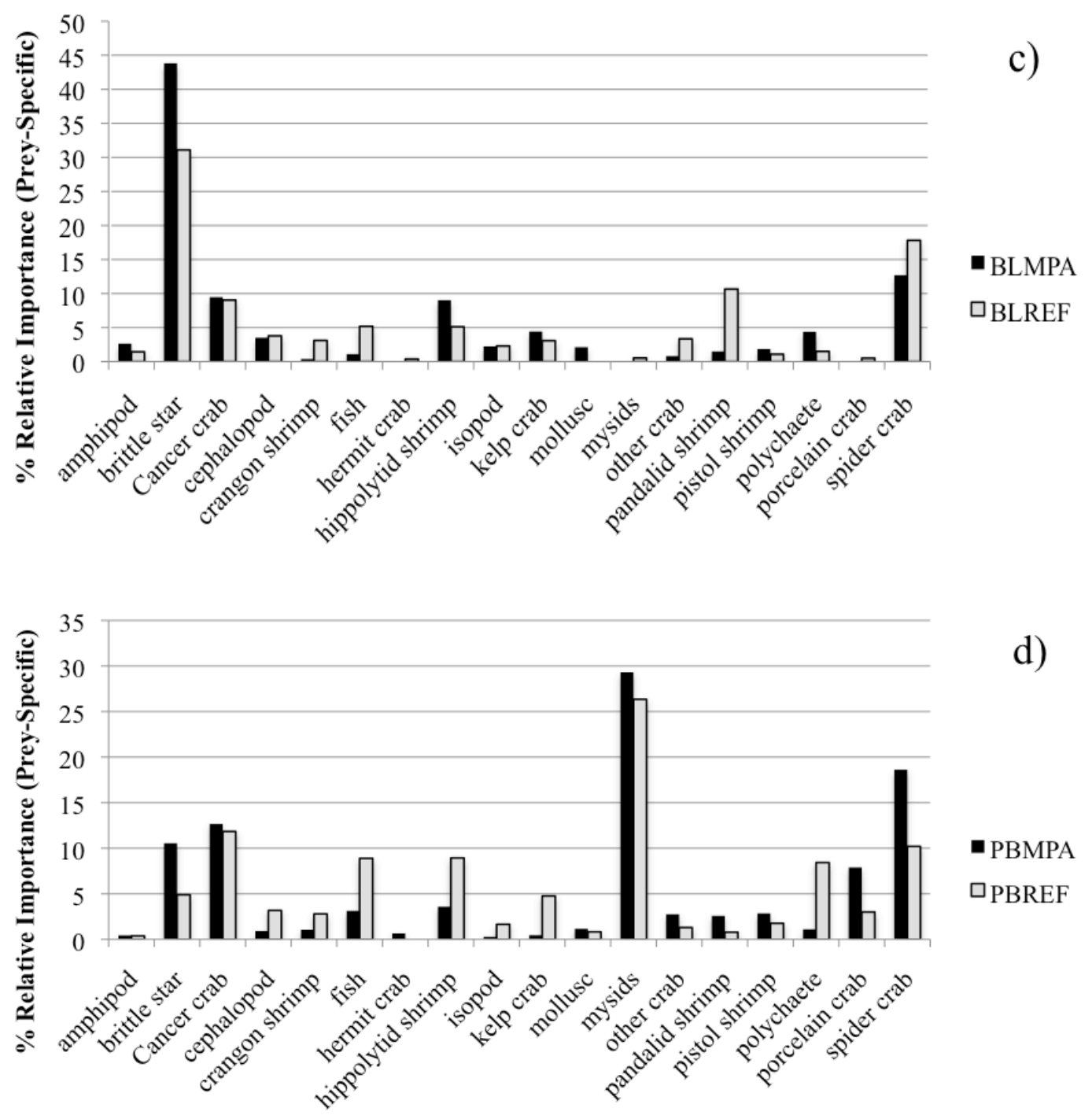

Fig. 15 continued. Prey composition by location and area at the prey taxon level. c) Piedras Blancas. Brittle stars and spider crabs were the most important prey taxa at both areas. d) Point Buchon. Mysids were the most important taxon at both areas. 
Prey guild composition also did not differ significantly inside and outside of MPAs; however, significant differences were observed among geographic locations. One of ten random draws of 31 fish from each area showed a significant difference in guild composition inside and outside of MPAs in terms of PCA Factor $1\left(\mathrm{~F}_{1,3}=11.390, \mathrm{p}=\right.$ 0.043). The inconsistency of significant results suggests that the observed difference is an artifact of resampling. However, prey guild composition significantly differed among geographic locations in six of the ten random draws (Fig. 16; first significant trial: PCA Factor 1: $F_{3,3}=279.704, p<0.001 ;$ PCA Factor $\left.2: F_{3,3}=6.390, p=0.085\right)$. Principal Component 1 explained 42.7\% of the variation on average, and Principal Component 2 explained $25.3 \%$ of the variation on average. These differences among locations reflect differences in the most important prey guilds among locations, as measured by the PSIRI, which included carnivores on invertebrates at Año Nuevo, detritivores at Point Lobos and Point Buchon, and suspension feeders at Piedras Blancas (Fig. 17). The most important guilds corresponded to most important prey taxa at each location. 


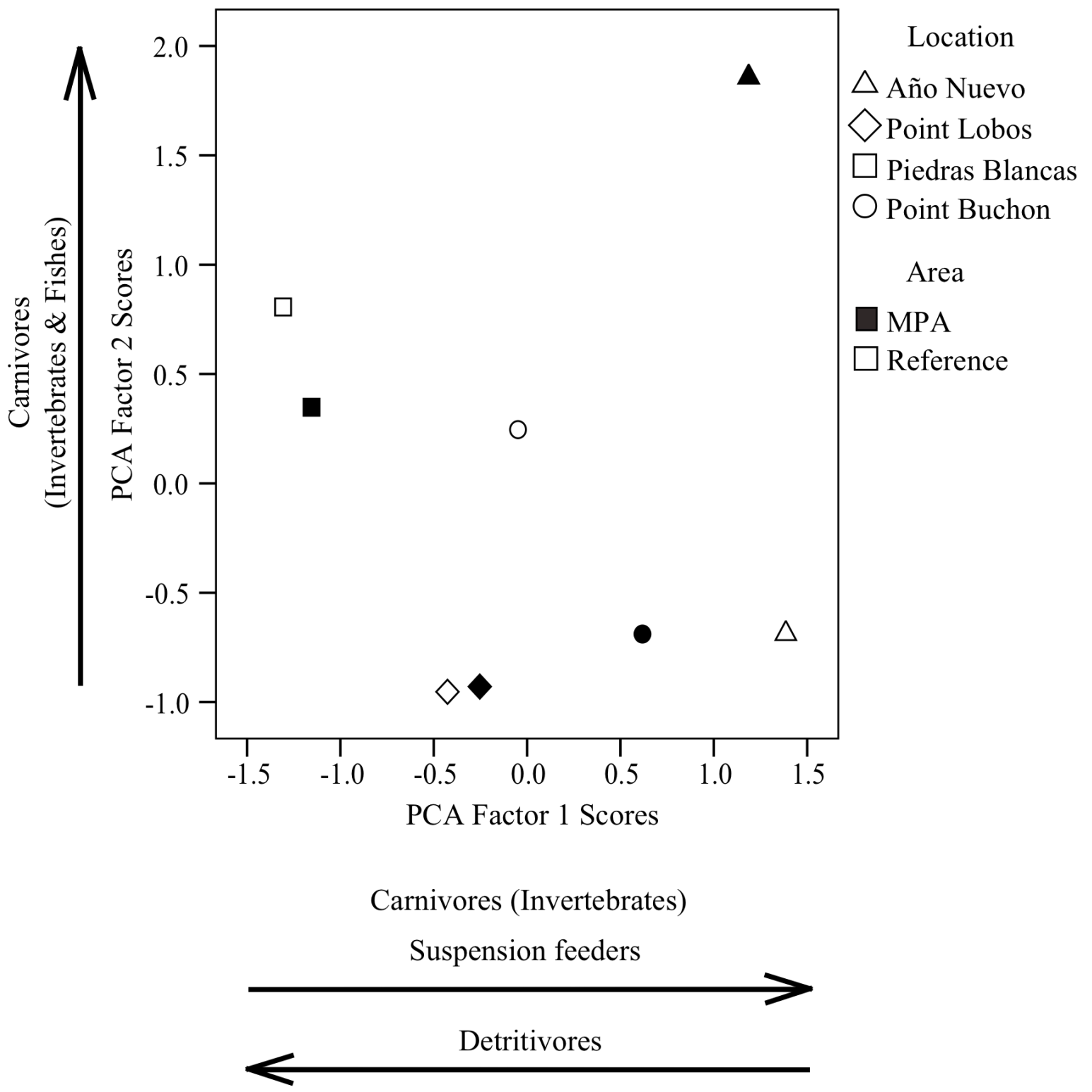

Fig. 16. Plot of Principal Components Analysis with prey guilds. While there was no consistent separation of MPAs and reference areas (shaded vs. unshaded symbols), the geographic locations (symbol shapes) significantly differed along factor 1 . Arrows represent loadings greater than 0.70 . 

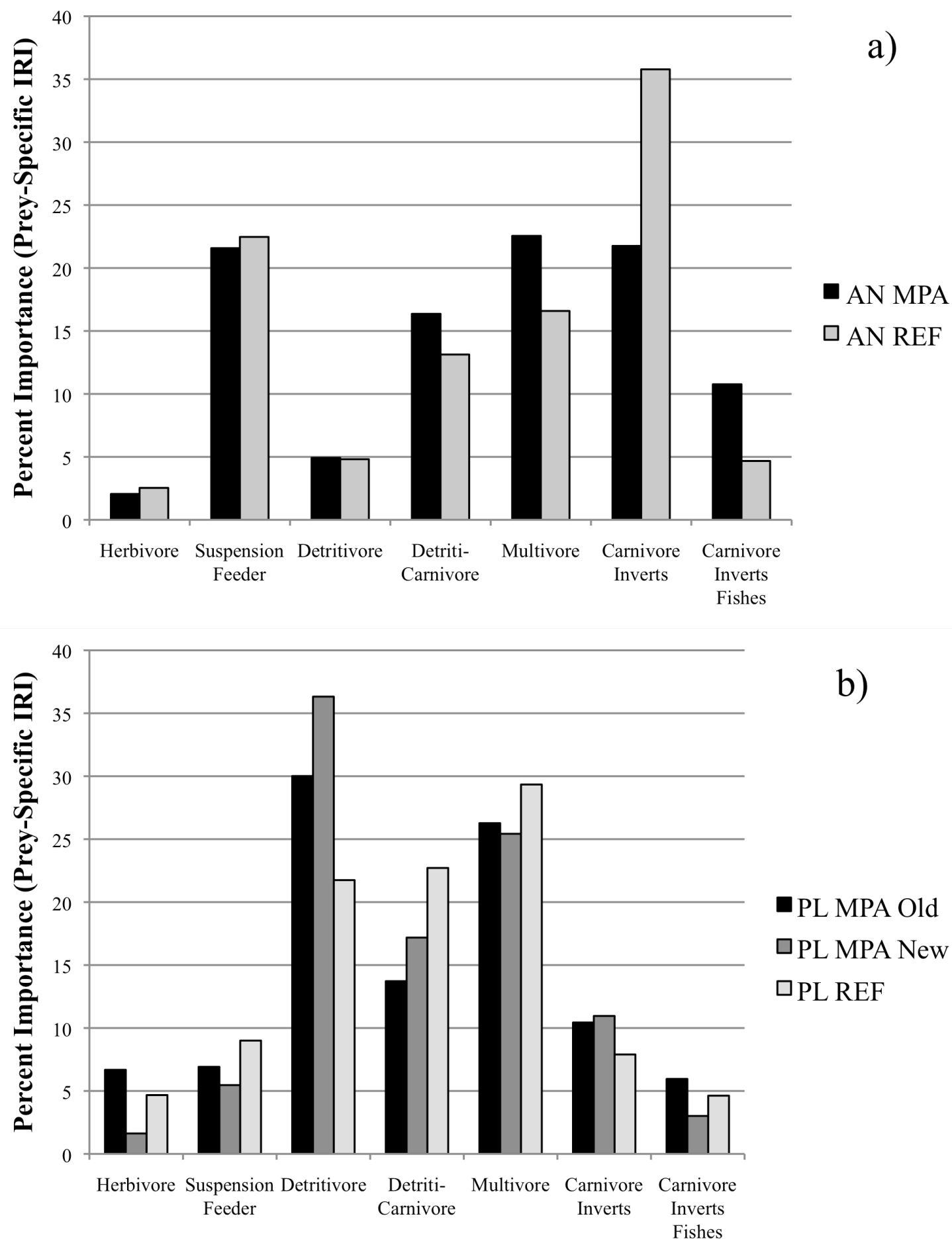

Fig. 17. Prey composition by location and area at the prey guild level. a) Año Nuevo. Carnivores on invertebrates and suspension feeders were important prey at both areas. b) Point Lobos. Detritivores and multivores were important prey at all areas. 

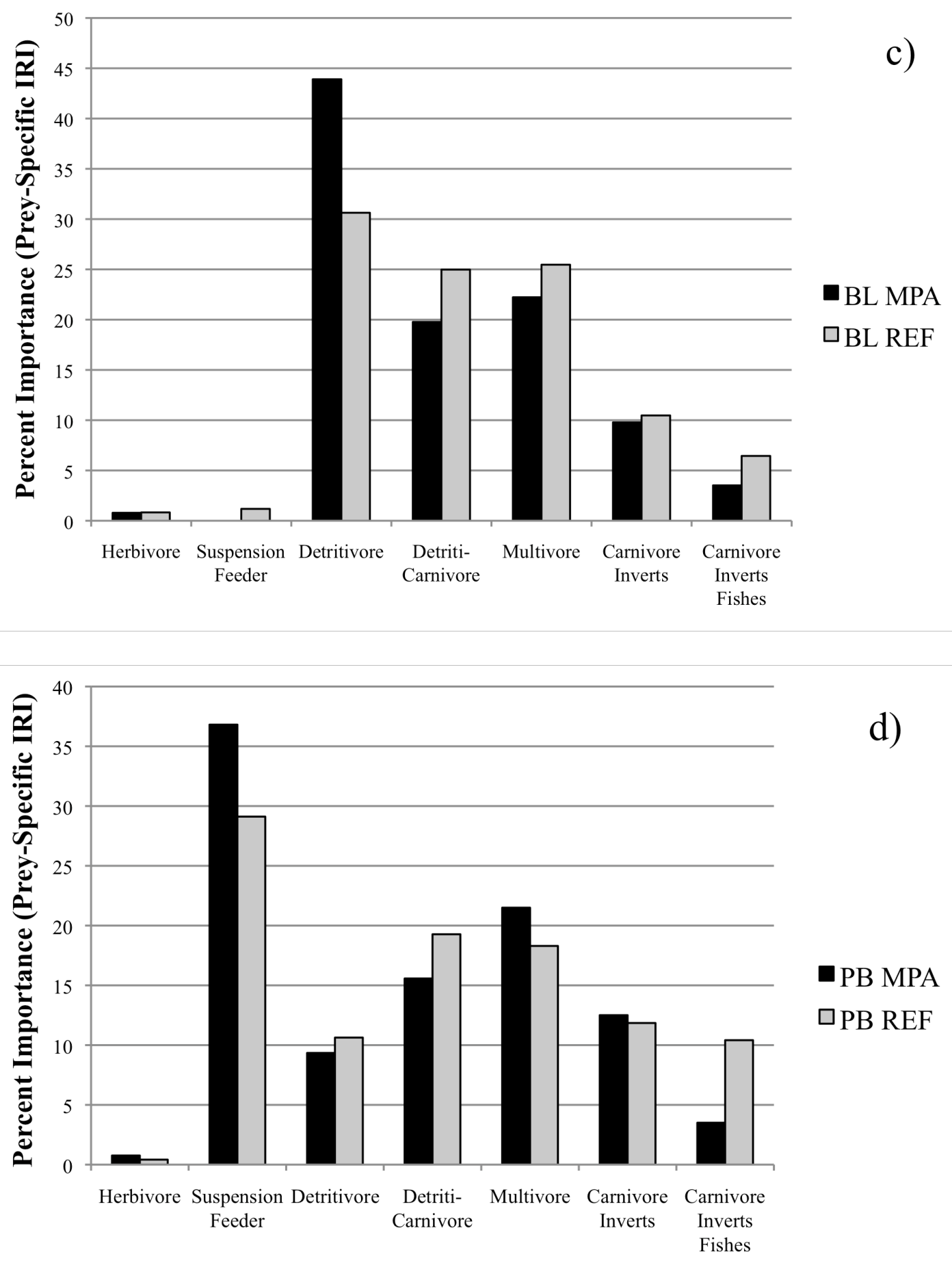

d)

- PB MPA

$\square$ PB REF

Fig. 17 continued. Prey composition by location and area at the prey guild level. a) Piedras Blancas. Detritivores were the most important prey guild at both areas. b) Point Buchon. Suspension feeders were the most important prey guild at both areas. 
Trophic Level. Mean trophic levels were highly similar for all areas, ranging from 3.50 in the Point Buchon MPA to 3.61 in the Año Nuevo MPA (Table 7). No significant differences in mean trophic level were observed inside versus outside new MPAs (ANOVA, $\left.\mathrm{F}_{1,3}=0.987, \mathrm{p}=0.394\right)$. The block factor of geographic location was also not significant $\left(\mathrm{F}_{3,3}=0.080, \mathrm{p}=0.966\right)$.

Individual Specialization. No significant differences in mean individual specialization were observed inside versus outside new MPAs (Table 7, ANOVA, $\mathrm{F}_{1,3}=$ $0.659, \mathrm{p}=0.476)$. The block factor of geographic location was also not significant $\left(\mathrm{F}_{3,3}=\right.$ $0.908, \mathrm{p}=0.531)$. However, IS values were higher inside all MPAs except for the Año Nuevo MPA, suggesting a possible interaction between geographic location and MPA effect (Fig. 18).

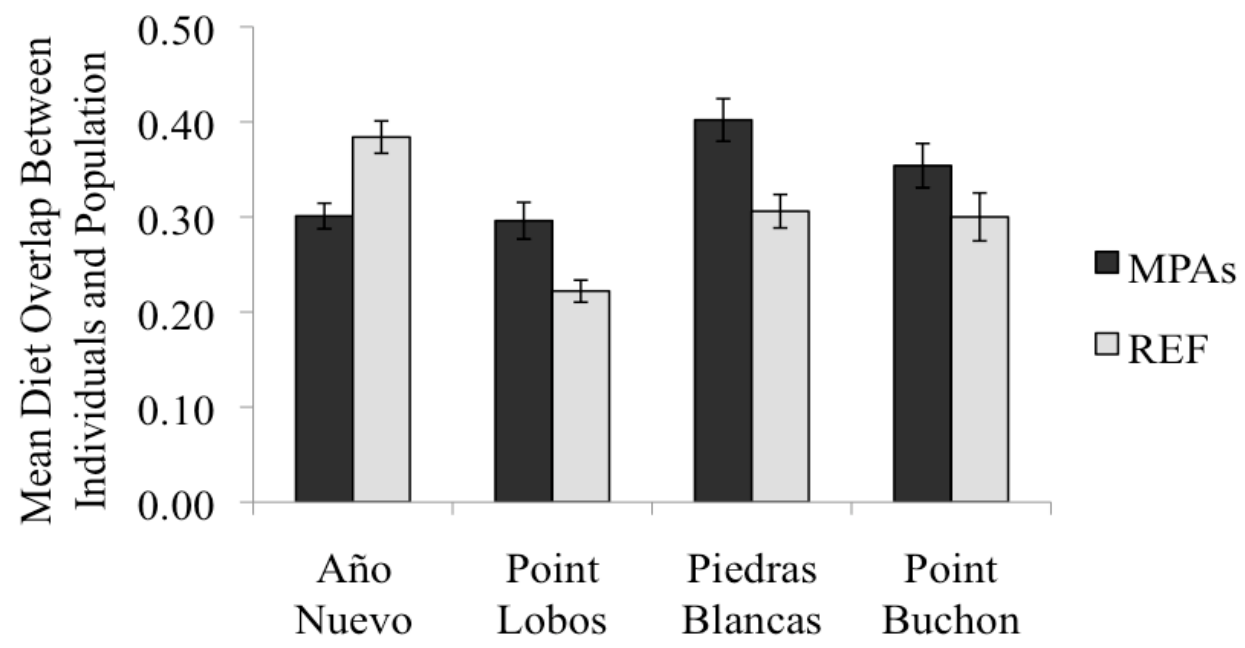

Fig. 18. Mean individual specialization at new MPAs and reference areas. While there was no consistent difference between MPAs and reference areas $(p=0.476)$, mean overlap between individuals and their respective populations was higher inside MPAs than outside at all locations except for Año Nuevo. This may suggest an interaction between MPA effect and geographic location. 
Similarity. The Horn-Morisita Similarity Index values were high between corresponding MPAs and reference areas in the same location, and lowest among areas in different locations. Similarity values between corresponding MPAs and reference areas ranged from 0.79 for the Point Buchon MPA and reference area to 0.93 for the Año Nuevo MPA and reference area (Table 8). Similarity was also high (0.87) between the new and old MPAs at Point Lobos. While a few areas in different locations showed high similarity (e.g., 0.89 between the old Point Lobos MPA and the Piedras Blancas MPA), similarity values among areas from different locations tended to be less than 0.65 , and the greatest degree of dissimilarity occurred between areas in different locations $(0.24$ between Año Nuevo reference area and Piedras Blancas MPA).

Table 8. Diet similarity between all MPAs and reference areas. Similarity values were calculated for equal numbers of samples using the Horn-Morisita Index. Numbers in bold represent the similarity between a marine protected area (MPA) and its corresponding reference area $(\mathrm{REF}) . \mathrm{AN}=\mathrm{Año}$ Nuevo, $\mathrm{PL}=$ Point Lobos, $\mathrm{BL}=$ Piedras Blancas, $\mathrm{PB}=$ Point Buchon.

\begin{tabular}{|l|cccccccc|}
\hline & & & PL & PL & & & & \\
& AN & AN & MPA & MPA & PL & BL & BL & PB \\
& MPA & REF & OLD & NEW & REF & MPA & REF & MPA \\
\hline AN REF & $\mathbf{0 . 9 3}$ & & & & & & & \\
PL MPA OLD & 0.42 & 0.31 & & & & & & \\
PL MPA NEW & 0.63 & 0.52 & 0.87 & & & & & \\
PL REF & 0.50 & 0.33 & $\mathbf{0 . 8 4}$ & $\mathbf{0 . 8 9}$ & & & & \\
BL MPA & 0.38 & 0.24 & 0.89 & 0.77 & 0.81 & & & \\
BL REF & 0.49 & 0.34 & 0.92 & 0.83 & 0.84 & $\mathbf{0 . 9 2}$ & & \\
PB MPA & 0.72 & 0.64 & 0.46 & 0.63 & 0.60 & 0.42 & 0.46 & \\
PB REF & 0.74 & 0.68 & 0.51 & 0.63 & 0.63 & 0.43 & 0.52 & $\mathbf{0 . 7 9}$ \\
\hline
\end{tabular}




\section{Determining Effects of Other Factors on Diet}

Relationship Between Diet and Fish Density. Gopher Rockfish density was not related to most dietary metrics (Table 9). Linear regression analyses did not find significant relationships $(\mathrm{p}>0.05)$ between Gopher Rockfish density and prey taxon or guild taxon richness, guild evenness, trophic level, or individual specialization.

However, there was a significant and moderately strong negative relationship $(p=0.035$, $\mathrm{R}^{2}=0.552$ ) between prey taxon evenness and Gopher Rockfish density (Fig. 19).

Table 9. Relationship between diet metrics and Gopher Rockfish density.

\begin{tabular}{|lccc|}
\hline \multicolumn{1}{|c}{ Metric } & $\mathbf{p}$ & $\mathbf{R}^{\mathbf{2}}$ & Direction \\
\hline Taxon Richness & 0.380 & 0.132 & None \\
Taxon Evenness & 0.035 & 0.552 & Negative \\
Guild Richness & 0.370 & 0.137 & None \\
Guild Evenness & 0.053 & 0.491 & Negative \\
Trophic Level & 0.310 & 0.167 & None \\
Individual Specialization & 0.985 & 0.167 & None \\
\hline
\end{tabular}




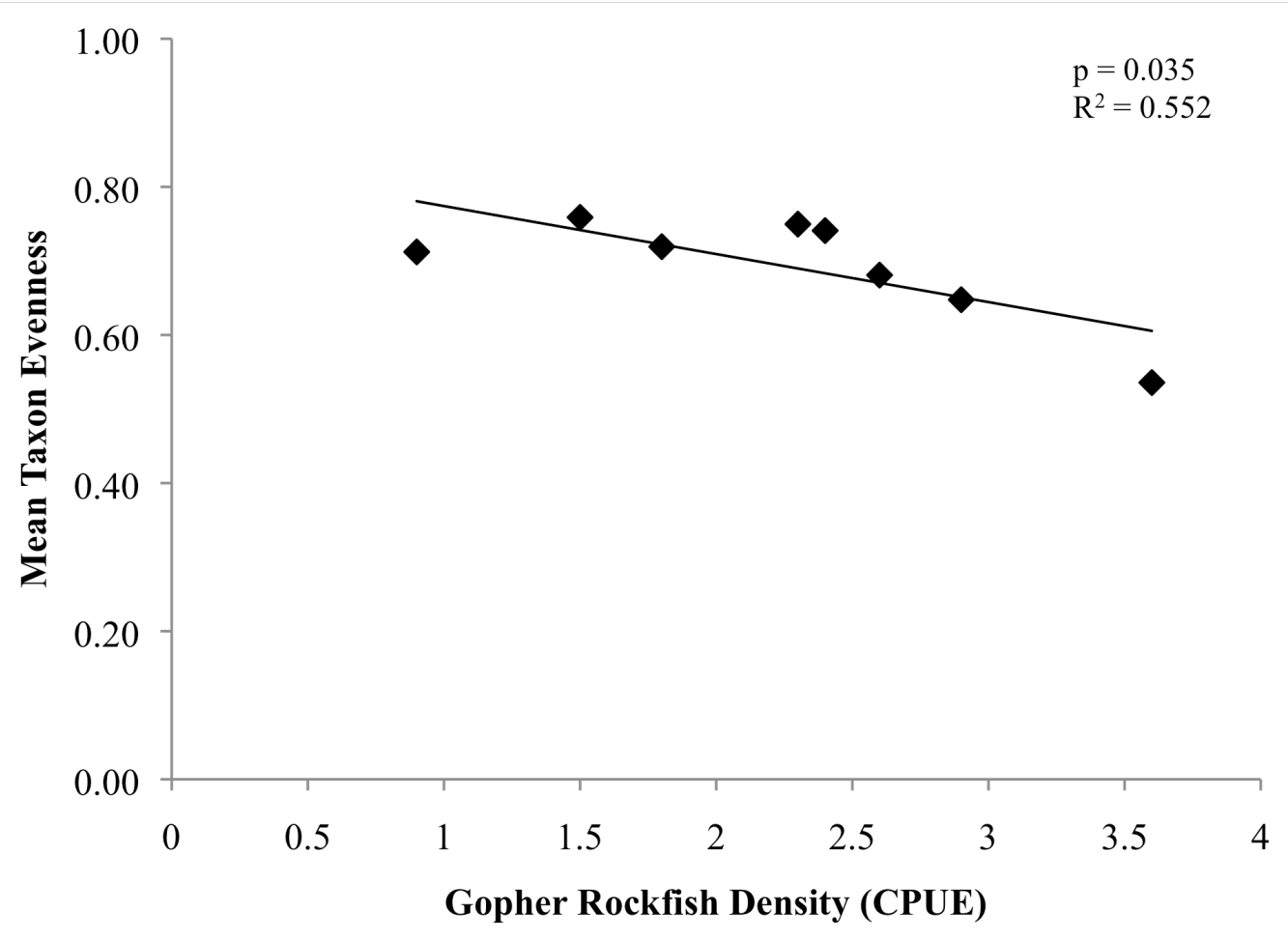

Fig. 19. Relationship between prey taxon evenness and Gopher Rockfish density. Mean evenness and density in catch per unit effort were calculated for each new MPA and reference area. Areas exhibited decreased evenness, indicative of increased specialization, at greater densities.

\section{Relationship Between Diet and Environmental Variables. Canonical}

Correlation Analysis showed a strong relationship between environmental variables and prey taxonomic groups (Table 10$)$. The first canonical root $(r=0.795)$ was significantly different from zero $(p=0.011)$. Deeper depths and lower latitudes were associated with more brittle stars and fewer porcelain crabs and Cancer crabs (Fig. 20). 
Table 10. Summary of Canonical Correlation Analysis performed on prey taxa. Coefficients and significance values are for the two canonical variates analyzed (CV1 and $\mathrm{CV} 2$ ), and the canonical loadings are for the one significant root (CV1).

\begin{tabular}{|l|l|l|}
\hline & \multicolumn{2}{c|}{} \\
Canonical Variates/Roots & \multicolumn{1}{l}{ Canonical Correlation } & \multicolumn{1}{c|}{-value } \\
\hline CV1 & 0.795 & 0.011 \\
CV2 & 0.753 & 0.374 \\
CV3 & 0.392 & 0.999 \\
CV4 & 0.308 & 0.993 \\
\hline
\end{tabular}

CV1 Canonical Loadings

\begin{tabular}{|l|l|l|}
\hline \multirow{5}{*}{ Environmental Variables } & Depth & -0.863 \\
& Latitude & 0.780 \\
& Proportion of rocky substrate & 0.418 \\
& Temperature at depth & 0.046 \\
\hline & Amphipod & -0.217 \\
& Brittle star & -0.534 \\
& Cancer crab & 0.688 \\
& Cephalopod & 0.117 \\
& Crangon shrimp & -0.014 \\
& Fish & -0.073 \\
& Hermit crab & -0.025 \\
& Hippolytid shrimp & 0.435 \\
& Isopod & -0.045 \\
& Kelp crab & -0.115 \\
& Mollusc & -0.021 \\
& Mysids & 0.057 \\
& Other crab & 0.163 \\
& Pandalid shrimp & -0.021 \\
& Pistol shrimp & 0.001 \\
& Polychaete & -0.239 \\
& Porcelain crab & 0.578 \\
& Spider crab & 0.037 \\
\hline
\end{tabular}




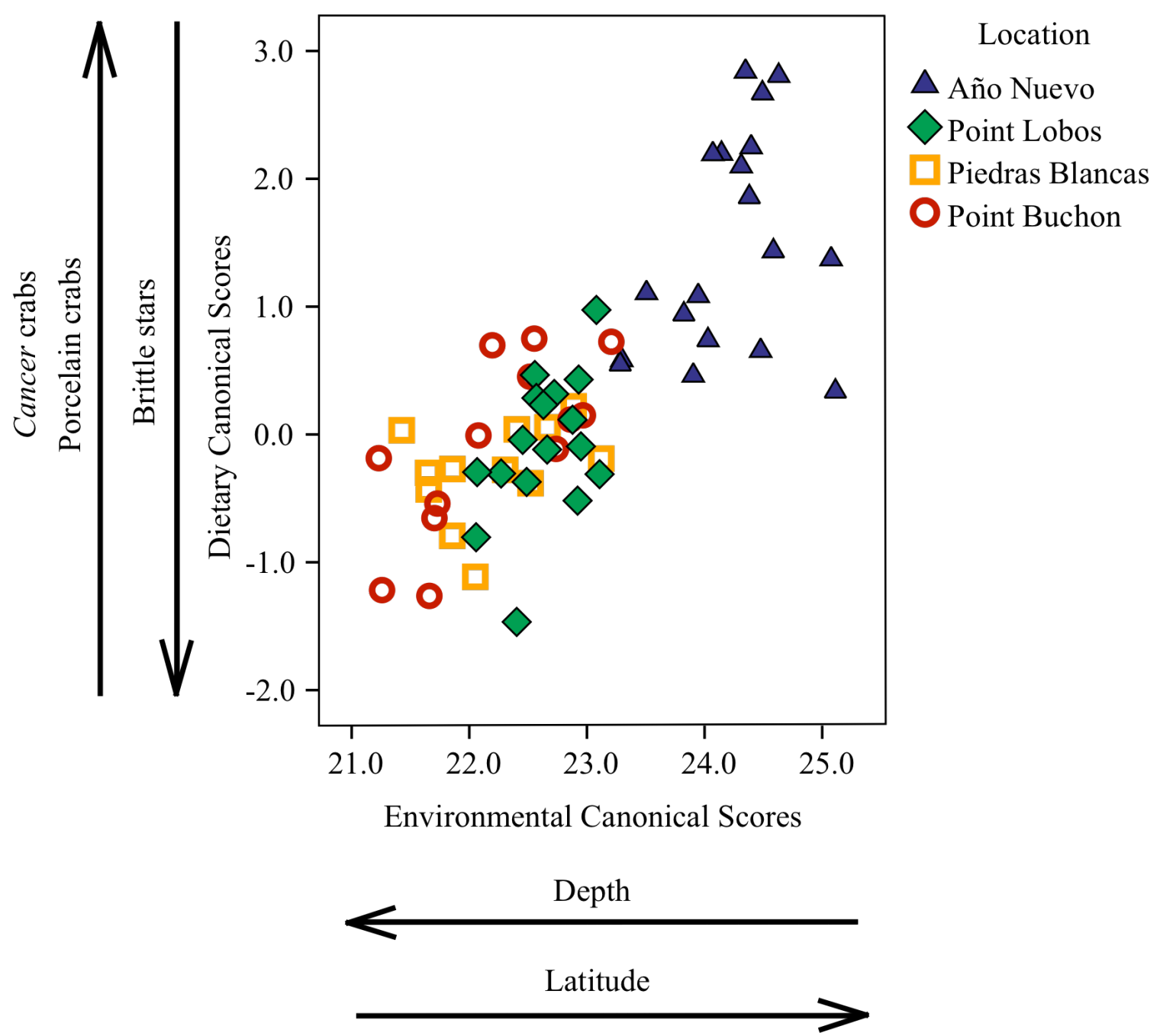

Fig. 20. Plot of Canonical Correlation Analysis with prey taxa. The relationship between environmental and dietary scores was significant for the first canonical root $(\mathrm{p}=0.011, \mathrm{r}$ $=0.795$ ). Arrows represent loadings greater than 0.50. Variable loadings: depth $=$ -0.863 ; latitude $=0.780 ;$ Cancer crabs $=0.688$, porcelain crabs $=0.578$; brittle stars $=$ -0.534 . 
Canonical Correlation Analysis also showed a strong relationship between environmental variables and prey guilds (Table 11$)$. The first canonical root $(r=0.742)$ was significantly different from zero $(p=0.001)$. Deeper depths were associated with more detritivores and fewer suspension feeders (Fig. 21).

Table 11. Summary of Canonical Correlation Analysis performed on prey feeding guilds. Coefficients and significance values are for the four canonical variates analyzed (CV1, CV2, CV3 and CV4), and the canonical loadings are for the one significant root (CV1).

\begin{tabular}{|ll|l|}
\hline Canonical & & \\
Variates/Roots & Canonical Correlation & p-value \\
\hline CV1 & 0.742 & 0.001 \\
CV2 & 0.478 & 0.605 \\
CV3 & 0.158 & 0.997 \\
CV4 & 0.093 & 0.977 \\
\hline
\end{tabular}

CV1 Canonical Loadings

\begin{tabular}{|l|l|l|}
\hline Environmental & Depth & -0.995 \\
Variables & Proportion Rocky Substrate & 0.493 \\
& Latitude & 0.363 \\
& Temperature at Depth & 0.154 \\
\hline \multirow{5}{*}{ Dietary Variables } & Carnivore (Invertebrates) & 0.469 \\
& Carnivore (Invertebrates \& Fishes) & -0.049 \\
& Detriti-Carnivores & 0.100 \\
& Detritivores & -0.761 \\
& Herbivores & 0.026 \\
& Multivores & -0.060 \\
& Suspension Feeders & 0.708 \\
\hline
\end{tabular}




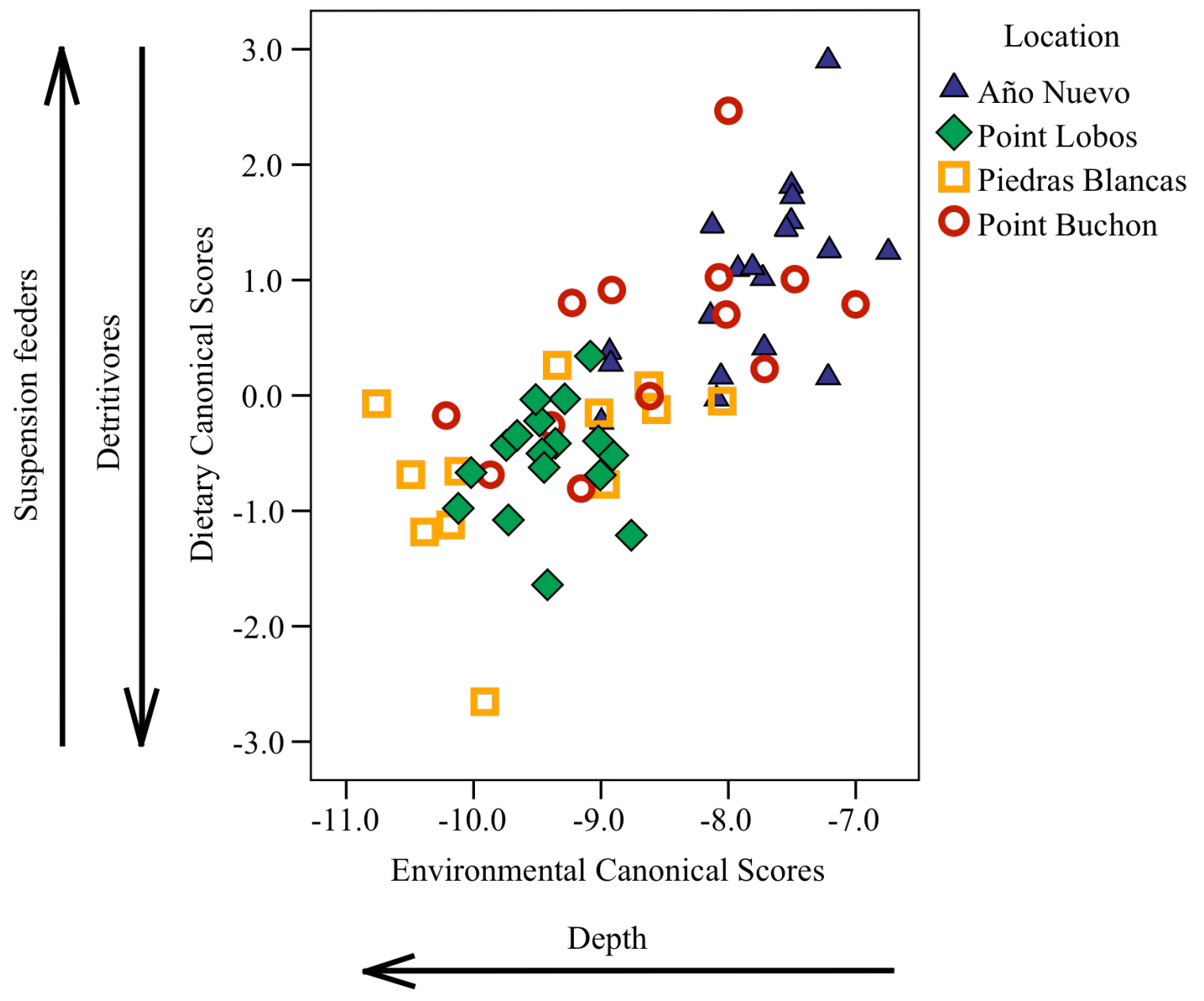

Fig. 21. Plot of Canonical Correlation Analysis with prey guilds. The relationship between environmental and dietary scores was significant for the first canonical root $(\mathrm{p}=$ $0.001, \mathrm{r}=0.742$ ). Arrows represent loadings greater than 0.50. Variable loadings: depth $=-0.995$; suspension feeders $=0.708$; detritivores $=-0.761$. 
Relationship Between Diet and Depth. Plotting the PCA factor 1 scores of prey taxon composition against average depth of fish collection revealed a significant, moderately strong relationship between diet and depth (Fig. $22, p=0.022, \mathrm{R}^{2}=0.611$ ). However, depth was confounded with geographic location. The average depth of fish collection ranged from $52.9 \mathrm{ft}$ at the Año Nuevo MPA to 94.4 feet at the Point Buchon MPA. Thus, it is difficult to tease apart the individual effects of depth and geographic location on diet.

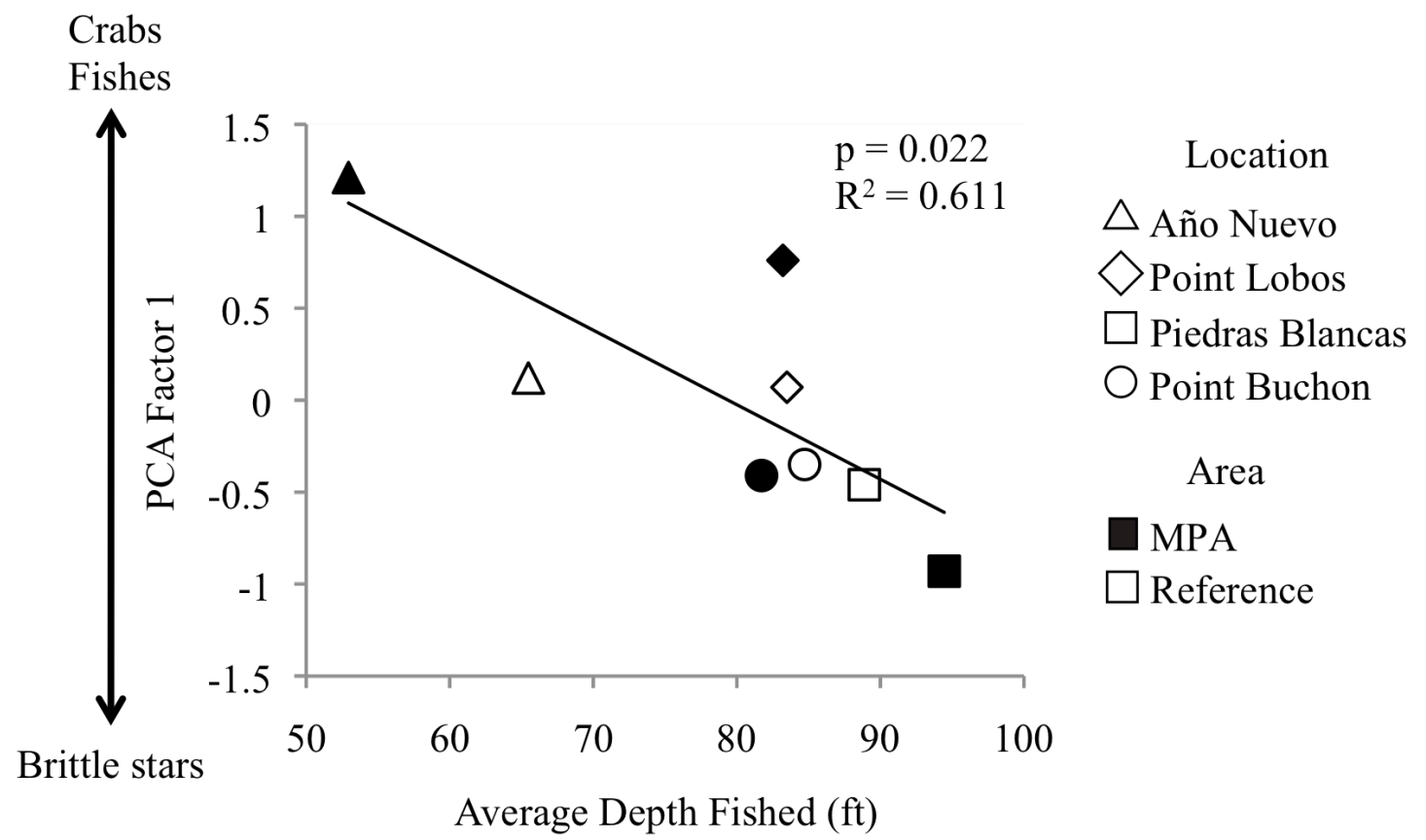

Fig. 22. Relationship between diet and depth. PCA Factor 1 represents the factor 1 scores depicted in Fig. 14. While the relationship between diet and depth is significant, depth is also confounded with geographic location. Fish from Año Nuevo (triangles) were collected at shallower depths than fish at the other locations. 


\section{DISCUSSION}

The high proportion of empty stomachs encountered in this study likely reflects some of the limitations of the sampling methods employed rather than natural frequencies of stomach vacuity. Reeling rockfishes to the surface from depth causes rapid decompression and the overexpansion of gasses in the swim bladder, which can lead to stomach eversion and regurgitation (Parker et al. 2006). Although collecting fish by hand using SCUBA gear allows greater control for preventing the loss of prey contents (Larson 1972), collecting fish as part of hook-and-line and trapping surveys provided a more feasible way to access all the desired sampling areas and achieve larger sample sizes for this study. While efforts were made to minimize the retention of fish that had regurgitated, fish may still have partially regurgitated before being reeled into the boat. Partial regurgitation may lead to underestimates of prey richness and overestimates of prey evenness by reducing the number of prey items and categories. Therefore, the mean individual richness and evenness values reported here should be interpreted as conservative estimates.

While fish collection in an otherwise protected area does decrease the fish density in that area, the fish removals for the purposes of this study were assumed to have negligible impact on the ecology of the otherwise unfished protected areas. The 1,018 fish retained for this study represented $11.4 \%$ of all Gopher Rockfish caught during the three-year monitoring survey of central California MPAs (Starr et al. 2010). Despite these removals, the catch per unit effort (CPUE) of Gopher Rockfish increased or stayed 
constant over the three years of the survey in all MPAs except for that at Point Buchon, where CPUE decreased in 2009 (Starr et al. 2010). Fewer fish were retained at Point Buchon than at Año Nuevo and Point Lobos, suggesting that removals for the present study did not cause the observed patterns in Gopher Rockfish abundance. However, nonlethal collection methods such as gastric lavage should be considered for future studies as the surest way to maintain population densities at unfished levels in MPAs.

This study presents the most extensive description and detailed taxonomic resolution of Gopher Rockfish diet to date. The findings of a broad, generalist diet agree with previous studies, in which similar dominant prey groups were also described. Prior to this study, Larson (1972) provided the most taxonomically detailed description of Gopher Rockfish diet, and all of the major groups observed in Larson's study, conducted in Santa Barbara, were also observed in the present study. Larson (1972) found the most important prey to be crabs, especially Cancer crabs, pistol shrimp, and other shrimps, including species in the genus Spirontocaris. Hallacher and Roberts (1985) sampled Gopher Rockfish from Carmel Bay, California, and found the most important prey to be juvenile rockfishes, ophiuroids, and brachyuran and caridean crustaceans. Another survey of Gopher Rockfish diet in central California reported the most important prey to be Cancer sp., Loxorhynchus crispatus, caridean shrimp, and juvenile rockfishes (Lea et al. 1999). Bonacci (2003) sampled Gopher Rockfish from Fort Bragg and San Miguel Island, California, and found the most important prey to be Cancer crabs, Loxorhynchus $s p$., fishes, and Ophiothrix spiculata. In the present study, fishes were not as important in Gopher Rockfish diet as in past studies, a fact possibly attributable to very low rockfish 
recruitment in 2007 and 2008 (S. Ralston, personal communication, April 12, 2011). Another notable difference between previous studies and the present study is the dietary importance of mysids described here. Previous studies of Gopher Rockfish diet reported mysids only in the diets of other rockfishes sampled during the same study, including Grass Rockfish (Sebastes rastrelliger; Larson 1972) and Blue Rockfish (Sebastes mystinus; Hallacher and Roberts 1985).

The overall richness of prey types documented in this study indicates that Gopher Rockfish utilize many of the species found in nearshore kelp forest and rocky reef assemblages in California. The most important prey types encountered in the present study represent common kelp forest inhabitants. Ophiothrix spiculata is one of the most common brittle stars encountered in California kelp forests (Foster \& Schiel 1985), and can occur in dense mats in kelp holdfasts and on the seafloor (Morris et al. 1980). When these brittle stars inhabit kelp holdfasts, they often extend their arms into the water to feed. The vast majority of brittle stars encountered in this study had central discs and multiple arms intact, suggesting that the fish either extracted the entire brittle star from a holdfast, or encountered it in a more exposed area such as the rocky reef or algal turf where the entire animal could be consumed. Crustaceans such as crabs and shrimps are the numerically dominant animals in kelp forests (Foster \& Schiel 1985) and naturally were also important constituents of Gopher Rockfish diet.

The ecology of the prey species described in this study provides some insights into Gopher Rockfish foraging behavior. The vast majority of encountered prey types occur demersally, suggesting that Gopher Rockfish predominantly forage demersally, and 
may occasionally make feeding excursions into the water column to feed on prey like squid and sardines. The numerical dominance of mysids in the diet likely reflects the congregation of these animals in dense swarms that can be meters thick and wide (Foster \& Schiel 1985). This swarming behavior may inflate the numerical importance of mysids. While percent number can be used to gauge foraging effort (Hyslop 1980), this assumes that each prey item corresponds to a unique feeding event. A large number of swarming mysids could be consumed in a single or few feeding events, so even though these animals dominated the diet numerically, they may not have required much greater effort to consume than other prey types. The prevalence of mysids at Point Buchon could deflate estimates of evenness and thus contribute to significant differences in prey evenness among locations.

The mean trophic level calculated from stomach contents places Gopher Rockfish midway between primary and secondary carnivores. This is approximately one trophic level higher than that of decapod crustaceans, underscoring the importance of these prey in Gopher Rockfish diet. The lack of a relationship between trophic level and total length is likely due to the limited size range sampled during this study, which did not include juveniles and had only limited representation of small adult size classes. Animals may switch prey types as they increase in size, which can cause ontogenetic shifts in trophic level (Reñones et al. 2002). However, common prey items such as brittle stars, Cancer crabs, and shrimps were found across all adult size classes sampled, which included large and small adults. 
The trophic levels calculated in this study align with those of Kline (2007), who calculated trophic level of rockfishes in Prince William Sound from stable isotopes. Although Kline (2007) did not sample Gopher Rockfish, he found that most rockfish species were within half a trophic level of 4 , or secondary carnivore. China Rockfish (Sebastes nebulosus) and Copper Rockfish (Sebastes caurinus), which feed on similar prey as Gopher Rockfish, were found to occupy trophic levels of about 3.75, which agrees closely with the trophic levels calculated in this study. The guild composition of Gopher Rockfish prey, in which multivores, detritivores, and detriti-carnivores were the most important prey guilds overall, also supports the role of Gopher Rockfish as primary and secondary carnivores.

Although the Gopher Rockfish as a species is considered a generalist feeder, the individual specialization values calculated in this study indicate that the diets of individuals can be relatively specialized compared to the population as a whole (between 20 and 40 percent overlap). The individual specialization documented in this study is likely the plastic response of behavior coupled with prey availability, not definitive specialization shaped by evolution. Although stomach contents represent only what a predator last ate and not necessarily what it is capable of eating over its lifetime, this study reveals that at any given time there may be considerable variation among Gopher Rockfish individuals. Given the broad array of potential prey items eaten by Gopher Rockfish, it also follows that an individual fish will only be able to consume a small subset of those prey at any given time, leading to relatively low overlap between each 
individual and the population as a whole. Stable isotope analysis is one way to determine if variability among individuals persists at longer time scales (Fry et al. 1999).

Although previous work suggests that individual specialization and amongindividual variability should increase with conspecific density (Svanbäck \& Bolnick 2007), there was no consistent effect associated with increased Gopher Rockfish densities in the MPAs surveyed. Significantly greater individual specialization compared to the reference area was measured in the Año Nuevo MPA, which had the lowest overall density of Gopher Rockfish of any MPA, but also exhibited the largest difference in density compared to its reference area ( 1.7 times). While these results are consistent with competition theory, all other MPAs exhibited lower individual specialization than their reference areas, or higher overlap between individuals and the overall population, which is the opposite of what competition theory predicts. The differing effect of the MPA at Año Nuevo suggests that there may be some interaction with geography that could affect MPA performance.

The lack of differences in diet inside and outside of MPAs suggests that although the densities of Gopher Rockfish inside MPAs are statistically greater, the magnitude of these differences compared to the reference areas may not be ecologically significant. Gopher Rockfish occur at significantly greater densities in central California MPAs, ranging from 1.4 to 1.7 times that of the corresponding reference areas (Starr et al. 2010). In contrast, Svanbäck and Bolnick (2007) documented changes to stickleback diet at high-density treatments that had three times the number of fish as low-density treatments. MPAs do show potential for increasing fish densities to substantially greater numbers 
than fished areas: fish densities in protected areas have been documented to be eight (Babcock et al. 1999), ten (Fanelli et al. 2010), and even 14 times greater than fished areas (Willis et al. 2003). Diet evenness, another measure of specialization, decreased with Gopher Rockfish density across areas in the present study, which exhibited a threefold difference in density. This suggests that density-driven feeding changes may yet be observed if fish densities in the central California MPAs increase over time.

While this study primarily focused on the effects of intraspecific density on diet, interspecific interactions may also influence Gopher Rockfish feeding habits. Cooccurring species that exploit similar prey resources include the Black-and-Yellow Rockfish (Sebastes chrysomelas), Brown Rockfish (Sebastes auriculatus), China Rockfish, Copper Rockfish, Kelp Rockfish (Sebastes atrovirens), Grass Rockfish (Sebastes rastrelliger), Treefish (Sebastes serriceps), and Cabezon (Scorpaenichthys marmoratus) (Lea et al. 1999, Love et al. 2002). Monitoring surveys of the MPAs revealed that densities of these species tended to be higher inside the MPAs than outside, although these differences were not significant (Starr et al. 2010). The trend of greater densities of interspecific as well as intraspecific competitors would presumably amplify the effects of competition inside the MPAs. However, no competitive effects such as decreased richness or increased specialization were observed in MPAs, suggesting that any differences in density are not substantial enough to significantly impact feeding interactions. 
Competition theory lays the groundwork for increased specialization and resource use diversification by positing that individuals switch or restrict their resource use as resources become scarce (Svanbäck \& Bolnick 2007). However, prey resources may not be limiting at the areas sampled in this study. The central California coast is a highly productive system that may be able to support rockfish populations at densities greater than those observed. The finding of no significant difference in prey richness inside and outside of the MPAs suggests that a similar suite of prey types is available to Gopher Rockfish at nearby locations irrespective of protected status, and indicates that the greater numbers of fish inside the MPAs have not depleted any major prey groups. Moreover, increased densities also do not necessarily guarantee changes in feeding ecology (Badalamenti et al. 2008). Previous findings of significant diet differences inside and outside of protected areas are likely due to habitat modification and changes in prey availability caused by trawling (Fanelli et al. 2009, Fanelli et al. 2010). The primary fishing practices in the reference areas of this study include hook-and-line and trapping gear, which are unlikely to directly affect the availability of Gopher Rockfish prey.

The abundance of top predators can also impact the feeding behavior of lower predators. MPAs provide protection not only for Gopher Rockfish, but also for their predators such as Lingcod (Ophiodon elongatus). Lingcod densities tended to be greater inside MPAs, although these differences were not significant (Star et al. 2010). Although Gopher Rockfish densities may increase inside MPAs, corresponding increases in predator densities may prevent rockfish populations from reaching densities that can impact feeding ecology. For example, Lingcod may negatively impact the abundance of 
rockfishes (Frid \& Marliave 2010), particularly in MPAs, where Lingcod predation rates on rockfishes have been recorded to be three times greater than in unprotected areas (Beaudreau \& Essington 2007). MPAs that protect and enhance the densities of both apex predators (Lingcod) and mesopredators (rockfishes) may therefore experience complex changes to the food web.

The high similarity in prey composition observed between corresponding MPAs and reference areas might suggest that Gopher Rockfish forage across MPA boundaries, essentially confounding the analysis of the MPA and reference area as two separate populations. However, this factor is unlikely to be the primary cause of high area similarity given the typically restricted movements of Gopher Rockfish (Lea et al. 1999). Recapture data of Gopher Rockfish from the MPAs in the present study indicated that Gopher Rockfish move an average of $300 \mathrm{~m}$ from their release location, well within the boundaries of a given MPA or reference area (Longabach et al. 2009). This fact, coupled with the observation that Gopher Rockfish defend territories of only a few square meters (Larson 1980), lead to the assumption in this study that Gopher Rockfish sampled at a given MPA or reference area had eaten prey within that area. Other factors such as similarity in habitat may better explain high similarities between MPAs and reference areas, since the reference areas were chosen specifically to represent habitats similar to those inside the MPAs (Starr et al. 2010).

The case study of the Point Lobos State Marine Reserve provides evidence that trophic changes in MPAs are not guaranteed, and may take several decades to occur. Despite greater fish density inside the MPA, Gopher Rockfish diets were no different 
than nearby unprotected areas after 35 years of protection. While changes in abundance and biomass can occur rapidly once protected areas are established (Halpern and Warner 2002), associated changes in species composition and trophic structure can occur gradually and over longer timeframes on the order of 10-15 years (Micheli et al. 2004, Babcock et al. 2010). Furthermore, a meta-analysis of reserve performance by Micheli et al. (2004) found significant species composition dissimilarities between protected and fished areas only in tropical assemblages. Thus, changes to trophic structure or species composition that result from changes in fish density may take many years to manifest in the central California MPAs, if they occur at all.

Without a historical baseline at Point Lobos, it is not truly possible to say that no changes in Gopher Rockfish feeding habits have occurred in 35 years, but only that diets did not differ compared to the fished reference areas. While recreational and commercial fishing with hook and line and traps do occur in the reference areas, this fishing pressure may not be extensive enough to produce drastic differences in feeding dynamics compared to the protected area. Thus, the reference area may still be relatively pristine and may not provide a drastic comparison to the MPA. The old Point Lobos MPA is a small reserve and does not necessarily reflect the future trajectory of all central California MPAs. This underscores the importance of collecting site-specific baseline information and monitoring the performance of reserves individually as well as collectively.

Differences in depth among the geographic locations may account for some of the differences in prey composition observed at the new MPAs. Fish from Año Nuevo, which were collected at shallower depths than other locations, ate more Cancer and 
porcelain crabs, which may be due to the low intertidal and shallow subtidal distribution of these species (Morris et al. 1980). Brittle stars, such as Ophiothrix spiculata, were important prey in fish collected at deeper depths in Point Lobos and Piedras Blancas, and indeed this species has a depth distribution that extends to over 2,000 $\mathrm{m}$ (Morris et al. 1980). However, Cancer and porcelain crabs do occur at deeper depths (90-100 m) and brittle stars can likewise inhabit the shallow regions of the low intertidal (Morris et al. 1980, Carroll \& Winn 1989). Thus, depth alone probably does not explain the differences in prey composition among geographic locations.

Differences in prey composition not explained by depth may be due to differences in habitat among geographic locations. Although substrate type was not strongly correlated with dietary variables in the Canonical Correlation Analysis, the analysis only included substrate information for a subset of the grid cells in a given location. The Piedras Blancas location includes several grid cells that are composed almost entirely of sediment rather than hard rock, which may differentiate the prey spectrum at this location from other locations. Future studies that assess habitat at a finer scale and also consider aspects such as rock type and relief may give better estimates of habitat composition and, by proxy, prey distribution, at these geographic locations. The patterns in prey composition across locations mirror those of groundfish species composition at these MPAs, where greatest differences in species composition occurred among locations rather than inside and outside of MPAs (Starr et al. 2010). These results all suggest that nearshore kelp forest and rocky reef communities are not uniform along the central California coast. 
Oceanographic conditions are unlikely to dramatically affect prey composition among locations, as all four locations are considered productive regions that experience similar large-scale oceanographic conditions influenced by the California Current. All of the MPAs studied are located around points, which are relatively small features in the context of California's oceanographic climate. However, there may be small-scale differences in currents or other oceanographic features that affect the ecology at these locations. Temperature at depth was not significantly correlated with dietary variation, so is not likely a cause of oceanographic differences among areas.

An investigation into the abundance and distribution of various prey species at each area was beyond the scope of this study, but such information could greatly improve our understanding of the ecology at these areas. Many of the species eaten by the Gopher Rockfish are small and cryptic, and not included in subtidal invertebrate surveys. The Partnership for Interdisciplinary Study of Coastal Oceans (PISCO) conducts subtidal surveys in the general geographic regions included in this study. However, their invertebrate surveys generally include larger organisms like bat stars and anemones, and not the species consumed by the Gopher Rockfish. Of the few surveyed crab species eaten by Gopher Rockfish, Loxorhynchus crispatus/Scyra acutifrons had a higher relative abundance at all areas compared to other crab species in 2007-2009 (PISCO, unpublished data). This could contribute to the high relative importance of these crabs in Gopher Rockfish diet at all areas. Based on the assumption that a generalist predator will show little or no selectivity in feeding, the stomach contents of generalist feeders can be used as a means to sample the marine environment (Frid \& Hall 1999, Link 2004). Thus, in 
the absence of prey availability data, the results of this study provide a characterization of the cryptic invertebrate communities of these MPAs and reference areas as sampled by the Gopher Rockfish.

The present study provides several contributions to the management of marine resources and the understanding of MPAs. As a generalist predator, the Gopher Rockfish can provide information about the presence of a wide diversity of invertebrate and fish prey to better characterize the ecosystem players in central California's MPAs. This study did not document trophic changes after 35 years of protection in the Point Lobos MPA, which suggests that trophic changes should not necessarily be expected to occur once MPAs are implemented. Furthermore, no consistent differences in feeding ecology were observed in new MPAs, despite greater densities of Gopher Rockfish inside three of the four MPAs surveyed. This may indicate that the food web is relatively stable at these locations, and increased densities may not necessarily be detrimental to Gopher Rockfish inside MPAs. The baseline information collected in this study will enable better detection of future trophic changes at these areas if they occur.

The differences in diet among geographic locations revealed in this study suggest that food web changes associated with MPAs may be location specific as well. This reinforces the fact that locational differences should be considered when assessing the collective performance of many MPAs. California's MPAs are being installed and monitored in regions along the coast; however, the differences observed among MPAs in the central California region suggest it may be necessary to group MPAs at a finer geographic scale to assess their overall effects. MPAs are intended to affect the entire 
ecosystem within their borders, often with the added hope of increasing fish abundances. To understand the full ecological implications of implementing MPAs, it is important to know how the effects of predator abundance could influence the food web. The central California MPAs show the potential to increase the size and density of some fish species within their borders, which may eventually lead to shifts in fish feeding ecology. Accounting for location-specific differences like those observed in this study is important to understand how each MPA performs over time, and should be considered when investigating general MPA effectiveness. 


\section{LITERATURE CITED}

Allison GW, Lubchenco J, Carr MH (1998) Marine reserves are necessary but not sufficient for marine conservation. Ecol Appl 8:S79-S92

Amundsen PA, Gabler HM, Staldvik FJ (1996) A new approach to graphical analysis of feeding strategy from stomach contents data - modification of the Costello (1990) method. J Fish Biol 48:607-614

Babcock RC, Kelly S, Shears NT, Walker JW, Willis TJ (1999) Changes in community structure in temperate marine reserves. Mar Ecol Prog Ser 189:125-134

Babcock RC, Shears NT, Alcala AC, Barrett NS and others (2010) Decadal trends in marine reserves reveal differential rates of change in direct and indirect effects. PNAS 107:18256-18261

Badalamenti F, Sweeting C, Polunin N, Pinnegar J, D’Anna G, Pipitone C (2008) Limited trophodynamics effects of trawling on three Mediterranean fishes. Mar Biol 154:765-773

Beaudreau AH, Essington TE (2007) Spatial, temporal, and ontogenetic patterns of predation on rockfishes by lingcod. Trans Am Fish Soc 136:1438-1452

Bizzarro J, Robinson H, Rinewalt C, Ebert D (2007) Comparative feeding ecology of four sympatric skate species off central California, USA. Environ Biol Fish 80:197-220

Bolnick DI, Yang LH, Fordyce JA, Davis JM, Svanback R (2002) Measuring individuallevel resource specialization. Ecology 83:2936-2941

Bonacci LL (2003) Stable isotope signatures and gut content analysis in determining food web position in a sibling pair of rockfishes (Scorpaenidae: Sebastes) of the california nearshore assemblage. MS thesis, Boston University, Boston, MA

Botsford LW, Castilla JC, Peterson CH (1997) The management of fisheries and marine ecosystems. Science 277:509-515

Brown SC (2010) Diet composition of Bathyraja Interrupta (Gill and Townsend, 1897) and Bathyraja Aleutica (Gilbert, 1896), from the northern Gulf of Alaska continenal shelf. MS Thesis, Moss Landing Marine Laboratories, Moss Landing, CA 
Brown WL, Jr., Wilson EO (1956) Character displacement. Syst Zool 5:49-64

California Department of Fish and Game (2008) California Marine Life Protection Act: Master plan for marine protected areas. Appendix O. Regional MPA management plans. Approved February 2008. Http://www.Dfg.Ca.Gov/mlpa/pdfs/revisedmp0108o.Pdf

Carlton JT (ed) (2007) The Light and Smith manual: Intertidal invertebrates from central Caifornia to Oregon. University of California Press, Berkeley and Los Angeles, CA

Carroll JC, Winn RN (1989) Species profiles: Life histories and environmental requirements of coastal fishes and invertebrates (Pacific Southwest)-brown rock crab, red rock crab, and yellow crab. US Fish Wildl Serv Biol Rep 82(11117) US Army Corps of Engineers, TR EL-82-4 16 pp

Clemente S, Hernández JC, Brito A (2009) Evidence of the top-down role of predators in structuring sublittoral rocky-reef communities in a marine protected area and nearby areas of the Canary Islands. ICES J Mar Sci 66:64-71

Cortés E (1997) A critical review of methods of studying fish feeding based on analysis of stomach contents: Application to elasmobranch fishes. Can J Fish Aquat Sci 54:726-738

Cortés E (1999) Standardized diet compositions and trophic levels of sharks. ICES J Mar Sci 56:707-717

Crowder LB, Hazen EL, Avissar N, Bjorkland R, Latanich C, Ogburn MB (2008) The impacts of fisheries on marine ecosystems and the transition to ecosystem-based management. Annu Rev Ecol Evol Syst 39:259-278

Ebert DA, Bizzarro JJ (2007) Standardized diet compositions and trophic levels of skates (Chondrichthyes: Rajiformes: Rajoidei). Environ Biol Fish 80:221-237

Eschmeyer WN, Herald ES (1983) A field guide to pacific coast fishes: North America. Houghton Miflin Company, Boston, MA

Fanelli E, Badalamenti F, D'Anna G, Pipitone C (2009) Diet and trophic level of scaldfish Arnoglossus laterna in the southern Tyrrhenian Sea (western Mediterranean): Contrasting trawled versus untrawled areas. J Mar Biol Assoc UK 89:817-82 
Fanelli E, Badalamenti F, D’Anna G, Pipitone C, Romano C (2010) Trophodynamic effects of trawling on the feeding ecology of pandora, Pagellus erythrinus, off the northern Sicily coast (Mediterranean Sea). Mar Freshw Res 61:408-417

Fanshawe S, Vanblaricom GR, Shelly AA (2003) Restored top carnivores as detriments to the performance of marine protected areas intended for fishery sustainability: A case study with red abalones and sea otters. Conserv Biol 17:273-283

Ferry LA, Cailliet GM (1996) Sample size and data analysis: Are we characterizing and comparing diet properly? In: MacKinlay D, Shearer K (eds) Feeding ecology and nutrition in fish: proceedings of the symposium on the feeding ecology and nutrition in fish. International congress on the biology of fishes, San Francisco, CA

Foster MS, Schiel DR (1985) The ecology of giant kelp forests in California: A community profile. US Fish Wildl Serv Biol Rep 85:152 pp

Frid A, Marliave J (2010) Predatory fishes affect trophic cascades and apparent competition in temperate reefs. Biol Lett 6:533-536

Frid CLJ, Hall SJ (1999) Inferring changes in North Sea benthos from fish stomach analysis. Mar Ecol Prog Ser 184:183-188

Fry B, Mumford PL, Tam F, Fox DD, Warren GL, Havens KE, Steinman AD (1999) Trophic position and individual feeding histories of fish from Lake Okeechobee, Florida. Can J Fish Aquat Sci 56:590-600

Gascuel D (2005) The trophic-level based model: A theoretical approach of fishing effects on marine ecosystems. Ecol Model 189:315-332

Guidetti P (2006) Marine reserves reestablish lost predatory interactions and cause community changes in rocky reefs. Ecol Appl 16:963-976

Guidetti P, Sala E (2007) Community-wide effects of marine reserves in the Mediterranean Sea. Mar Ecol Prog Ser 335:43-56

Hallacher L, Roberts D (1985) Differential utilization of space and food by the inshore rockfishes (Scorpaenidae: Sebastes) of Carmel Bay, California. Environ Biol Fish 12:91-110

Halpern BS, Warner RR (2002) Marine reserves have rapid and lasting effects. Ecol Lett 5:361-366 
Hyslop EJ (1980) Stomach contents analysis-a review of methods and their application. J Fish Biol 17:411-429

Jensen GC (1995) Pacific coast crabs and shrimps. Sea Challengers, Monterey, CA

Key M, MacCall AD, Bishop T, Leos B (2005) Stock assessment of the gopher rockfish (Sebastes Carnatus). In Volume V: Status of the Pacific coast groundfish fishery through 2005, stock assessment and fishery evaluation: Stock assessments and rebuilding analyses. Pacific Fishery Management Council, Portland, OR

Kline TC, Jr. (2007) Rockfish trophic relationships in Prince William Sound, Alaska, based on natural abundance of stable isotopes. In: Biology, assessment, and management of north pacific rockfishes, $\mathrm{p} 21-37$

Krebs CJ (1999) Ecological methodology. Addison Wesley Longman, Menlo Park, CA

Lance M, Orr A, Riemer S, Weise M, Laake J (2001) Pinniped food habits and prey identification techniques protocol. AFSC processed report 2001-04, NMFS Alaska Fisheries Science Center

Larson RJ (1972) The food habits of four kelp-bed rockfishes (Scorpaenidae, Sebastes) off Santa Barbara, California. MS thesis, University of California, Santa Barbara, CA

Larson RJ (1980) Territorial behavior of the black and yellow rockfish and gopher rockfish (Scorpaenidae, Sebastes). Mar Biol 58:111-122

Lea RN, McaAllister RD, VenTresca DA (1999) Biological aspects of nearshore rockfishes of the genus Sebastes from central California. California Department of Fish and Game, Fish Bulletin 177

Lester S, Halpern B, Grorud-Colvert K, Lubchenco J and others (2009) Biological effects within no-take marine reserves: A global synthesis. Mar Ecol Prog Ser 384:33-46

Link JS (2004) Using fish stomachs as samplers of the benthos: Integrating long-term and broad scales. Mar Ecol Prog Ser 269:265-275

Longabach LJ, Yochum N, Starr RM, Nakamura R, Wendt DE (2009) Movement of gopher rockfish as determined by tag-recapture data in central California marine protected areas [abstract]. Western Society of Naturalists Conference, Seaside, CA

Love MS (1996) Probably more than you want to know about the fishes of the Pacific coast. Really Big Press, Santa Barbara, CA. 
Love MS, Yoklavich M, Thorsteinson L (2002) The rockfishes of the northeast Pacific, University of California Press, Berkeley, CA

McClanahan TR (2000) Recovery of a coral reef keystone predator, Balistapus undulatus, in east African marine parks. Biol Conserv 94:191-198

McClanahan TR, Arthur R (2001) The effect of marine reserves and habitat on populations of east African coral reef fishes. Ecol Appl 11:559-569

Micheli F, Halpern BS, Botsford LW, Warner RR (2004) Trajectories and correlates of community change in no-take marine reserves. Ecol Appl 14:1709-1723

Morris RH, Abbott DP, Haderlie EC (1980) Intertidal invertebrates of California. Stanford University Press, Stanford, CA

Mumby PJ, Harborne AR, Williams J, Kappel CV and others (2007) Trophic cascade facilitates coral recruitment in a marine reserve. PNAS 104:8362-8367

Oksanen J, Blanchet FG, Kindt R, Legendre P and others (2010) Vegan: Community ecology package. R package version 117-2 http://CRANRprojectorg/package $=$ vegan

Parker SJ, McElderry HI, Rankin PS, Hannah RW (2006) Buoyancy regulation and barotrauma in two species of nearshore rockfish. Trans Am Fish Soc 135:1213 1223

Pinkas L, Oliphant MS, Iverson LK (1971) Food habits of albacore, bluefin tuna, and bonito in California waters. Fish Bull 52:105 p.

Pinnegar JK, Polunin NVC, Francour P, Badalamenti F and others (2000) Trophic cascades in benthic marine ecosystems: Lessons for fisheries and protected-area management. Environ Conserv 27:179-200

Quinn GP, Keough MJ (2002) Experimental design and data analysis for biologists. Cambridge Press, Cambridge, UK

Reñones O, Polunin NVC, Goni R (2002) Size related dietary shifts of Epinephelus marginatus in a western Mediterranean littoral ecosystem: An isotope and stomach content analysis. J Fish Biol 61:122-137

Schmitt WL (1921) The marine decapod crustacea of California. University of California Press, Berkeley, CA 
Simenstad C, Miller B, Nyblade C, Thornburgh K, Bledsoe L (1979) Food web relationships of northern Puget Sound and the Strait of Juan de Fuca: A synthesis of the available knowledge. Interagency Energy-Environment R\&d program report, United States Environmental Protection Agency

Starr RM, Wendt D, Schmidt KT, Romero R and others (2010) Baseline surveys of nearshore fishes in and near central California marine protected areas 2007-2009. Final project report submitted to the Ocean Protection Council.

Starr RM, Wendt D, Yochum N, Green K, Longabach L (2008) Surveys of nearshore fishes in and near central California marine protected areas. Final report submitted to the Ocean Protection Council and California Sea Grant College Program, California Sea Grant RRMPA-4

Svanbäck R, Bolnick DI (2007) Intraspecific competition drives increased resource use diversity within a natural population. Proc R Soc B 274:839-844

Tetreault I, Ambrose RF (2007) Temperate marine reserves enhance targeted but not untargeted fishes in multiple no-take MPAs. Ecol Appl 17:2251-2267

Willis TJ, Millar RB, Babcock RC (2003) Protection of exploited fish in temperate regions: High density and biomass of snapper Pagrus auratus (Sparidae) in northern New Zealand marine reserves. J Appl Ecol 40:214-227 